UNIVERSIDADE DE BRASÍLIA

FACULDADE DE CIÊNCIAS DA SAÚDE

DAYANE GABRIELE ALVES SILVEIRA

NOVAS TECNOLOGIAS PARA O MANEJO DO DIABETES TIPO I: CENÁRIO NACIONAL E INTERNACIONAL

BRASÍLIA

2016 


\section{NOVAS TECNOLOGIAS PARA O MANEJO DO DIABETES TIPO I: CENÁRIO NACIONAL E INTERNACIONAL}

Dissertação de Mestrado apresentada ao Programa de Pós-Graduação em Ciências Farmacêuticas da Faculdade de Ciências da Saúde, Universidade de Brasília, como requisito parcial à obtenção do título de Mestre em Ciências Farmacêuticas.

Área de Concentração: Fármacos, Medicamentos e Cosméticos.

Orientadora: Prof ${ }^{a}$. Dr. ${ }^{a}$ Tais Gratieri

Brasília

2016 


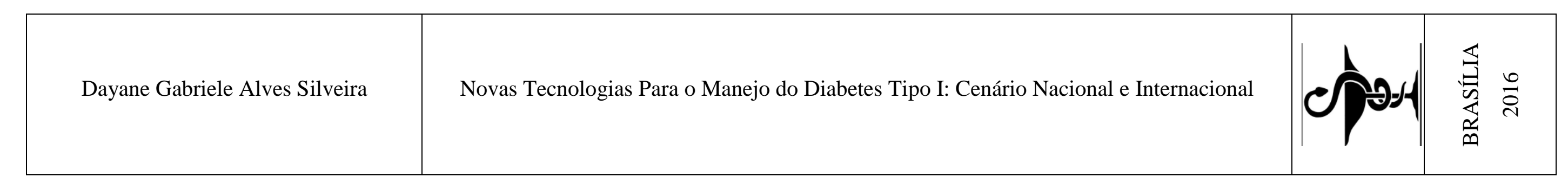


Ficha catalográfica elaborada automaticamente, com os dados fornecidos pelo(a) autor(a)

Alves Silveira, Dayane Gabriele

Novas tecnologias para o manejo do diabetes tipo

$\mathrm{n}$ I: Cenário Nacional e Internacional / Dayane

Gabriele Alves Silveira; orientador Tais Gratieri.

- Brasília, 2016. $100 \mathrm{p}$.

Dissertação (Mestrado - Mestrado em Ciências Farmacêticas) -- Universidade de Brasília, 2016.

1. Sistema de Infusão de Insulina. 2. Diabetes Mellitus. 3. Insulina. 4. Avaliação da Tecnologia Biomédica. 5. Decisões Judiciais. I. , Tais Gratieri, orient. II. Título. 


\section{REFERÊNCIA BIBLIOGRÁFICA}

SILVEIRA D. G. A. Novas tecnologias para o manejo do diabetes tipo I: Cenário Nacional e Internacional: Departamento de Ciências Farmacêuticas, Faculdade de Ciências da Saúde, Universidade de Brasília, 2016, XX f, Dissertação de Mestrado.

\section{CESSÃO DE DIREITOS}

NOME DO AUTOR: Dayane Gabriele Alves Silveira

TÍTULO DA DISSERTAÇÃO: Novas tecnologias para o manejo do diabetes tipo I: Cenário Nacional e Internacional.

GRAU: Mestre

ANO: 2016

É concedida à Universidade de Brasília de Brasília permissão para reproduzir cópias desta dissertação de mestrado para única e exclusivamente propósitos acadêmicos e científicos. O autor reserva para si os outros direitos autorais, de publicação. Nenhuma parte desta dissertação de mestrado pode ser reproduzida sem a autorização por escrito do autor. Citações são estimuladas, desde que citada a fonte.

Nome: Dayane Gabriele Alves Silveira

e-mail: dayanegaby@gmail.com 


\section{DAYANE GABRIELE ALVES SILVEIRA}

Novas tecnologias para o manejo do diabetes tipo I: Cenário Nacional e Internacional

Dissertação de Mestrado apresentada ao Programa de Pós-Graduação em Ciências Farmacêuticas, Faculdade de Ciências da Saúde, Universidade de Brasília, como requisito parcial à obtenção do título de Mestre em Ciências Farmacêuticas.

Aprovada em 02 de maio de 2016.

\section{Banca Examinadora}

Prof. ${ }^{a}$ Dr. ${ }^{a}$ Tais Gratieri - Universidade de Brasília (Faculdade de Ciências da Saúde)

Presidente

Prof. Dr. Guilherme Martins Gelfuso - Universidade de Brasília - (Faculdade de Ciências da Saúde)

Membro titular

Prof. Dr. Rafael Mota Pinheiro - Universidade de Brasília - (Faculdade de Ciências da Saúde)

Membro titular

Prof. ${ }^{a}$ Dr. ${ }^{a}$ Lívia Cristina Lira de Sá Barreto - Universidade de Brasília - (Faculdade de Ceilândia)

Membro suplente

Data da avaliação: 02 de maio de 2016.

Local de defesa: Sala nº 01, Faculdade de Ciências da Saúde - Brasília - DF. 


\section{DEDICATÓRIA}

"Cada pessoa que passa na nossa vida, passa sozinha, porque cada pessoa é única e nenhuma substitui a outra. Cada pessoa que passa pela nossa vida, não nos deixa só, porque deixa um pouco de si e leva um pouquinho de nós. Essa é a mais bela responsabilidade da vida e a prova de que as pessoas não se encontram por acaso". 


\section{AGRADECIMENTOS}

Agradecida a Deus por sempre me guiar pelo melhor caminho.

À minha orientadora Dr. ${ }^{a}$ Tais Gratieri pela amizade, dedicação, incentivo, carinho e presteza, e por se fazer presente em todos os momentos, apresentando caminhos mais claros nas horas de dificuldades.

Aos demais professores da FCS que deixaram sementes de sabedoria em minha caminhada.

Aos demais funcionários da Universidade de Brasília, especialmente aos da secretaria de pósgraduação, pela atenção e paciência.

Aos colegas, em especial Tamara Damasceno, pela disponibilidade na troca de informações e saberes numa rara demonstração de amizade e solidariedade.

Aos colegas e chefes do Departamento de Ciência e Tecnologia do Ministério da Saúde pelo apoio administrativo neste percurso.

À minha família pela paciência em tolerar a minha ausência.

E, finalmente, a todos os amigos que contribuíram com as suas experiências para tornar esse trabalho melhor. 


\section{MENSAGEM}

"Uma boa mente e um bom coração são sempre uma combinação formidável. Mas quando você adiciona a isso um idioma bem falado ou uma caneta, então você tem uma coisa realmente especial".

Nelson Mandela 


\section{RESUMO}

SILVEIRA, D. G. A. Novas tecnologias para o manejo do diabetes tipo I: Cenário Nacional e Internacional. 100p. Brasília, 2016. Dissertação (Mestrado em Ciências Farmacêutica). Faculdade de Ciências da Saúde, Universidade de Brasília, Brasília, 2016.

O diabetes é uma patologia cuja prevalência vem aumentando cerca de $25 \%$ ao ano na população brasileira. A doença está associada a complicações que podem afetar significativamente a qualidade de vida do paciente. Esse trabalho se propõe identificar novas alternativas terapêuticas em fase de desenvolvimento para o manejo do diabetes tipo 1, não só pela sua relevância para a saúde pública brasileira, mas também por estar associado a um alto custo para o Sistema Único de Saúde (SUS). Diante dos numerosos avanços na área, o estudo objetivou construir um panorama atual das pesquisas, incluindo estudos em fase pré-clínica, ensaios clínicos e patentes, apontando uma nova alternativa terapêutica potencialmente apta para uso no SUS. A tecnologia identificada potencialmente apta para uso foi o Sistema de Infusão contínua de Insulina (SIC), por ser dentre as alternativas terapêuticas a que está autorizada para comercialização no país e ainda não foi avaliada na Comissão Nacional de Incorporação de Tecnologias no SUS (CONITEC). A partir desta análise, procurou-se identificar práticas e experiências de secretarias, governo federal e organizações de saúde internacionais quanto ao uso do SIC. Para isso, realizou- um enfoque qualitativo com aplicação de questionários e de formulários de solicitações de informações ao governo federal. No cenário nacional, a maioria das secretarias (83\%) tem recebido demandas judiciais e tem constatado um aumento destas demandas nos últimos 5 anos. Já no cenário internacional, a maioria das organizações que participaram do estudo (47\%) já reembolsam completamente o SIC aos pacientes diabéticos tipo 1, por favorecer melhor controle da glicemia e da hemoglobina glicada, além de uma considerável melhoria na qualidade de vida. Esses resultados estão vinculados a um custo adicional de cerca de R 9.500 quando comparado ao tratamento tradicional, o que demonstra uma necessidade de estudos clínicos para avaliação do SIC por um período longo e de custo-efetividade, além da previsão do impacto financeiro dessa tecnologia na perspectiva do SUS.

Palavras-chave: Sistemas de Infusão de Insulina; Diabetes Mellitus; Insulina; Avaliação da Tecnologia Biomédica; Decisões Judiciais; Sistema Único de Saúde. 


\begin{abstract}
SILVEIRA, D. G. A. New technologies for the management of type I diabetes: National and International Scenario. 100p. Brasília, 2016. Dissertação (Mestrado em Ciências Farmacêutica). Faculdade de Ciências da Saúde, Universidade de Brasília, Brasília, 2016.

Diabetes is a disease whose prevalence is increasing about $25 \%$ per year in the Brazilian population. The disease is associated with complications that can significantly affect the quality of life of patients, besides having a high cost to the National Health System (SUS). Given the numerous advances in the field, the present study describes the current situation of research in the area, including studies in laboratory phase, clinical trials and patents, pointing to the technology that would be ready for incorporation by the SUS. Such technology identified suitable for use was the continuous infusion of insulin System (SIC). From this analysis, we sought to identify practices and experiences of departments, federal government and health organizations with the introduction of insulin continuous subcutaneous infusion system (SIC). For this, a qualitative approach was adopted with the use of questionnaires and forms of information requests to the federal government. On the national scenario, most departments $(83 \%)$ have received claims for SIC purchase and an increase in demand is noticed in the past 5 years. In the international scenario, most of the organizations that participated in the study (47\%) provide the SIC to type 1 diabetic patients, claiming it promotes better blood glucose control and glycated hemoglobin, and a considerably improves the quality of life. These results are linked to an additional cost of approximately $\mathrm{R} \$ 9,500$ when compared to traditional treatment, which demonstrates a need for studies to establish which would be the SIC more cost-effective for the system and the financial impact of this technology in the SUS.
\end{abstract}

Keywords: Insulin Infusion Systems; Diabetes Mellitus; Insulin; Technology Assessment Biomedical; Judicial Decisions; Unified Health System. 


\section{LISTA DE FIGURAS}

Figura 1. Países entrevistados e ano de incorporação da Sistema de Infusão Contínua de Insulina. 10

Figura 2. As 20 principais causas de morte nas Américas no ano 2015 e projeção para 2030 de acordo com a OMS. 14

Figura 3. As 10 principais causas de DALY no Brasil em 2013 …....................................... 15

Figura 4. Comparação da carga global de doença entre países de 1990 e 2010...................... 16

Figura 5. Número de Diabéticos por tipo e risco, 01/2005 até 08/2015; Brasil..................... 17

Figura 6. Taxa de mortalidade específica para o diabetes mellitus por faixa etária e sexo, 2005 a 2011; Brasil 19

Figura 7. Linha do tempo dos primeiros avanços nos sistemas de liberação de insulina 21

Figura 8. Representação de moléculas, partículas, células e objetos representados sobre uma escala nanométrica $(1 \mathrm{~nm}=0,000000001 \mathrm{~m})$.

Figura 9. Sistema de infusão de insulina e monitoramento contínuo da glicemia (Pâncreas artificial).

Figura 10. Sistema de infusão de insulina e glucagon com sistema de monitoramento contínuo da glicemia (Pâncreas Biônico). 31

Figura 11AB. Evolução dos dispositivos de administração de insulina via pulmonar. 40

Figura 12. Tipos de microagulhas transdérmicas $(\mathrm{MN})$ na liberação de insulina. 44

Figura 13. Lente de Contato para Monitoramento Glicêmico (Google X) 49

Figura 14. Modelo de um Sistema de infusão contínua de insulina (Accu-Chek Spirit)........59

Figura 15. Imagem de um Sistema de infusão contínua de insulina em uso pelo paciente.....59

Figura 16. Secretarias de Saúde (SES): número de ações judiciais em saúde de Bomba de Infusão Contínua de Insulina nos últimos 5 anos. 61 


\section{LISTA DE QUADROS E TABELAS}

Quadro 1. Questões dos Questionários Aplicados.

Tabela 1. Características estruturais no desenvolvimento dos Análogos de Insulina (AI) ....22

Tabela 2. Classificação dos tipos de insulina quanto à velocidade de ação. .23

Tabela 3. Novas formulações de insulina em estudo clínico.

Tabela 4. Horizonte dos sistemas de infusão subcutânea contínua de insulina em estudo préclínico.

Tabela 5. Horizonte dos sistemas de infusão subcutânea contínua de insulina em estudo clínico.

Tabela 6. Barreiras na liberação da insulina quando administrada por vias alternativas. 32

Tabela 7. Horizonte tecnológico das formulações orais na liberação de insulina em desenvolvimento.

Tabela 8. Horizonte tecnológico das formulações orais para liberação de insulina em estudo clínico.

Tabela 9. Horizonte das formulações intranasais para liberação de insulina em estudo clínico.

Tabela 10. Horizonte das formulações pulmonares para liberação de insulina em estudo clínico.

Tabela 11. Horizonte das formulações transdermais para liberação de insulina em estudo clínico.

Tabela 12. Horizonte das formulações não baseadas na liberação de insulina para o diabetes em estudo clínico.

Tabela 13. Horizonte tecnológico de dispositivos em desenvolvimento para o controle da glicemia.

Tabela 14. Horizonte tecnológico de dispositivos e aplicações no controle e gestão da glicemia em clínico.

Tabela 15. Pedidos de patente de processos e produtos para diagnóstico, profilaxia ou cura do diabetes depositados por brasileiros no INPI.

Tabela 16. Sistemas de Infusão Contínua de Insulina com registro aprovado pela ANVISA.57

Tabela 17. Bomba Externa de Infusão de Insulina com registro aprovada pela ANVISA. ....58 


\section{LISTA DE ABREVIATURAS E SIGLAS}

ANVISA

ATS

CNPQ

CONASS

CONITEC

DALY

DCNT

DM1

DM2

EMA

FDA

$\mathrm{G}(2)-\beta-\mathrm{CyD}$

GBD

HA1c

IDF

IHME

INPI

MDI

MS

OMS

PFBP

PLA-PEG-PLA

PLGA

PSA

REBRATS

RS

SES

SIC

SUS

UNB

YLLs
Agência Nacional de Vigilância Sanitária.

Avaliação de Tecnologias de Saúde.

Conselho Nacional de Desenvolvimento Científico e Tecnológico.

Conselho Nacional dos Secretários de Saúde.

Comissão Nacional de Incorporação de Tecnologias no SUS.

Anos de vida perdidos ajustados por incapacidade (disability adjusted life of years).

Doenças crônicas não transmissíveis.

Diabetes mellitus tipo 1.

Diabetes mellitus tipo 2.

Agência europeia, European Medicines Agency.

Agência Americana, Food and Drug Administration.

Maltosil- $\beta$-ciclodextrina.

Global Burden of Disease.

Hemoglobina glicada.

Federação Internacional do Diabetes.

Institute for Health Metrics and Evaluation.

Instituto Nacional de Propriedade Industrial.

Aplicação múltipla diária de insulina.

Ministério da Saúde.

Organização Mundial de Saúde.

Programa Farmácia Popular do Brasil.

Poly(lactic acid)-poly(ethylene glycol)-poly(lactic acid).

Ácido poli(láctico-co-glicólico.

Ácido polissiálico.

Rede Brasileira de Avaliação de Tecnologias em Saúde.

Revisão Sistemática

Secretarias de saúde dos estados.

Sistema de Infusão subcutânea Contínua de Insulina.

Sistema Único de Saúde.

Universidade de Brasília.

Anos de vida perdidos (number of years of life lost). 


\section{SUMÁRIO}

1. INTRODUÇÃ $O$....................................................................................................................................

2. OBJETIVOS GERAL E ESPECÍFICOS....................................................................5

2.1. OBJETIVO GERAL .....................................................................................

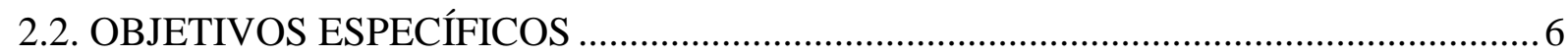

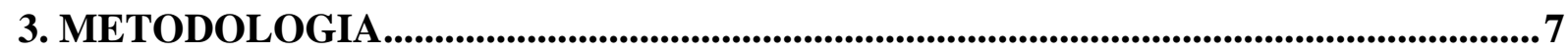

4. RESULTADOS E DISCUSSÃO ……...................................................................................13

4.1. TERAPIAS BASEADAS NA LIBERAÇÃO DE INSULINA …………………….....20

4.2. PANORAMA TECNOLÓGICO NA LBERAÇÃO DE INSULINA PARA O

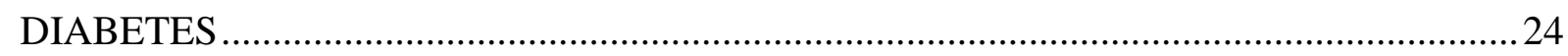

4.2.1. FORMULAÇÕES EM DESENVOLVIMENTO NA LIBERAÇÃO DE INSULINA PELA

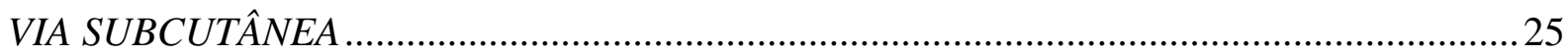

4.2.2. ESTUDOS CLÍNICOS DE FORMULAÇÕES NA LIBERAÇÃO DE INSULINA PELA

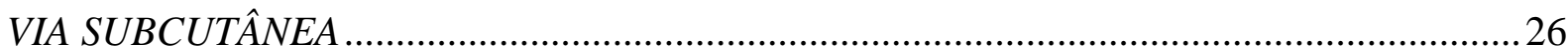

4.2.3. DISPOSITIVOS EM DESENVOLVIMENTO NA LIBERAÇÃO DE INSULINA PELA

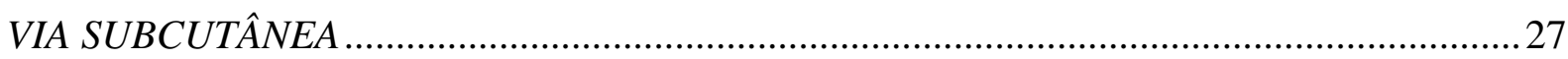

4.2.4. ESTUDOS CLÍNICOS DE DISPOSITIVOS PARA LIBERAÇÃO DE INSULINA PELA

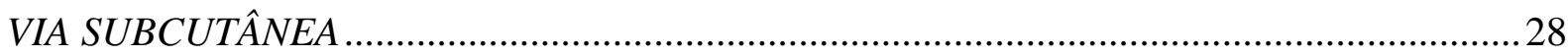

4.2.5. FORMULAÇÕES ORAIS PARA LIBERAÇÃO DE INSULINA EM DESENVOLVIMENTO

4.2.6. FORMULAÇÕES PARA LIBERAÇÃO DE INSULINA VIA INTRANASAL E

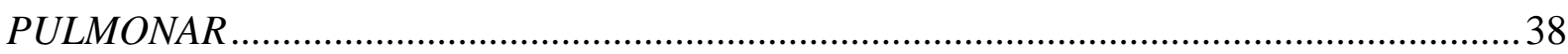

4.2.7. FORMULAÇÕES PARA LIBERAÇÃO DE INSULINA VIA TRANSDÉRMICA ...........42

4.3. TERAPIAS NÃO BASEADAS NA LIBERAÇÃO DE INSULINA ……………….....46

4.4. PANORAMA TECNOLÓGICO DAS TECNOLOGIAS NÃO BASEADAS NA LIBERAÇÃO DE INSULINA PARA O MANEJO E GESTÃO DO DIABETES ....................46

4.4.1. DISPOSITIVOS PARA DIAGNÓSTICO E MONITORAMENTO DA GLICEMIA .......48

4.5. PANORAMA DAS PESQUISAS EM DIABETES NO BRASIL.................................51

4.6. TECNOLOGIA APTA PARA USO EM PACIENTES DIABÉTICOS NO ÂMBITO

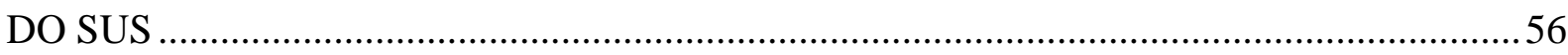

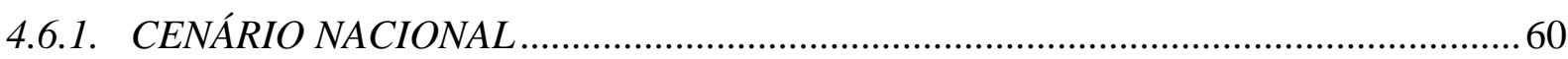

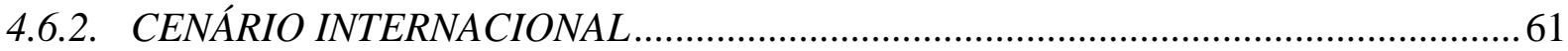

5. CONSIDERAÇÕES FINAIS.............................................................................................65 
6. CONCLUSÃ

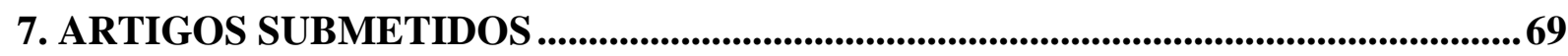

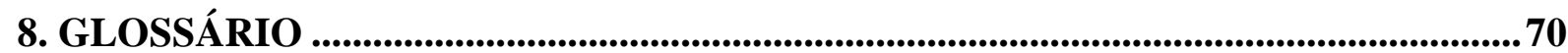

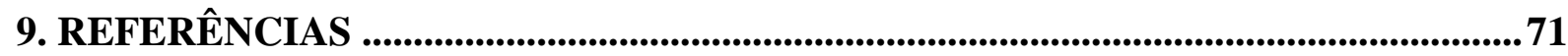

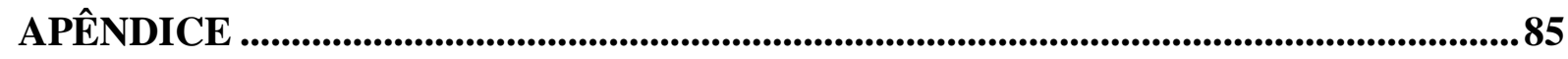




\section{INTRODUÇÃO}




\section{INTRODUÇÃO}

A insulina é um hormônio produzido pelo pâncreas e exerce um papel metabólico primordial na utilização da glicose como fonte de energia. Quando o corpo não é apto a produzir ou utilizar a insulina de forma adequada se desenvolve o diabetes. Essa patologia pode ser classificada clinicamente em três tipos principais: tipo 1 (diabetes insulinodependente, que aparece com frequência durante a infância ou adolescência), tipo 2 (diabetes não insulinodependente, que está relacionada à obesidade e ao sedentarismo) e gestacional (AL-TABAKHA; ARIDA, 2008; International Diabetes Federation. IDF Diabetes Atlas, 2013).

O paciente diabético não metaboliza a glicose apropriadamente, que permanece em altos níveis no sangue, podendo levar a lesões em diferentes órgãos e tecidos. Como consequência, estima-se que $2 \%$ dos pacientes desenvolvem cegueira e $10 \%$ desenvolvem deficiência visual grave. Ao longo dos anos, 30 a $45 \%$ dos diabéticos podem desenvolver algum grau de retinopatia, 10 a $20 \%$ nefropatia, 20 a $35 \%$ neuropatia e 10 a $25 \%$ doenças cardiovasculares (KING; AUBERT; HERMAN, 1998).

O diabetes tipo 1 é uma condição na qual o sistema imunológico do paciente ataca as células $\beta$ produtoras de insulina no pâncreas. Além do monitoramento dos níveis de glicose, dieta adequada e prática de exercícios físicos regulares, esses pacientes necessitam da administração de insulina diariamente. Apesar de ser mais frequente o surgimento durante a infância, o número de diabéticos tipo 1 vem aumentando consideravelmente, inclusive em outras faixas etárias (International Diabetes Federation. IDF Diabetes Atlas, 2013). Quando essa condição autoimune ocorre em pacientes adultos, ela tem sido classificada como LADA (latent autoimmune diabetes) (HERNANDEZ et al., 2015).

Pacientes com diabetes tipo 2 podem permanecer não-diagnosticados por muitos anos, até que os primeiros danos em órgãos e tecidos comecem a se manifestar. Esse é o tipo mais comum da doença e também necessitam do monitoramento das taxas de glicose no sangue, bem como do controle da dieta e praticar exercícios físicos. Nessa condição, o corpo pode produzir insulina, mas o organismo não é capaz de responder satisfatoriamente a ela (também conhecido como insulinorresistente) ou a quantidade de insulina produzida não é suficiente. 
Nestes casos, a administração de insulina também pode ser necessária (AL-TABAKHA; ARIDA, 2008; International Diabetes Federation. IDF Diabetes Atlas, 2013).

Diabetes mellitus tipo 2 (DM2) se torna mais prevalente conforme o aumento da obesidade. Pacientes com DM2 possuem deficiência parcial na secreção de insulina e adquirem resistência à insulina por diversas causas, podendo ter origens genéticas ou ambientais. Isso provoca eventos de hiperglicemia que prejudica a função da célula beta e vai agravando a resistência à insulina (MCCULLOCH; NATHAN; MULDER, 2015).

Já o diabetes gestacional que tem relação com a resistência à inslina que ocorre quando a função do pâncreas não supera os efeitos dos hormônios anti-insulina comumente secretados durante a gravidez, como por exemplo, o estrógeno, prolactina, cortisol e progesterona (MCCULLOCH; NATHAN; MULDER, 2015). Isso leva ao aumento das taxas de glicose no sangue e quando não controlada, a doença pode resultar em graves consequências, tanto para a mãe, quanto para o bebê (International Diabetes Federation. IDF Diabetes Atlas, 2013). O controle se dá por dieta equilibrada, exercícios físicos moderados e, em alguns casos, assim como no diabetes tipo 2, pode ser necessária a administração de insulina juntamente com outros medicamentos, como glibenclamida e metformina (BALSELLS et al., 2015; HEMMINGSEN et al., 2014). Em geral, essa condição desaparece após o parto, mas pode levar ao subsequente desenvolvimento de diabetes tipo 2 na mãe (International Diabetes Federation. IDF Diabetes Atlas, 2013).

A expansão da população idosa, além de fatores do aumento no consumo de alimentos ultraprocessados, dietas inadequadas e sedentarismo, contribuem para o aumento da prevalência do diabetes de forma muito rápida (International Diabetes Federation. IDF Diabetes Atlas, 2013; OLIVEIRA et al., 2009). Em 2014, a prevalência de adultos ( $\geq 18$ anos) com diabetes no Brasil foi de 8,5\% para homens e 7,2\% para mulheres (World Health Organization., 2015). Pesquisas confirmam que esta prevalência aumentou $25 \%$ ao ano de 2006 a 2013 (ISER et al., 2015).

Por outro lado, esses números apontam um impacto financeiro significativo. Estima-se que apenas três doenças crônicas não transmissíveis podem vir a ser responsáveis por uma perda de US\$ 4,18 bilhões na economia brasileira entre 2006 e 2015: cardiopatia, acidente vascular encefálico e diabetes (MALTA; MORAIS NETO; SILVA JUNIOR, 2011). O custo 
do tratamento do paciente diabético tipo 1 usuário do SUS é de US\$1. 216,33 por pessoa por ano (COBAS et al., 2013).

Em relação ao tratamento, todos os pacientes com diabetes tipo 1 e alguns pacientes tipo 2 ou gestantes necessitam de fornecimento de insulina para sobreviverem. A terapia convencional se constitui na administração subcutânea de insulina 30 a 40 minutos antes das refeições e os pacientes podem levar mais de 60.000 injeções ao longo da vida (ALTABAKHA; ARIDA, 2008; International Diabetes Federation. IDF Diabetes Atlas, 2013). Entretanto, nos últimos anos, várias pesquisas vêm sendo realizadas para aumentar o arsenal terapêutico para o controle do diabetes.

Diante da relevância do diabetes tipo 1 para a saúde pública brasileira, não só pela sua prevalência, mas também pelas complicações associadas, que diminui a qualidade de vida do paciente e aumenta os gastos no sistema de saúde e, o mais preocupante, as mortes, esse trabalho se propõe identificar novas alternativas terapêuticas em fase de desenvolvimento para o manejo do diabetes tipo 1. Além de apontar uma alternativa terapêutica promissora para o diabetes tipo 1 e que esteja aprovada para comercialização no país, mas que ainda não seja reembolsada pelo Sistema Único de Saúde (SUS).

Para verificar a necessidade da tecnologia apontada como alternativa promissora para o paciente diabético tipo 1 usuário do SUS foi realizada uma pesquisa envolvendo profissionais da área de Avaliação de Tecnologias de Saúde (ATS) e de departamentos de saúde governamentais no âmbito nacional como também a nível internacional, com o objetivo de construir cenários da demanda e do reembolso de tal tecnologia.

Este trabalho se torna significativo por ser o primeiro estudo nacional do horizonte tecnológico do diabetes melittus tipo 1 e também por ser pioneiro ao indicar uma nova alternativa terapêutica ainda não reembolsada no cenário brasileiro, tendo em vista as ações judiciais já realizadas em nosso país que beneficiaram sem critérios alguns pacientes ou grupo de pacientes. 


\section{OBJETIVOS GERAL E ESPECÍFICOS}




\subsection{OBJETIVO GERAL}

Identificar novas tecnologias para o manejo do diabetes tipo I e o potencial de uso no cenário nacional e internacional.

\subsection{OBJETIVOS ESPECÍFICOS}

2.2.1. Revisar e Identificar tecnologias em desenvolvimento para o manejo do diabetes tipo 1 no âmbito nacional e internacional;

2.2.2. Apontar a tecnologia mais promissora no sentido de estar apta para uso pelos diabéticos tipo 1 usuários do Sistema Único de Saúde (SUS);

2.2.3. Investigar as experiências das secretarias de saúde nacionais quanto à necessidade da tecnologia identificada, mas ainda não reembolsada;

2.2.4. Investigar as experiências de organizações internacionais que já incorporaram tal tecnologia promissora em seus sistemas de saúde. 
3. METODOLOGIA 


\section{METODOLOGIA}

Para definir um panorama atual das pesquisas na área do diabetes, no dia 06 de setembro de 2015, foram revisadas as bases de dados Biblioteca Virtual em Saúde (BVS), Medline (via Pubmed), The Cochrane Library, Centre for Reviews and Dissemination (CRD), Web of Science, ClinicalTrials.gov, incluindo estudos na fase laboratorial (pré-clínica), ensaios clínicos e revisões. Foram utilizados os termos '"Diabetes Mellitus" e "treatment" e "technologies" ou "'Diabetes Mellitus" e "treatment", período de 2000 a 2015. No total, foram identificados 6721 artigos. Ademais, foi revisado o Diretório dos Grupos de Pesquisa no Brasil (Plataforma Lattes - CNPQ) para identificar pesquisas nacionais e realizada busca de patentes no Instituto Nacional da Propriedade Industrial (INPI).

Foram excluídas as duplicatas, por meio de um sistema de gerenciamento de referências bibliográficas e estudos que envolviam somente diabetes tipo 2 ou gestacional. $\mathrm{O}$ critério de inclusão foi estudos que avaliassem novas tecnologias para o manejo do diabetes tipo 1. No final resultou em 89 artigos selecionados para o presente trabalho. A partir dessa seleção foi construído um panorama das tecnologias em desenvolvimento para o diabetes tipo 1 e sinalizando aquelas mais promissoras.

Após identificação de tecnologias promissoras por meio do panorama tecnológico, foi realizada buscas no repositório de registros de produtos da Agência Nacional de Vigilância Nacional (ANVISA) para apontar a nova alternativa terapêutica para o diabetes tipo 1 aprovada para comercialização no país. Em seguida foi revisado o repositório de solicitações de incorporações tecnológicas da Comissão Nacional de Incorporação de Tecnologias no SUS (CONITEC), com o objetivo de identificar se havia solicitações ou decisões para reembolso pelo Sistema Único de Saúde (SUS) de tal tecnologia.

Para coleta de dados sobre as experiências das secretarias nacionais e organizações internacionais sobre tal tecnologia foram aplicados dois questionários. O questionário 1 (Quadro 1) foi aplicado aos membros de secretarias de saúde dos estados (SES) por meio da Rede Brasileira de Avaliação de Tecnologias em Saúde (REBRATS) e do Conselho Nacional dos Secretários de Saúde (CONASS). O questionário 2 (Quadro 1) foi aplicado às organizações internacionais de Avaliação de Tecnologias em Saúde (ATS) por meio da lista de membros da rede Internacional de Avaliação de Tecnologias em Saúde (INAHTA). 
Quadro 1. Questões dos Questionários Aplicados.

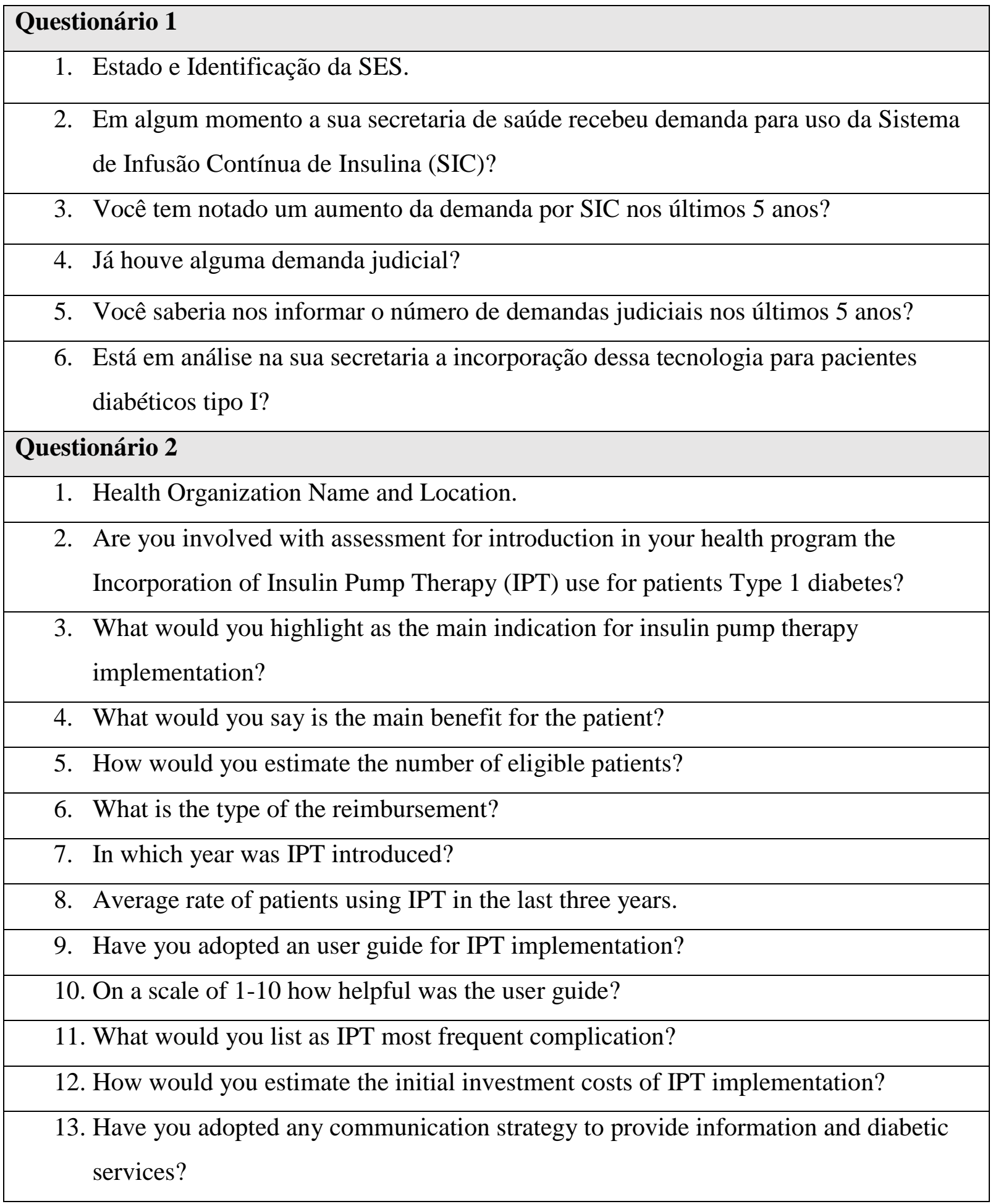

Fonte: Elaboração própria. 
A INAHTA possui membros de 31 países e o questionário 2 (Quadro 1) foi enviado a todos eles. A Figura 1 demonstra os 15 países que participaram desse inquérito. Alguns países informaram o ano da incorporação do SIC nos seus respectivos sistemas de saúde e outros também informaram o número médio de usuários (Figura 1).

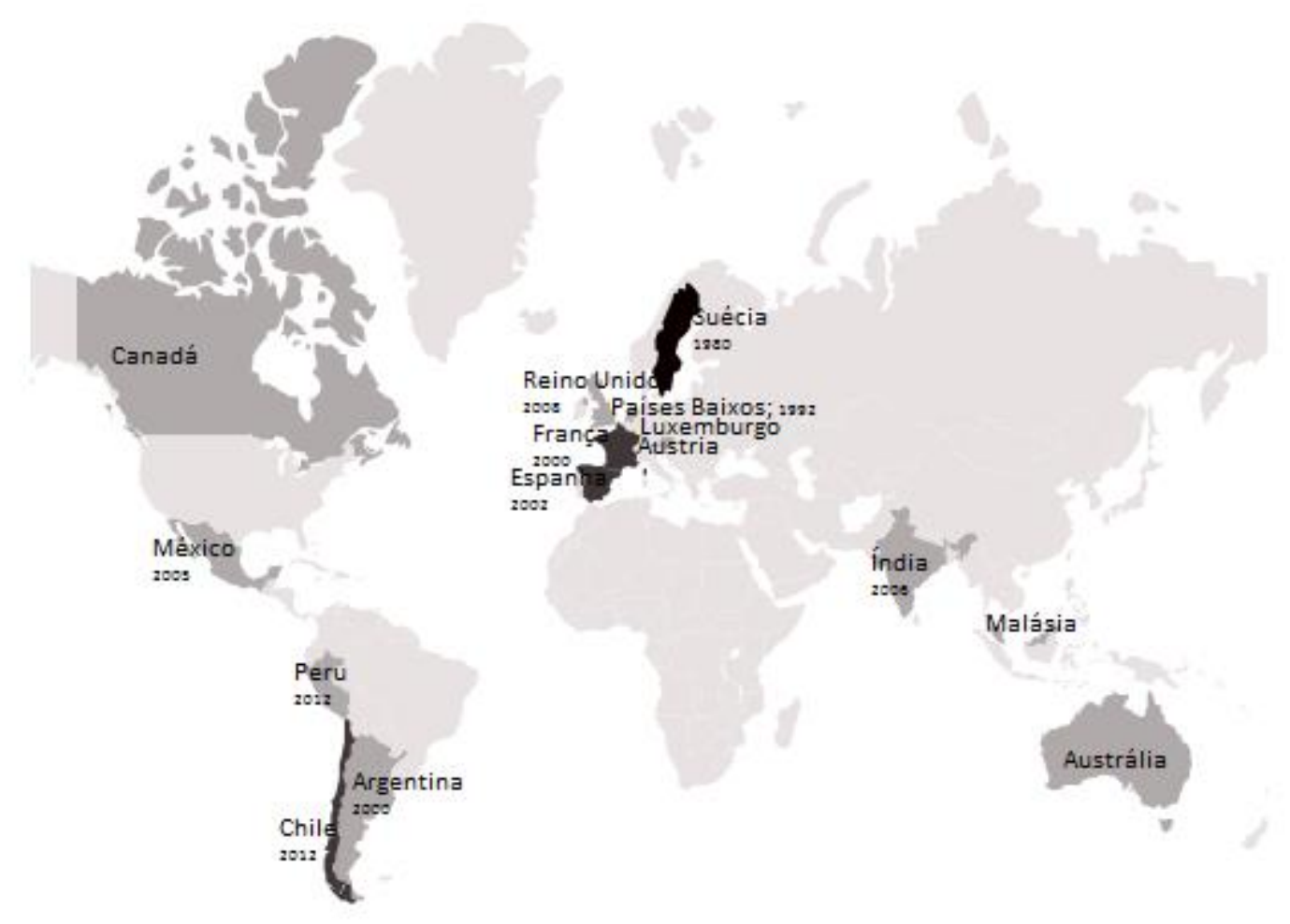

Região que não participou da pesquisa

Países que participaram da pesquisa

Países que participaram da pesquisa e informaram o número médio de usuários do SIC

Fonte: Elaboração própria.

Figura 1. Países entrevistados e ano de incorporação do Sistema de Infusão Contínua de Insulina. 
Além disso, foi solicitado ao governo federal por meio da Lei de Acesso a Informações (CGU, 2013), dados de aquisições de SIC por via judicial de 2011 a 2014 (Apêndice A e B). 


\section{RESULTADOS E DISCUSSÃO}




\section{RESULTADOS E DISCUSSÃO}

Pacientes com diabetes mellitus tipo 1 (DM1) possuem uma destruição progressiva das células $\beta$ pancreáticas, levando à insulinopenia e à hiperglicemia. A velocidade desse processo destrutivo é variável de paciente para paciente, alguns levam anos, outros em alguns meses para acometer às células e consequentemente mudam clinicamente o efeito da doença no organismo. Já no diabetes mellitus tipo 2 (DM2) os eventos de hiperglicemia prejudicam a função da célula beta e vai agravando a resistência à insulina, podendo com o tempo levar a perda total da função das células betas e consequentemente à dependência de insulina externa para o controle da glicemia (MCCULLOCH; NATHAN; MULDER, 2015).

O termo "terapia intensiva de insulina" descreve o tratamento por infusão subcutânea contínua de insulina através de uma bomba de infusão visando favorecer um perfil mais fisiológico. O início da insulinoterapia intensiva nos pacientes diabéticos resistentes à insulina interfere na perda da função residual das células betas (células $\beta$ pancreáticas). Quando iniciam a insulinoterapia intensiva em tempo o risco dessa perda cai $57 \%$ em relação à terapia convencional ou aplicações múltiplas diárias (MDI). Destarte, ao promover a preservação destas células favorecerá uma hemoglobina glicada (HA1c) baixa e uma diminuição de 50\% do risco de desenvolvimento de complicações em comparação àqueles que realizaram a terapia intensiva sem ter a função residual preservada. (MCCULLOCH; NATHAN; MULDER, 2015).

A Organização Mundial de Saúde (OMS) considera as doenças crônicas não transmissíveis (DCNT) como doenças multifatoriais que se desenvolvem ao longo da vida e que possuem elevado período de duração (WHO, 2014). Por essas e outras características, as DNCTs são extremamente relevantes por diminuírem a qualidade de vida dos portadores, por causarem muitas mortes (são responsáveis por 63\% das mortes no mundo) (WHO, 2014) e por onerarem os sistemas de saúde pública.

No Brasil, as DNCTs acompanham esse cenário mundial, e correspondem a $72 \%$ das causas de mortes. As doenças que fortemente contribuem para essa estatística são as doenças do aparelho circulatório (31,3\%), câncer (16,3\%), doença respiratória crônica $(5,8 \%)$ e diabetes $(5,2 \%)$, atingindo indivíduos de todas as camadas socioeconômicas (MALTA et al., 
2011). Isso se confirma com os dados estatísticos da OMS para as Américas sobre as vinte principais causas de morte para o ano de 2015 e 2030 (Figura 2), em que a isquemia cardíaca, infarto e o diabetes são as três principais doenças causadoras de morte nos dois períodos (MATHERS; LONCAR, 2006; WHO, 2013).

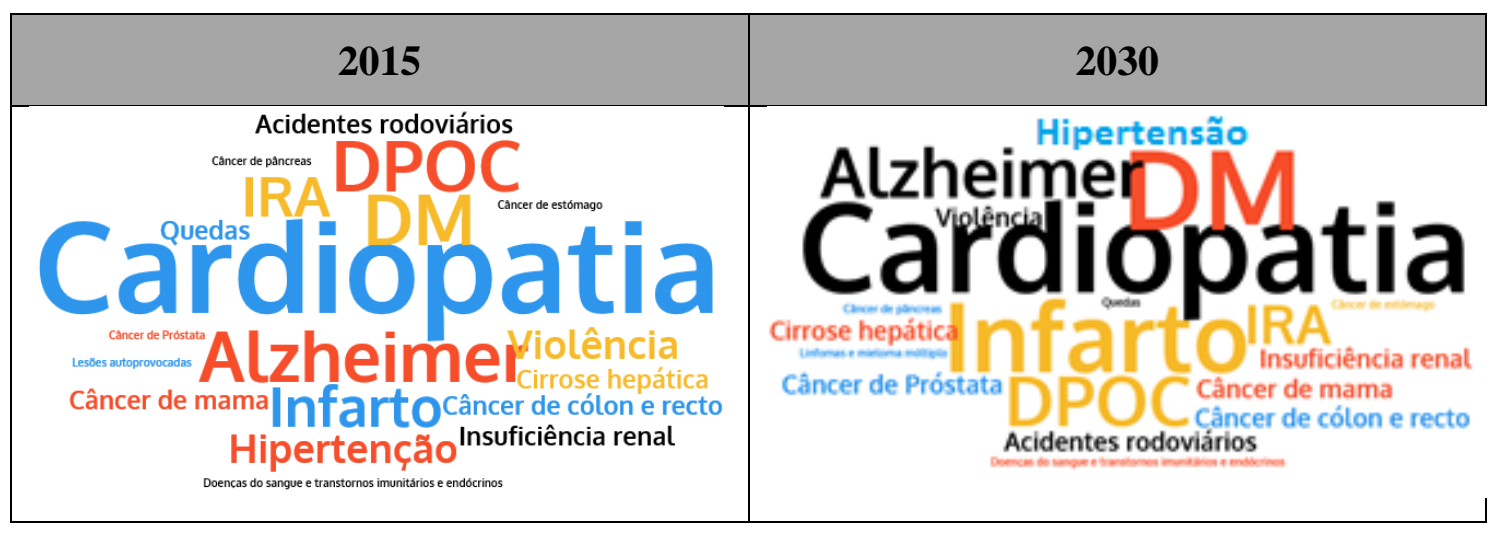

Fonte: Elaboração própria.

Figura 2. As 20 principais causas de morte nas Américas no ano 2015 e projeção para 2030 de acordo com a OMS.

Legenda: DPOC: Doença Pulmonar Obstrutiva Crônica; IRA: Infecção Respiratória Aguda; DM: Diabetes Mellitus.

A expansão da população idosa e da epidemia da obesidade faz com que o diabetes aumente na população de forma muito rápida. Além disso, o diabetes está associado a graves efeitos colaterais no sistema cardiovascular e renal, o que a torna ainda mais preocupante e provedora de mortes prematuras. Um estudo colaborativo liderado pelo Institute for Health Metrics and Evaluation (IHME) da Universidade de Washington, envolveu 500 pesquisadores de 50 países para avaliar a Carga Global de Doença, Lesões e Fatores de Risco (GLOBAL BURDEN OF DISEASE (GBD)., 2010). Dentre os achados para o Brasil em termos de anos de vida perdidos (number of years of life lost; YLLs), as mortes prematuras por doença isquêmica do coração e cerebrovasculares obtiveram uma das mais altas taxas em 2010. A carga global da doença utiliza também o indicador, e o estudo encontrou que no Brasil dentre as 25 importantes causas, o principal fator de risco é a alimentação (GLOBAL BURDEN OF DISEASE (GBD)., 2010).

$\mathrm{Na}$ hierarquização das 25 principais causas de YLLs por mortes prematuras no Brasil de 1990 a 2010, em 1990 o diabetes ocupava a $17^{\text {a }}$ posição e em 2010 passou a ocupar a $7^{\text {a }}$ 
posição (GLOBAL BURDEN OF DISEASE (GBD)., 2010). Isso demonstra a grande relevância para saúde pública do cuidado do portador de diabetes nos contextos atuais, que incluem alimentação balanceada com a possibilidade de autogestão do controle da glicemia no sangue, acompanhamento multiprofissional, e incorporação de hábitos saudáveis de vida.

O diabetes não esteve presente entre as 10 principais causas de DALYs, em 1990, mas entrou na lista em 2010 e permaneceu em 2013 (Figura 3) (GLOBAL BURDEN OF DISEASE (GBD)., 2010, 2013).

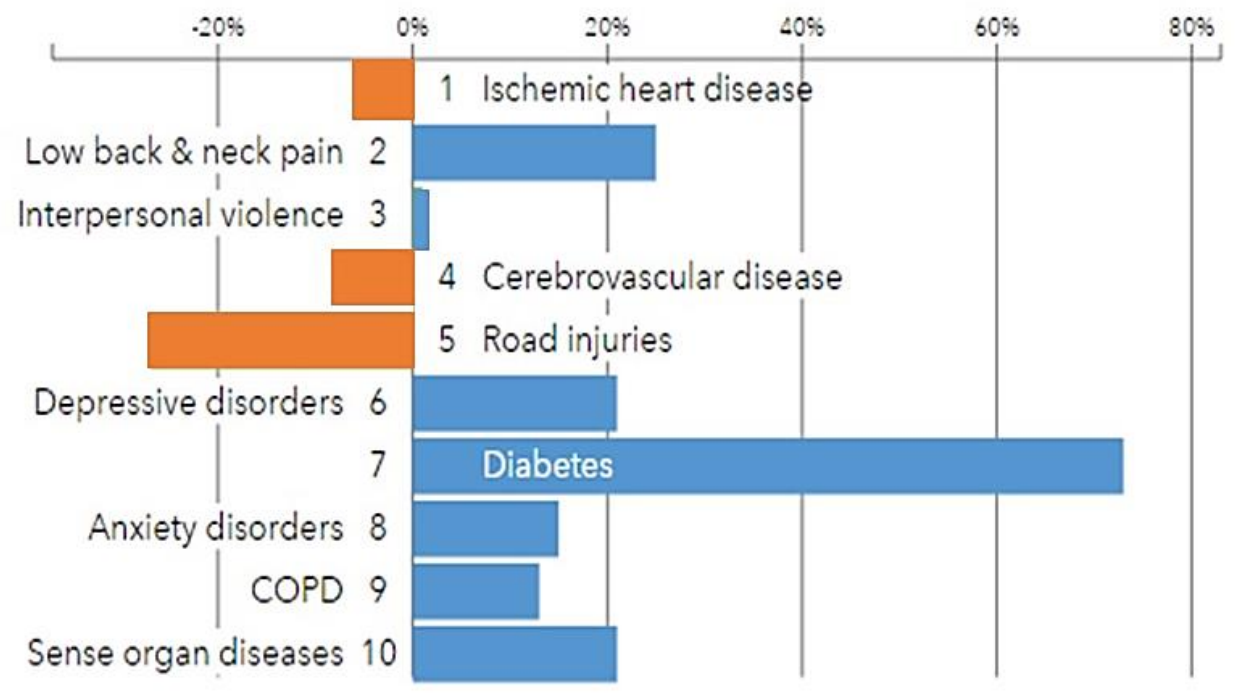

Fonte: GBD, 2013.

Figura 3. As 10 principais causas de DALY no Brasil em 2013.

No ranking dos fatores de riscos, o hábito alimentar ficou em primeiro lugar no Brasil, seguido da hipertensão; ambos demonstraram relação com o diabetes. $\mathrm{O}$ alto índice de massa corporal ficou em quarto lugar e a alta concentração de glicose no sangue ficou em sexto lugar, ambos fatores também demonstrou forte relação com problemas cardiovasculares e diabetes (GLOBAL BURDEN OF DISEASE (GBD)., 2010). 
E no ranking para as principais causas de DALYs em 1990 e 2010 para o diabetes (Figura 4), países da América como, por exemplo, Costa Rica e Cuba possuíam em 1990 taxa de DALY padronizado por idade igual a 2 e 10, respectivamente. E em 2010, os mesmos apresentaram taxa de DALY padronizada por idade igual a 1 e 5, respectivamente. Diferentemente, o Brasil que tinha taxa de DALY padronizada por idade em 1990 igual a 7 , em 2010 essa taxa subiu para 8 (Figura 4) (GLOBAL BURDEN OF DISEASE (GBD)., 2010).

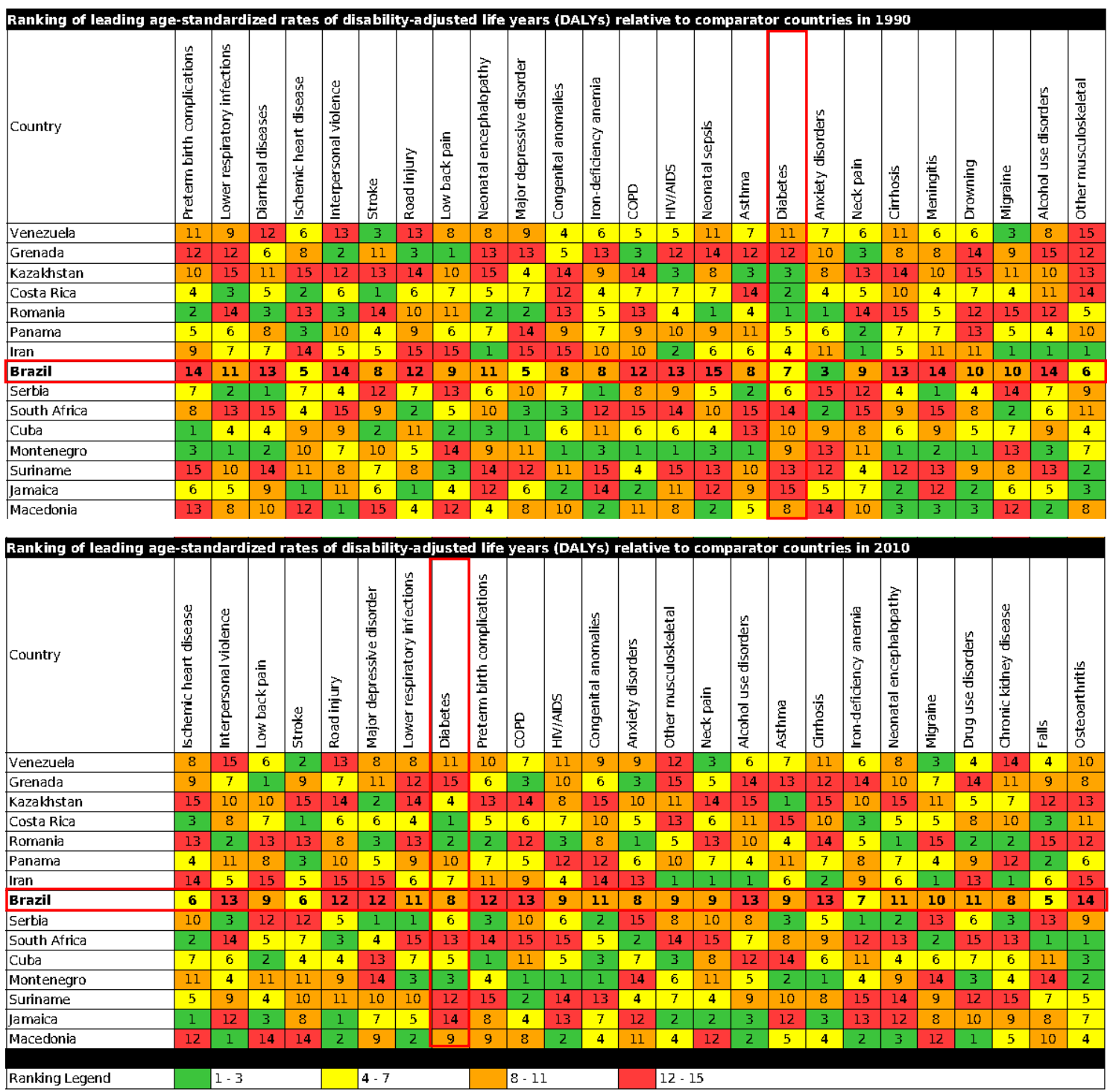

Nota: As colunas são ordenadas pelo número absoluto de DALYs no Brasil para determinado ano, com maior peso no lado esquerdo. Os números indicam a posição dos países para cada causa em termos de taxas de DALY padronizado por idade, sendo que 1 como a melhor performance e 15 como a pior.

Fonte: GBD, 2010.

Figura 4. Comparação da carga global de doença entre países de 1990 e 2010. 
A Vigilância dos Fatores de Risco e Proteção para Doenças Crônicas por Inquérito Telefônico realizada em 2013 verificou que os casos de diabetes tende a aumentar com o avanço da idade em ambos os sexos, com uma tendência maior após os 45 anos, uma vez que aos 65 anos, um quinto da população já apresentava diagnóstico médico de diabetes. Além disso, a frequência de indivíduos com diagnóstico médico de diabetes aumenta em média de 0,2 pontos percentuais ao ano (BRASIL. MINISTÉRIO DA SAÚDE., 2014, 2015). E a projeção para 2035 para o Brasil não é das melhores: de acordo com as estimativas da Federação Internacional do Diabetes (IDF) o Brasil poderá ter 19,2 milhões de casos (“International Diabetes Federation.”, 2013).

A fim de identificar dados atuais da prevalência do diabetes no Brasil, utilizou-se o Sistema de Cadastramento e Acompanhamento de Hipertensos e Diabéticos (Sistema HiperDia). Identificou-se um contingente de 7,1 milhões de casos de diabetes nos últimos 10 anos no Brasil (Figura 5). No entanto, o HiperDia possui algumas limitações, uma vez que o monitoramento de pacientes atendidos e cadastrados na rede ambulatorial do SUS pode variar de região para região. Além disso, a alimentação contínua e adequada do sistema depende muito da capacidade técnica e de infraestrutura de cada rede regional.

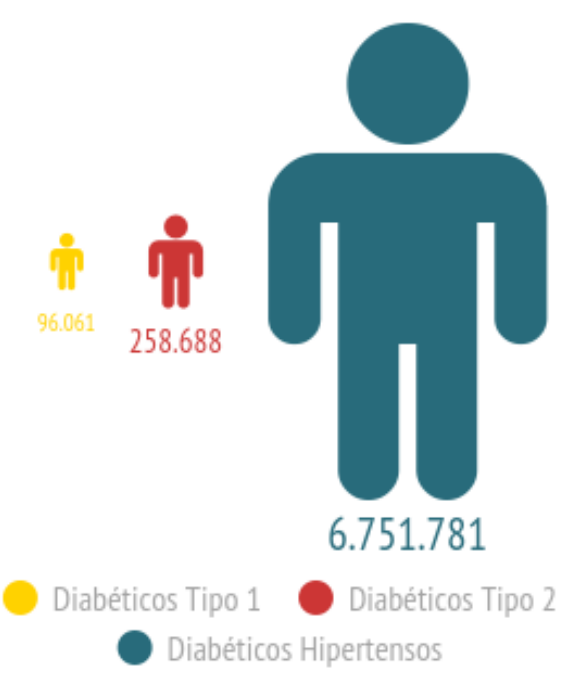

Fonte: Sistema Hiperdia, Ministério da Saúde, 2015.

Figura 5. Número de Diabéticos por tipo e risco, 01/2005 até 08/2015; Brasil. 
De 2000 a 2009, a taxa de internação hospitalar por diabetes permaneceu entre 65 a 75 internações a cada 100 mil habitantes por ano (MALTA et al., 2011). Já em 2011 a taxa de internação hospitalar por diabetes foi de 126 a cada 100 mil habitantes (MALTA et al., 2011). Estima-se que com 15 anos após o início do diabetes, 2\% dos diabéticos desenvolvem cegueira e $10 \%$ desenvolvem deficiência visual grave. Ao longo da doença (dependendo do grau de controle da glicemia no decorrer do tempo, dos hábitos de vida, e das características de cada um) 30 a $45 \%$ dos diabéticos desenvolvem algum grau de retinopatia, 10 a $20 \%$ desenvolvem nefropatia, 20 a 35\% neuropatia e 10 a 25\% doenças cardiovasculares (KING; AUBERT; HERMAN, 1998).

Todos esses fatores contribuem para o aumento dos casos de morte relacionados ao diabetes no mundo. No Brasil, estima-se que o diabetes causa mais de 80.000 mortes por ano (10 mortes por hora) (“International Diabetes Federation.”, 2013). Em 2014, 6\% dos óbitos no Brasil foram provocados pelo diabetes (WHO, 2014). Mais de 10\% dos óbitos ocorrem a partir dos 50 anos de idade para ambos os sexos (Figura 6). 


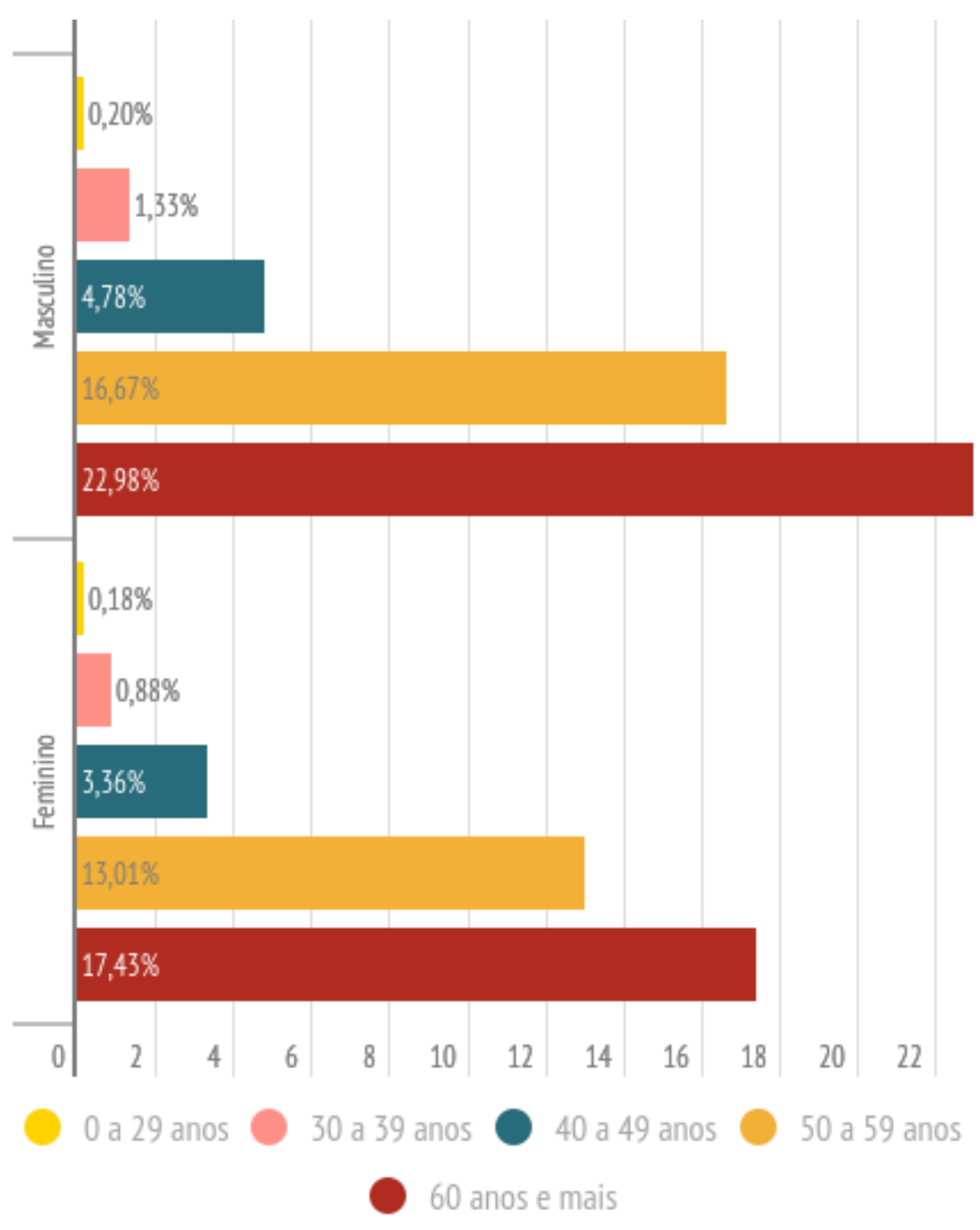

Fonte: Ministério da Saúde/SVS - Sistema de Informações de Mortalidade (SIM) e IBGE, 2015.

Figura 6. Taxa de mortalidade específica para o diabetes mellitus por faixa etária e sexo, 2005 a 2011; Brasil.

Em 2011, o diabetes foi responsável por 30,1 óbitos a cada 100 mil habitantes, e óbitos devido a complicações agudas do diabetes foi de 2,45 a cada 100 mil habitantes em 2010, sendo que 0,29 a cada 100 mil habitantes eram menores de 40 anos de idade (ISER et al., 2015). 
Por meio do Componente Básico da Assistência Farmacêutica descentralizado, o Ministério da Saúde (MS) financia e adquire as insulinas (insulina humana NPH 100 UI/ml e a insulina humana regular $100 \mathrm{UI} / \mathrm{ml}$ ) de forma centralizada para as Centrais de Abastecimento Farmacêutico Estaduais e do Distrito Federal (BRASIL, 2013). A distribuição das insulinas no Estado e Municípios compete às Secretarias Estaduais de Saúde (SES) (BRASIL, 2013). Em 2006 foi aprovada a Lei $n^{\circ}$ 11. 347, que definiu os medicamentos orais (glibenclamida, glicazida e metformina) e injetáveis (insulinas humana NPH e Regular), além dos insumos (fitas reativas, lancetas e seringas com agulha acoplada) para o tratamento dos pacientes diabéticos usuários do SUS nas unidades básicas de saúde (BOTEGA, 2013). Nesse sentido, as insulinas são adquiridas e fornecidas por meio de dois programas federais: Componente Básico da Assistência Farmacêutica e Programa Farmácia Popular do Brasil (PFBP).

Em 2011, o MS lançou o Plano de Ações Estratégicas para o Enfretamento das DNCTs no Brasil, de 2011 a 2022, que estabelece objetivos, metas e ações no período de 10 anos para combater principalmente o acidente vascular cerebral, infarto, hipertensão arterial, câncer, diabetes e doenças respiratórias crônicas. Uma das metas é alcançar a redução de $2 \%$ ao ano na mortalidade das DNCTs responsáveis pelas causas de morte conforme destaca OMS (MALTA et al., 2011). Observa-se que no eixo "Cuidado Integral" o Plano prevê o "fortalecimento de mecanismos de verificação de custo-efetividade para a incorporação de novas tecnologias voltadas às DCNT na Comissão de Incorporação de Tecnologias do Ministério da Saúde (CONITEC)" e o "fortalecimento de processos de monitoramento de equipamentos, produtos, insumos e medicamentos, garantindo a qualidade e a segurança das tecnologias" (MALTA et al., 2011).

\subsection{TERAPIAS BASEADAS NA LIBERAÇÃO DE INSULINA}

As primeiras insulinas utilizadas para o tratamento do diabetes foram de origem suína e bovina. No entanto, eram comuns eventos adversos como formação de abcessos, alergia e lipodistrofia, principalmente relacionados às impurezas da preparação e à presença de anticorpos. Devido a isso, novas pesquisas focaram no desenvolvimento de moléculas biocompatíveis. Desde que a insulina humana foi isolada, os estudos avançaram consideravelmente, principalmente no desenvolvimento de novas preparações e novos dispositivos de liberação de insulina (Figura 7). Dessa forma, foi possível diminuir os eventos 
adversos, melhorar a adesão do paciente ao tratamento e aumentar a eficácia no controle da glicemia (GARBER, 2014; ROBERTSON; GLAZER; CAMPBELL, 1999).

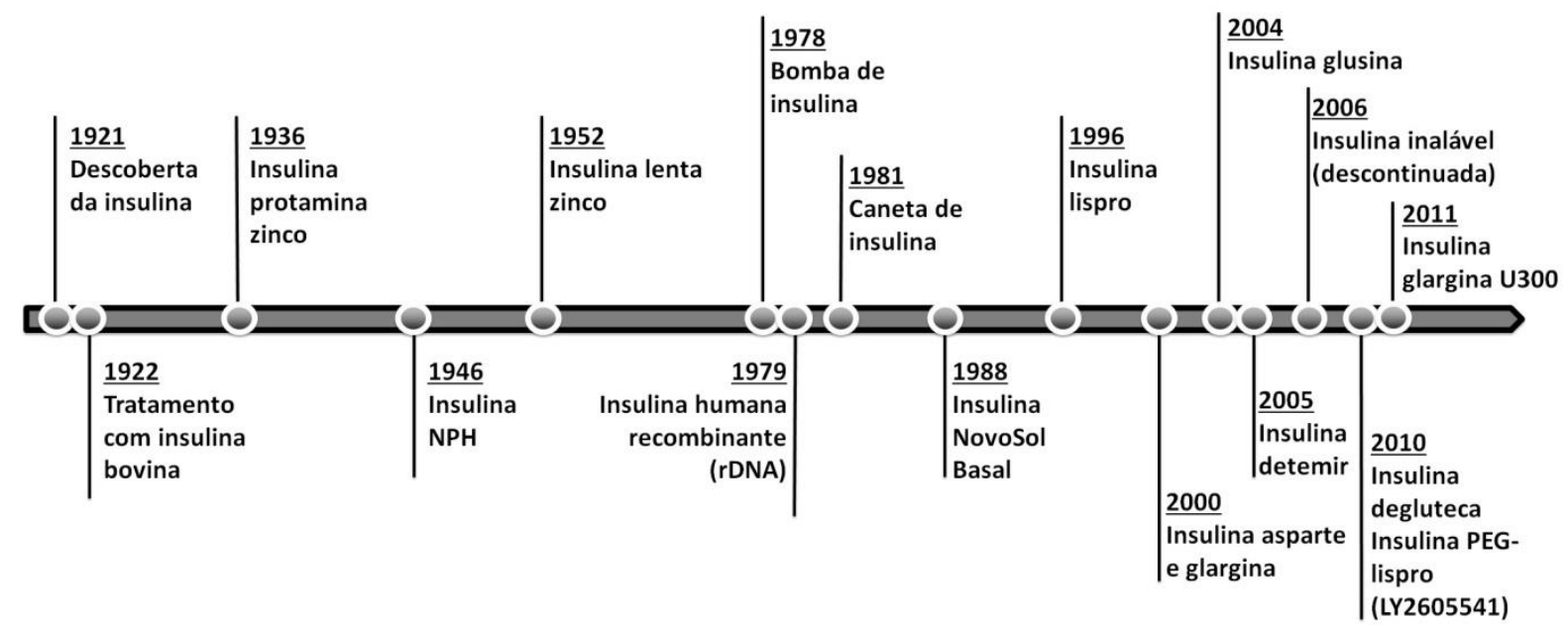

Fonte: Elaboração própria.

Figura 7. Linha do tempo dos primeiros avanços nos sistemas de liberação de insulina.

O início da utilização da insulina humana na terapêutica fez com que as insulinas de origem suína e bovina fossem descontinuadas do mercado (GARBER, 2014). A insulina humana regular é uma preparação que possui a mesma estrutura da insulina fisiológica e apresenta curta duração de ação. Já a insulina NPH (Neutral Protamine Hagedorn) é uma suspensão de insulina regular complexada com zinco e protamina em tampão fosfato e capaz de promover um efeito intermediário (MOHAN et al., 2014). A insulina humana DNA recombinante, obtida por biotecnologia, foi um passo adiante, ao modificar a insulina suína para produzir uma molécula quimicamente idêntica à insulina humana (MO et al., 2014). Em seguida, foram desenvolvidos os análogos de insulina e novos sistemas de liberação.

A insulina humana é um polipeptídio de duas cadeias, tendo as cadeias A (contendo 21 aminoácidos) e B (contendo 30 aminoácidos) unidas por pontes dissulfeto (Cys-S-S-Cys) (MOHAN et al., 2014). A modificação dessas cadeias levou ao desenvolvimento de análogos de insulina (AI) de ação ultrarrápida, o que possibilitou a administração do medicamento no momento da alimentação, ao contrário da insulina humana que exige administração 30-40 
minutos antes da ingestão de carboidratos. Adicionalmente, os AIs surgiram com o objetivo de oferecer uma redução do risco de hipoglicemia (GARBER, 2014). As principais modificações estruturais estão descritas na Tabela 1.

Tabela 1. Características estruturais no desenvolvimento dos Análogos de Insulina (AI).

\begin{tabular}{|c|c|}
\hline $\begin{array}{l}\text { Análogo de } \\
\text { Insulina }\end{array}$ & Modificações \\
\hline Lispro & $\begin{array}{l}\text { Inversão da sequência nas posições B28 e B29 da insulina humana, além } \\
\text { das moléculas estarem na forma de hexâmetros }\end{array}$ \\
\hline Asparte & $\begin{array}{l}\text { Substituição da prolina pelo ácido aspártico em B28, desfavorecendo a } \\
\text { auto-associação em mesmo grau da lispro. }\end{array}$ \\
\hline Glulisina & $\begin{array}{l}\text { Substituição da lisina por ácido glutâmico em B29 e substituição da } \\
\text { asparagina pela lisina em B3, levando a uma redução da auto-associação. }\end{array}$ \\
\hline Glargina & $\begin{array}{l}\text { Substituição da } \mathrm{Asn}^{21 \mathrm{~A}} \text { e alongamento da cadeia B pela edição } \mathrm{Arg}^{31} \text { e } \\
\mathrm{Arg}^{32} \text { com solubilidade reduzida em } \mathrm{pH} \text { de } 7,4 \text {, que, consequentemente, é } \\
\text { absorvido de modo mais lento e atua por um período mais longo. }\end{array}$ \\
\hline Detemir & $\begin{array}{l}\text { Supressão de Tre }{ }^{30 \mathrm{~B}} \text { e adição de um grupo miristoil ao grupo } \varepsilon \text {-amino a } \\
\text { Lis }{ }^{29 \mathrm{~B}} \text {, o que aumenta a ligação reversível à albumina, diminuindo a } \\
\text { velocidade do transporte do endotélio vascular para os tecidos e } \\
\text { proporcionando uma ação prolongada. }\end{array}$ \\
\hline
\end{tabular}

Fonte: BRUNTON, Laurence L., 12 ed., 2012.

Aos pacientes inclui administração de insulina no regime basal-bolus. A dose basal, de acordo com o perfil fisiológico do pâncreas, é constituída pelo fornecimento contínuo de insulinas de ação lenta. Já a dose em bolus é constituída por grandes quantidades de insulina de ação mais rápida, administradas antes das refeições, que são liberadas quando há aumento de glicose no sangue (GARBER, 2014; MOHAN et al., 2014). Assim, a combinação de diferentes tipos de insulina pode ser utilizada, de acordo com o perfil do paciente (Tabela 2). 
Tabela 2. Classificação dos tipos de insulina quanto à velocidade de ação.

\begin{tabular}{|c|c|c|c|c|}
\hline $\begin{array}{c}\text { Categoria de } \\
\text { ação }\end{array}$ & Insulina & Início (h) & Pico (h) & $\begin{array}{l}\text { Duração } \\
\text { efetiva }(h)\end{array}$ \\
\hline \multirow{3}{*}{$\begin{array}{l}\text { Ação } \\
\text { ultrarrápida } \\
\text { (curta duração) }\end{array}$} & Lispro (Humalog ${ }^{\circledR} ;$ Eli Lilly) & $<0,25$ & $0,5-1,5$ & $3-5$ \\
\hline & $\begin{array}{l}\text { Glulisina } \text { (Apidra }^{\circledR} ; \text { Sanofi- } \\
\text { aventis) }\end{array}$ & $<0,25$ & $0,5-1,5$ & $3-5$ \\
\hline & $\begin{array}{l}\text { Asparte } \text { (Novorapid }^{\circledR} ; \text { Novo } \\
\text { Nordisk) }\end{array}$ & $<0,25$ & $0,5-1,5$ & $3-5$ \\
\hline $\begin{array}{c}\text { Ação rápida } \\
\text { (curta duração) }\end{array}$ & $\begin{array}{l}\left.\text { Regular } \text { (Humulin }^{(}\right) \text {R; } \text { Eli } \\
\text { Lilly e } \text { Novolin }^{\circledR} \text { R; Novo } \\
\text { Nordisk) }\end{array}$ & $0,5-1,0$ & $2-3$ & $3-6$ \\
\hline $\begin{array}{l}\text { Ação } \\
\text { intermediária }\end{array}$ & $\begin{array}{l}\text { NPH (Humulin } \text { NPH }^{\circledR} ; \text { Eli } \\
\text { Lilly e Novolin }{ }^{\circledR} \mathrm{N} \text {; Novo } \\
\text { Nordisk) }\end{array}$ & $2-4$ & $4-12$ & $12-18$ \\
\hline \multirow{2}{*}{$\begin{array}{l}\text { Insulina de ação } \\
\text { lenta (longa } \\
\text { duração) }\end{array}$} & 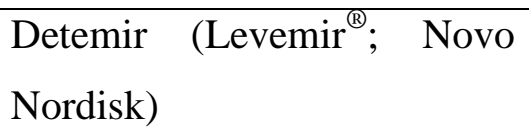 & $1-2$ & $6-8$ & $6-23$ \\
\hline & $\begin{array}{l}\text { Glargina } \quad \text { (Lantus }{ }^{\circledR} ; \text { Sanofi- } \\
\text { aventis) }\end{array}$ & 1 & Mínimo & 24 \\
\hline \multirow{4}{*}{ Combinações } & $\begin{array}{l}75 / 25-75 \% \text { lispro protamina, } \\
25 \% \text { lispro }\end{array}$ & $<0,25$ & 1,5 & $\begin{array}{c}\text { Até } 10- \\
16\end{array}$ \\
\hline & $\begin{array}{l}70 / 30 \quad-70 \% \quad \text { asparte } \\
\text { protamina, } 30 \% \text { asparte }\end{array}$ & $<0,25$ & 1,5 & $\begin{array}{c}\text { Até } 10 \text { - } \\
16\end{array}$ \\
\hline & $\begin{array}{l}50 / 50-50 \% \text { lispro protamina, } \\
50 \% \text { lispro }\end{array}$ & $<0,25$ & 1,5 & $\begin{array}{c}\text { Até } 10 \text { - } \\
16\end{array}$ \\
\hline & $\begin{array}{llll}70 / 30 & -70 \% & \mathrm{NPH}, & 30 \% \\
\text { regular } & & & \end{array}$ & $0,5-1,0$ & Duplo $^{\mathrm{a}}$ & $10-16$ \\
\hline
\end{tabular}

a Duplo: dois picos, um nas $2-3$ primeiras horas, e outro várias horas depois.

Fonte: Modificado de Hardman et al., 2012. 
Formulações incluindo diversas combinações de insulinas tiveram o objetivo de melhorar o controle da glicemia. No entanto, o arsenal terapêutico ainda não é o ideal. A baixa frequência (44 - 63\%) no monitoramento das taxas glicêmicas, somada aos eventos de hipoglicemia noturnos, dificulta a percepção dos pacientes quanto à necessidade de um ajuste na dose de insulina (GARBER, 2014). Além disso, a necessidade de repetidas aplicações subcutâneas é um fator importante, que diminui a adesão do paciente ao tratamento, tornando o controle eficiente do diabetes mais difícil (MO et al., 2014).

\subsection{PANORAMA TECNOLÓGICO NA LBERAÇÃO DE INSULINA PARA O DIABETES}

Aplicações repetidas de injeções subcutâneas de insulina são frequentemente associadas a dor, sensibilidade, necrose tecidual local e contaminação microbiana (MO et al., 2014). A fim de tentar solucionar estes problemas e a baixa adesão ao tratamento, novas formulações, novas técnicas de aplicação e novos dispositivos para liberação controlada de peptídeo vêm sendo desenvolvidos com o uso da nanotecnologia.

O princípio da nanotecnologia envolve o desenvolvimento de formulações ou estruturas ou materiais ou sistemas que irão apresentar propriedades químicas, físico-químicas e comportamentais diferentes na escala manométrica (Figura 8). Em 2014, a ANVISA criou um comitê interno de nanotecnologia, com o objetivo de elaborar normas ou guias específicos para a avaliação e controle de produtos que utilizam nanotecnologia (BRASIL, 2014).

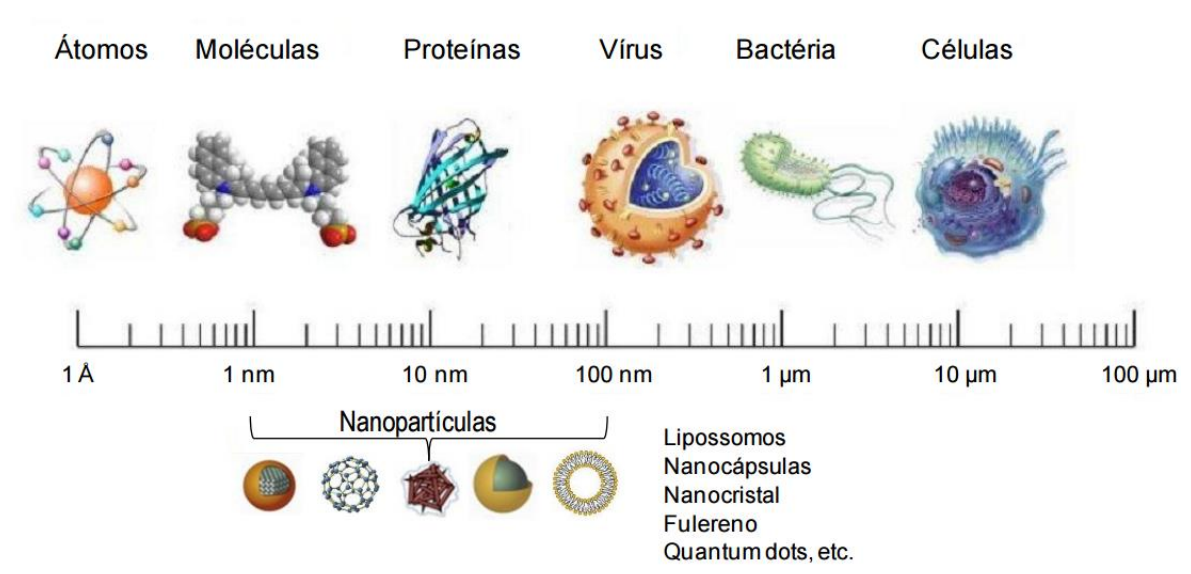

Fonte: Binsfeld, 2013.

Figura 8. Representação de moléculas, partículas, células e objetos representados sobre uma escala nanométrica $(1 \mathrm{~nm}=0,000000001 \mathrm{~m})$. 


\subsubsection{Formulações em desenvolvimento na liberação de insulina pela via subcutânea}

Existem vários desenvolvimentos de formulações em fase pré-clínica envolvendo a nanotecnologia para liberação da insulina pela via subcutânea. Tem-se pesquisado a ligação covalente do ácido polissiálico (PSA) à insulina com a proposta de aumentar sua solubilidade, prevenindo agregação, melhorando a estabilidade e o tempo de circulação sanguínea. Essa estratégia aumenta a eficácia e diminui a frequência de administração. Um estudo em camundongos observou que após a aplicação da insulina livre, os níveis glicêmicos nadir foram alcançados em cerca de $1 \mathrm{~h}$ e retornaram aos valores de antes da aplicação após $3 \mathrm{~h}$. Quando utilizada a formulação proposta, o valor nadir também foi alcançado dentro de $1 \mathrm{~h}$, entretanto, o retorno à taxa glicêmica inicial demorou cerca de 9 horas. Outra possível vantagem dessa formulação é a diminuição da imunogenicidade, o que ampliaria sua utilização (JAIN et al., 2003).

A complexação da insulina glargina com a maltosil- $\beta$-ciclodextrina (G(2)- $\beta$-CyD) aumentou a solubilidade da insulina e diminuiu a sua agregação. Após o complexo ser administrado a camundongos diabéticos, foi observado que a diminuição dos níveis glicêmicos foi realizada de forma sustentada, sem apresentação de picos de glicose (UEHATA et al., 2012). Esse efeito pode resultar em diminuição de complicações relacionadas a picos de hiperglicemia ao longo do tratamento.

Uma formulação de insulina em hidrogel contendo nanofibras de peptídeos, após ser aplicada pela via subcutânea em camundongos, diminuiu os níveis glicêmicos entre 70 e 80 \% e apresentou liberação prolongada de insulina, com manutenção dos baixos níveis de glicose plasmática por até 24 horas (NISHIMURA et al., 2012).

Além do desenvolvimento de formulações com dispersão de insulina, uma abordagem que vem sendo muito utilizada consiste na encapsulação nanofibras de peptídeos em carreadores específicos. Tais carreadores nano ou micrométricos podem retardar a degradação ou desnaturação da insulina, tornando possível a diminuição da dose e aumento da sua eficácia.

Como exemplo, a injeção subcutânea de um hidrogel contendo nanopartículas de poli 3-hidroxibutirato-co-3-hidroxi-hexanoato com insulina foi capaz de promover um efeito hipoglicemiante em camundongos diabéticos, com duração superior a 5 dias. Em adição, o 
hidrogel com as nanopartículas possibilitou um aumento da biodisponibilidade da insulina de 379,85\% quando comparada à da insulina livre dispersa no mesmo hidrogel (PENG et al., 2013).

Nanopartículas de dextrana contendo insulina e a enzima glucose oxidase foram capazes de modular in vitro a liberação de insulina de acordo com a concentração de glicose no meio. Em estudos in vivo, após uma única injeção em camundongos diabéticos, o sistema proporcionou o estado normoglicêmico por até 10 dias (GU et al., 2013).

A microencapsulação de insulina utilizando o polímero PLGA (ácido poli(láctico-coglicólico) resultou em uma formulação capaz de manter normais os níveis plasmáticos de glicose em jejum por período superior a 55 dias após uma única administração em camundongos diabéticos (KIM et al., 2009).

Outro estudo desenvolveu um complexo de insulina com quitosana e zinco e o dispersou no poliéster biodegradável PLA-PEG-PLA. Em modelos de camundongos diabéticos, além de diminuir significativamente o efeito de liberação burst da insulina injetável, a formulação foi capaz de manter normal a glicemia em jejum por um período extenso de até 3 meses (OAK; SINGH, 2012).

\subsubsection{Estudos clínicos de formulações na liberação de insulina pela via subcutânea}

Existem algumas formulações para liberação da insulina pela via subcutânea em fase de desenvolvimento mais avançada. Alguns estudos em fase clínica avaliaram a adição de um sistema de entrega molecular para proteínas terapêuticas (BioChaperone ${ }^{\circledR}$; ADOCIA) à AI já comercializados, como por exemplo a Insulina HinsBet ${ }^{\circledR}$ U100 com BioChaperone ${ }^{\circledR}$ (Tabela 3), que é a insulina lispro com o sistema BioChaperone ${ }^{\circledR}$ com o objetivo de diminuir a duração do efeito e facilitar a absorção do AI lispro.

Também se tem estudado a insulina lispro peguilada com o objetivo de retardar a absorção e promover uma ação prolongada do AI lispro (Tabela 3). Essa combinação pretende oferecer uma redução da dose de insulina e diminuir casos de hipoglicemia grave. 
Tabela 3. Novas formulações de insulina em estudo clínico.

\begin{tabular}{|c|c|c|c|c|c|c|c|c|}
\hline Formulação & $\begin{array}{c}\text { Fase do } \\
\text { estudo }\end{array}$ & $\begin{array}{l}\mathbf{N}^{0} \text { estudo } \\
\text { clínico }\end{array}$ & Status & VA & Função & $\begin{array}{c}\text { Categoria } \\
\text { de ação }\end{array}$ & Responsável & Fonte \\
\hline $\begin{array}{l}\text { Insulina, } \\
\text { HinsBet } \AA \\
\text { U100 com } \\
\text { BioChaperon } \\
\text { e }{ }^{\circ} \\
\text { (ADOCIA) }\end{array}$ & $\begin{array}{l}\text { Clínica } \\
\text { (I) }\end{array}$ & $\begin{array}{l}\text { NCT02344992 } \\
\text { NCT02514850 } \\
\text { NCT02514954 } \\
\text { NCT02528396 } \\
\text { NCT02529293 } \\
\text { NCT02562313 } \\
\text { NCT02562326 }\end{array}$ & $\begin{array}{c}\mathrm{C} \\
\text { REC } \\
\text { REC } \\
\text { REC } \\
\text { REC } \\
\text { REC } \\
\text { REC }\end{array}$ & $\mathrm{SC}$ & I & $\mathrm{R}$ & $\begin{array}{c}\text { Adocia / } \\
\text { França }\end{array}$ & $\begin{array}{l}\text { (“CenterWat } \\
\text { ch.", 2015) }\end{array}$ \\
\hline $\begin{array}{l}\text { Insulina } \\
\text { lispro } \\
\text { PEGuilada } \\
\text { (LY2605541) }\end{array}$ & $\begin{array}{l}\text { Clínica } \\
\text { (III) }\end{array}$ & $\begin{array}{l}\text { NCT01792284 } \\
\text { NCT01894568 } \\
\text { NCT01790438 } \\
\text { NCT01435616 } \\
\text { NCT01481779 } \\
\text { NCT01468987 } \\
\text { NCT02106364 }\end{array}$ & $\begin{array}{c}\mathrm{C} \\
\mathrm{C} \\
\mathrm{C} \\
\mathrm{C} \\
\mathrm{C} \\
\mathrm{C} \\
\mathrm{NR}\end{array}$ & $\mathrm{SC}$ & I & L & Eli Lilly & $\begin{array}{l}\text { (MO et al., } \\
\text { 2014) }\end{array}$ \\
\hline
\end{tabular}

SIGLAS: C: o estudo clínico terminou, e os participantes não estão mais sendo examinados ou tratados; I: tecnologia para liberação de insulina no organismo; L: lenta; NR: o estudo clínico não começou a recrutar participantes ainda; R: rápida; REC: o estudo clínico está neste momento recrutando participantes; SC: subcutâneo; VA: via de administração.

Fonte: Elaboração própria.

\subsubsection{Dispositivos em desenvolvimento na liberação de insulina pela via subcutânea}

Os Sistemas de infusão contínua de insulina (SIC), ou comumente conhecidos como bomba de infusão de insulina, se apresentam como alternativa à MDI. Com o objetivo de eliminar tubulações e diminuir o volume do SIC, estão em desenvolvimento bombas de insulina adesivas (em inglês, insulin patch pumps) (Tabela 4). Esses novos dispositivos promovem maior discrição e conveniência, por serem leves, sem fios, aderentes ao corpo, parcialmente ou completamente descartáveis e com possibilidade de manipulação sob a roupa, ou por um dispositivo externo via wireless, além de evitarem múltiplas injeções diárias. No entanto, ainda existe baixa adesão por ser uma tecnologia de custo muito alto (ALTABAKHA; ARIDA, 2008; ANHALT; BOHANNON, 2010). 
Tabela 4. Horizonte dos sistemas de infusão subcutânea contínua de insulina em estudo préclínico.

\begin{tabular}{l|c|c|c|c|c}
\hline \multicolumn{1}{c|}{ Dispositivo } & $\begin{array}{c}\text { Fase do } \\
\text { estudo }\end{array}$ & VA & Função & Responsável & Fonte \\
\hline Bomba Cellnovo & Pré-clínica & SC & SIC & Cellnovo Ltd. & $\begin{array}{c}\text { (ANHALT; } \\
\text { BOHANNON, } \\
\text { 2010) }\end{array}$ \\
\hline Bomba Freehand & Pré-clínica & SC & SIC & $\begin{array}{c}\text { MedSolve } \\
\text { Technologies }\end{array}$ & $\begin{array}{c}\text { BOHANALT; } \\
\text { 2010) }\end{array}$ \\
\hline Bomba Medipacs & Pré-clínica & SC & SIC & Medipacs & $\begin{array}{c}\text { (ANHALT; } \\
\text { BOHANNON, } \\
\text { 2010) }\end{array}$ \\
\hline Bomba Medtronic & Pré-clínica & SC & SIC & Medtronic & $\begin{array}{c}\text { (ANHALT; } \\
\text { BOHANNON, } \\
\text { 2010) }\end{array}$ \\
\hline $\begin{array}{l}\text { Bomba SteadyMed } \\
\text { patch pump }\end{array}$ & Pré-clínica & SC & SIC & SteadyMed Ltd. & $\begin{array}{c}\text { (ANHALT; } \\
\text { BOHANNON, } \\
\text { 2010) }\end{array}$ \\
\hline
\end{tabular}

SIGLAS: SC: subcutâneo; SIC: Sistema de infusão contínua de insulina; VA: via de administração.

Fonte: Elaboração própria.

\subsubsection{Estudos clínicos de dispositivos para liberação de insulina pela via subcutânea}

Existem vários sistemas fechados de liberação inteligente de insulina (em inglês, closed-loop smart insulin delivery) em desenvolvimento, eles se destacam por imitarem a função do pâncreas, liberando a insulina de acordo com os níveis plasmáticos de glicose, minimizando os riscos de eventos hipo ou hiperglicêmicos (Tabela 5). 
Tabela 5. Horizonte dos sistemas de infusão subcutânea contínua de insulina em estudo clínico.

\begin{tabular}{|c|c|c|c|c|c|c|c|}
\hline Dispositivo & $\begin{array}{l}\text { Fase do } \\
\text { estudo }\end{array}$ & $\begin{array}{l}\mathbf{N}^{0} \text { estudo } \\
\text { clínico }\end{array}$ & Status & VA & Função & $\begin{array}{c}\text { Respon } \\
\text { sável }\end{array}$ & Fonte \\
\hline $\begin{array}{l}\text { Bomba } \\
\text { Combo }\end{array}$ & Observacional & NCT01657630 & $\mathrm{C}$ & $\mathrm{SC}$ & SIC+MCG & Roche & $\begin{array}{c}\text { (“Diabetes } \\
\text { Forecast.27”, 2015) }\end{array}$ \\
\hline $\begin{array}{l}\text { Bomba } \quad \text { MiniMed } \\
\text { Revel 2.0 Enlite CGM }\end{array}$ & Intervencional & NCT01881009 & $\mathrm{C}$ & $\mathrm{SC}$ & SIC+MCG & $\begin{array}{c}\text { Medtroni } \\
\mathrm{c}\end{array}$ & $\begin{array}{c}\text { (“Diabetes } \\
\text { Forecast.27”, 2015) }\end{array}$ \\
\hline $\begin{array}{l}\text { Bomba Accu-Chek } \\
\text { Insight }\end{array}$ & Intervencional & NCT02105103 & $\mathrm{C}$ & $\mathrm{SC}$ & SIC+MCG & Roche & $\begin{array}{c}\text { (“Diabetes } \\
\text { Forecast.27”, 2015) }\end{array}$ \\
\hline Bomba NiliPatch & Intervencional & $\begin{array}{l}\text { NCT00797771 } \\
\text { NCT00592241 } \\
\end{array}$ & $\mathrm{C}$ & $\mathrm{SC}$ & SIC & \begin{tabular}{|l|} 
NiliMED \\
IX Ltd. \\
\end{tabular} & $\begin{array}{c}\text { (ANHALT; } \\
\text { BOHANNON, 2010) } \\
\end{array}$ \\
\hline Bomba OmniPod $®$ & Intervencional & NCT00935129 & $\mathrm{C}$ & $\mathrm{SC}$ & SIC & $\begin{array}{c}\text { Insulet } \\
\text { Corp. }\end{array}$ & $\begin{array}{c}\text { (ANHALT; } \\
\text { BOHANNON, 2010) }\end{array}$ \\
\hline Bomba $\mathrm{PaQ}$ pump & $\begin{array}{c}\text { Intervencional/ } \\
\text { Observacional }\end{array}$ & $\begin{array}{l}\text { NCT02419859 } \\
\text { NCT02158078 }\end{array}$ & $\begin{array}{c}\text { REC } \\
\text { C }\end{array}$ & $\mathrm{SC}$ & SIC & CeQur & $\begin{array}{c}\text { (ANHALT; } \\
\text { BOHANNON, 2010) }\end{array}$ \\
\hline $\begin{array}{l}\text { Bomba Implantada } \\
\text { NovoRapid PumpCart } \\
\text { (Accu-Chek Insight) }\end{array}$ & & Trial 024/UK & & $\mathrm{SC}$ & SIC & $\begin{array}{l}\text { Novo } \\
\text { Nordisk }\end{array}$ & $\begin{array}{c}\text { (“Diabetes } \\
\text { Forecast.27”, 2015) }\end{array}$ \\
\hline Bomba Solo ${ }^{\mathrm{TM}}$ & Clínica (I) & $\begin{array}{l}\text { NCT01055951 } \\
\text { NCT01500928 } \\
\end{array}$ & $\begin{array}{c}\mathrm{C} \\
\mathrm{ND} \\
\end{array}$ & $\mathrm{SC}$ & SIC & Medingo & $\begin{array}{c}\text { (ANHALT; } \\
\text { BOHANNON, 2010) } \\
\end{array}$ \\
\hline $\begin{array}{ll}\text { Bomba } & \text { Animas } \\
\text { Vibe }^{\mathrm{TM}} & \\
\end{array}$ & Clínica (I) & $\begin{array}{l}\text { NCT01638299 } \\
\text { NCT00874809 }\end{array}$ & $\mathrm{C}$ & $\mathrm{SC}$ & SIC+MCG & Animas & $\begin{array}{c}\text { (ANHALT; } \\
\text { BOHANNON, 2010) }\end{array}$ \\
\hline Bomba Finesse $\mathrm{e}^{\mathrm{TM}}$ & Clínica (II) & NCT02542631 & REC & $\mathrm{SC}$ & SIC & \begin{tabular}{|c|} 
Calibra \\
Medical \\
Inc. \\
\end{tabular} & $\begin{array}{c}\text { (ANHALT; } \\
\text { BOHANNON, 2010) }\end{array}$ \\
\hline Pâncreas Biônico & Clínica (II / III) & $\begin{array}{l}\text { NCT02509065 } \\
\text { NCT02092220 } \\
\text { NCT02105324 } \\
\text { NCT01833988 } \\
\text { NCT02181127 } \\
\text { NCT02536950 } \\
\text { NCT02516150 } \\
\text { NCT02018627 } \\
\text { NCT01819844 } \\
\text { NCT01762059 }\end{array}$ & NR & $\mathrm{SC}$ & $\mathrm{SICg}+\mathrm{MCG}$ & & $\begin{array}{l}\text { (DENECKE, 2015; } \\
\text { RUSSELL, 2015) }\end{array}$ \\
\hline $\begin{array}{l}\text { Bomba JewelPUMPTM } \\
\text {, Nanopump }\end{array}$ & Clínica (III) & $\begin{array}{l}\text { NCT02097316 } \\
\text { NCT01640210 }\end{array}$ & $\mathrm{C}$ & $\mathrm{SC}$ & SIC & $\begin{array}{c}\text { Debiotec } \\
\text { h, } \\
\text { STMicro } \\
\text { electroni } \\
\text { cs }\end{array}$ & $\begin{array}{c}\text { (ANHALT; } \\
\text { BOHANNON, 2010) }\end{array}$ \\
\hline $\begin{array}{lr}\text { Bomba } & \mathrm{V}-\mathrm{Go}^{\mathrm{TM}} \\
\text { transdérmica } & \text { h-Patch } \\
\end{array}$ & Clínica (IV) & $\begin{array}{l}\text { NCT02361489 } \\
\text { NCT01326598 }\end{array}$ & $\begin{array}{c}\text { REC } \\
\text { C }\end{array}$ & $\mathrm{SC}$ & SIC & $\begin{array}{c}\text { Valeritas } \\
\text { Inc. }\end{array}$ & $\begin{array}{c}\text { (ANHALT; } \\
\text { BOHANNON, 2010) }\end{array}$ \\
\hline
\end{tabular}

SIGLAS: C: o estudo clínico terminou, e os participantes não estão mais sendo examinados ou tratados; NR: o estudo clínico não começou a recrutar participantes ainda; REC: o estudo clínico está neste momento recrutando participantes; SC: subcutâneo; SIC: Sistema de infusão contínua de insulina; SIC+MCG: Sistema de infusão contínua de insulina com sistema para monitoramento contínuo da glicemia; SICg+MCG: Sistema de infusão contínua de insulina e glucagon com sistema para monitoramento contínuo da glicemia; VA: via de administração.

Fonte: Elaboração própria. 
Tais pesquisas têm avançado pela utilização de biomateriais poliméricos, biossensores e nanotecnologia. No "pâncreas artificial" (Figura 9), o controlador utiliza algoritmos individualizados para liberação de insulina sem necessidade de intervenção do usuário, possibilitando uma automação no monitoramento contínuo da glicemia (MCG) e maior liberdade ao paciente (ANHALT; BOHANNON, 2010).

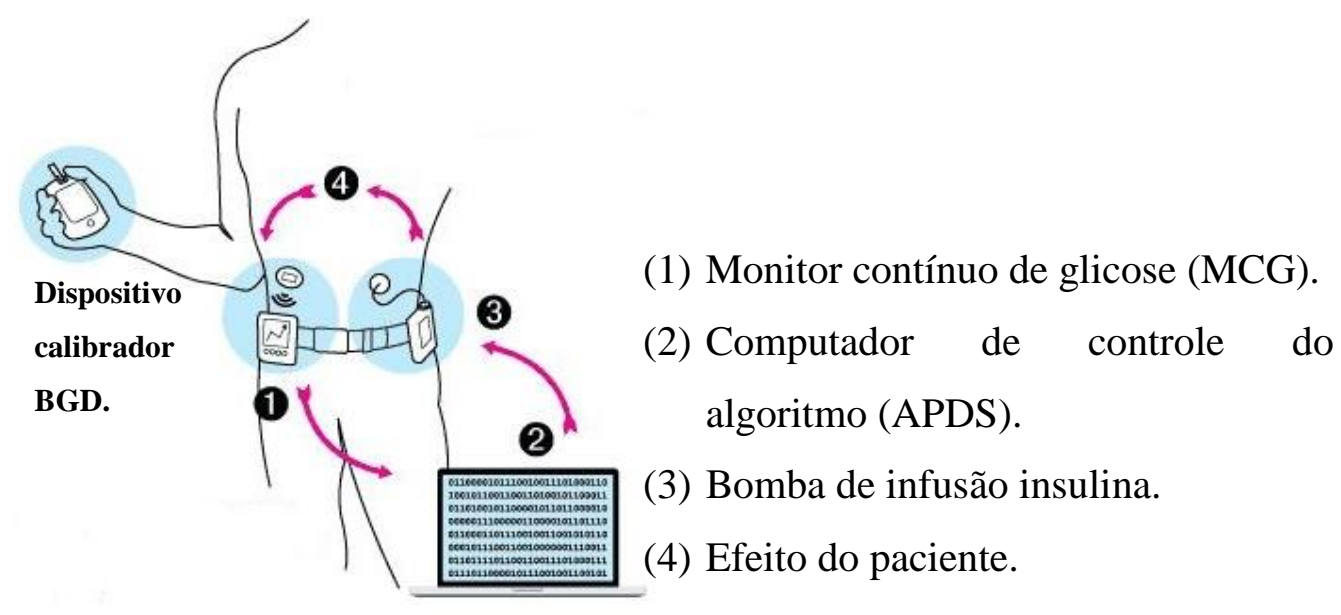

Nota:

(1) O Monitor contínuo de glicose (MCG). O MCG fornece um fluxo constante de informação que se destina a refletir os níveis de glicose no sangue do paciente. Um sensor colocado sob a pele do paciente (por via subcutânea) mede a glicose no fluido (líquido intersticial), para correlacionar com níveis de glicose no sangue. Um pequeno transmissor envia informações para um receptor. O MCG continuamente exibe uma estimativa dos níveis de glicose no sangue e a taxa de variação destas estimativas. Para obter as estimativas mais precisas de sangue glicose o paciente precisa calibrar periodicamente o MCG através de outro dispositivo medidor de glicose do sangue (BGD).

(2) Computador de controle do algoritmo (APDS). Um computador de controle de algoritmo possui um software em um processador externo (controlador) que recebe as informações do paciente via o sistema MCG e executa uma série de cálculos matemáticos. Baseado nesses cálculos, o controlador envia instruções de dosagem para a bomba de infusão de insulina.

(3) Bomba de infusão insulina. A bomba ajusta a liberação da infusão de insulina subcutânea de acordo com as instruções enviadas pelo controlados do APDS.

(4) Efeito do paciente. A concentração de glicose no sangue do paciente está em constante mudança e isso afeta a sua dieta, atividades e a metabolização. Isso faz com que o paciente seja a parte mais importante do ADPS.

Fonte: FDA. Disponível em:

http://www.fda.gov/downloads/MedicalDevices/DeviceRegulationandGuidance/GuidanceDoc uments/UCM259305.pdf.

Figura 9. Sistema de infusão de insulina e monitoramento contínuo da glicemia (Pâncreas artificial). 
Entre os dispositivos, o Pâncreas Biônico (Figura 10) promete permitir o monitoramento contínuo de glicose juntamente com a liberação subcutânea de insulina de ação rápida e glucagon, controlado por um algoritmo de computador ("Bionic Pancreas", 2015). Os estudos dessa tecnologia já estão bem avançados, estudos clínicos de fase 2 e 3 (Tabela 5) e a prospecção é que se iniciem as solicitações para autorização de comercialização em breve, sendo disponibilizado até 2018.

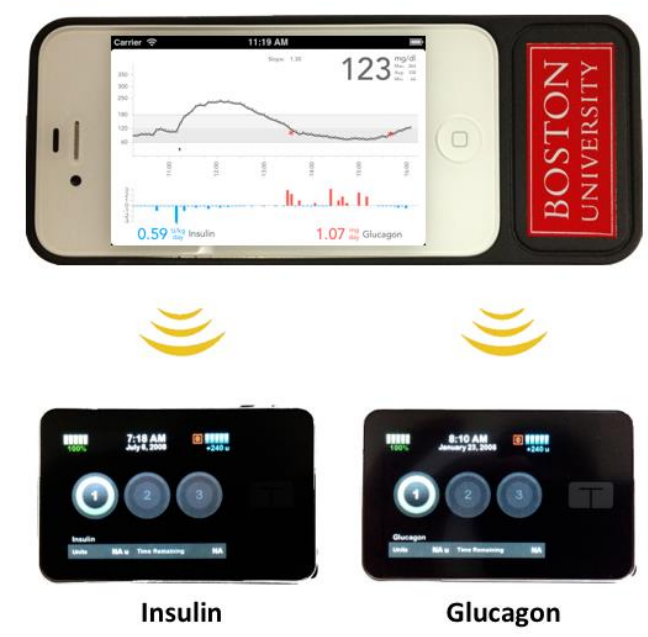

Fonte: http://www.artificialpancreas.org/.

Figura 10. Sistema de infusão de insulina e glucagon com sistema de monitoramento contínuo da glicemia (Pâncreas Biônico).

Todas essas inovações, entretanto, envolvem técnicas invasivas. Por esse motivo, a busca por métodos não invasivos tem grande potencial para melhorar a qualidade de vida e promover melhor adesão dos pacientes ao tratamento, diminuindo, consequentemente, as complicações associadas ao descontrole glicêmico. A administração por vias alternativas pode favorecer uma terapia indolor em relação à terapia tradicional (VEISEH et al., 2014). Ainda assim, é importante ressaltar que a insulina apresenta várias barreiras para absorção no trato gastrointestinal, cavidade nasal, região pulmonar e na aplicação tópica, trazendo desafios ao desenvolvimento de formulações para administração por essas vias (Tabela 6). 
Tabela 6. Barreiras na liberação da insulina quando administrada por vias alternativas.

\begin{tabular}{|c|c|c|c|}
\hline $\begin{array}{c}\text { Via de } \\
\text { administracão }\end{array}$ & \multicolumn{2}{|c|}{ Barreira } & Motivo \\
\hline \multirow[b]{3}{*}{ Oral } & Física & $\begin{array}{l}\text { Células epiteliais } \\
\text { intestinais }\end{array}$ & $\begin{array}{l}\text { Repulsão eletrostática e impedimento } \\
\text { do transporte via difusão passiva devido } \\
\text { ao peso molecular da insulina }\end{array}$ \\
\hline & Química & $\begin{array}{l}\mathrm{pH} \text { ácido }(1.2- \\
\text { 3.0) ou } \mathrm{pH} \text { muito } \\
\text { alcalino }(6,5-8.0)\end{array}$ & Modificação da molécula de insulina \\
\hline & Enzimática & Enzimas digestivas & $\begin{array}{l}\text { Degradação da insulina pelas enzimas } \\
\text { tripsina, quimiotripsina e } \\
\text { carboxipeptidase e enzima degradante } \\
\text { de insulina (IDE). } \\
\left.\text { O citocromo P450 (CYP } \mathrm{CY}_{40}\right) \text { também } \\
\text { pode reduzir ainda mais a quantidade de } \\
\text { insulina absorvida que esteja na } \\
\text { circulação sistêmica }\end{array}$ \\
\hline \multirow{5}{*}{ Nasal } & \multirow[b]{2}{*}{ Física } & Muco, pelos & Não absorção \\
\hline & & $\begin{array}{c}\text { Permeabilidade } \\
\text { através da camada } \\
\text { de muco }\end{array}$ & $\begin{array}{l}\text { Repulsão eletrostática pela presença do } \\
\text { ácido siálico carregado negativamente e } \\
\text { pelas glicoproteínas com grupos sulfato }\end{array}$ \\
\hline & Enzimática & $\begin{array}{c}\text { Enzimas } \\
\text { proteolíticas }\end{array}$ & Degradação enzimática \\
\hline & \multirow[b]{2}{*}{$\begin{array}{l}\text { Físico- } \\
\text { química }\end{array}$} & $\begin{array}{l}\text { Rápida meia-vida } \\
\text { de eliminação }\end{array}$ & Baixa duração do efeito farmacológico \\
\hline & & $\begin{array}{l}\text { Tamanho, } \\
\text { densidade, forma e } \\
\text { higroscopicidade } \\
\text { da substância }\end{array}$ & Não absorção \\
\hline \multirow{4}{*}{ Pulmonar } & \multirow[t]{2}{*}{ Física } & Muco respiratório & $\begin{array}{l}\text { Impedimento para permear através da } \\
\text { bicamada de fosfolipídios da membrana } \\
\text { plasmática }\end{array}$ \\
\hline & & Epitélio alveolar & $\begin{array}{l}\text { Interferência do tamanho da partícula na } \\
\text { aerodinâmica para inalação }\end{array}$ \\
\hline & Enzimática & $\begin{array}{l}\text { Enzimas } \\
\text { pulmonares }\end{array}$ & $\begin{array}{l}\text { Boa parte das proteínas estão sujeitas à } \\
\text { degradação pela protease e dificulta o } \\
\text { carreamento proteico da insulina }\end{array}$ \\
\hline & Química & Macrófagos & $\begin{array}{l}\text { As proteínas em alvéolos estão sujeitas } \\
\text { ao afastamento por macrófagos, que } \\
\text { pode também secretar peroxidasses de } \\
\text { curta duração, mediadores inflamatórios } \\
\text { e imunomoduladores capazes de } \\
\text { degradar as proteínas. }\end{array}$ \\
\hline Transdérmica & Física & $\begin{array}{l}\text { Mecanismo de } \\
\text { proteção da pele } \\
\text { contra agentes } \\
\text { externos }\end{array}$ & $\begin{array}{l}\text { Dificuldade de penetração e de } \\
\text { liberação da insulina no organismo }\end{array}$ \\
\hline
\end{tabular}

Fonte: Elaboração própria. 


\subsubsection{Formulações orais para liberação de insulina em desenvolvimento}

Entre as vias alternativas de administração de medicamentos, a via oral é a mais utilizada por ser muito conveniente, devido à discrição e a não invasão. No entanto, essa via possui várias barreiras que dificultam a passagem da insulina para a corrente sanguínea. A fim de diminuir a degradação hidrolítica e enzimática da insulina pelo sistema gastrointestinal e aumentar a sua absorção através das membranas, a nanotecnologia vem sendo utilizada.

Um dos primeiros estudos publicados com nanopartículas de insulina para administração oral utilizou polialquilcianoacrilato como nanocarreador. Após administração em camundongos diabéticos, a glicemia em jejum diminuiu em cerca de 50-60\% no segundo dia após a administração oral de nanocápsulas com dose de insulina, 12,5 ou 50 U/kg e esse efeito se manteve durante 6 ou 20 dias, respectivamente (DAMGÉ et al., 1988).

A partir dos primeiros resultados promissores, com o passar do tempo, o interesse em desenvolver formulações para essa via foi crescendo e hoje mais de 400 pesquisas relacionadas à insulina oral já foram publicadas (ZIJLSTRA; HEINEMANN; PLUMMORSCHEL, 2014). Como exemplo, lipossomas com diferentes componentes como quitosana (MUKHOPADHYAY et al., 2012; SONG; ZHI; PICKUP, 2014; TAKEUCHI et al., 1996), biotina (ZHANG et al., 2014) e até sais biliares (NIU et al., 2014) vêm sendo desenvolvidos para proteger a insulina e melhorar sua biodisponibilidade. Nanopartículas lipídicas sólidas (LIU et al., 2007; SARMENTO et al., 2007; ZHANG et al., 2006), micro/nanocarreadores poliméricos (CHEN et al., 2011), complexos com ciclodextrina (D 'SOUZA et al., 2014; SAJEESH; SHARMA, 2006), nanopartículas metálicas ou magnéticas (CHO et al., 2014; TURCHENIUK et al., 2014), micro/nanogéis (CHATURVEDI et al., 2013; KARNOOSH-YAMCHI et al., 2014), e outros sistemas nanoparticulados também vem sendo estudados para a administração oral da insulina (Tabela 7). 
Tabela 7. Horizonte tecnológico das formulações orais na liberação de insulina em desenvolvimento.

\begin{tabular}{l|c|c|c|c|c|c|c}
\hline Formulação & $\begin{array}{c}\text { Fase do } \\
\text { estudo }\end{array}$ & $\begin{array}{c}\mathbf{N}^{\mathbf{0}} \text { estudo } \\
\text { clínico }\end{array}$ & VA & Função & $\begin{array}{c}\text { Categoria } \\
\text { de ação }\end{array}$ & Responsável & Fonte \\
\hline $\begin{array}{l}\text { Nanoesferas de } \\
\text { insulina e } \\
\text { polímero } \\
\text { biodegradável } \\
\text { (APH-0907) }\end{array}$ & Pré-clínica & $\begin{array}{c}\text { Teste Pré- } \\
\text { clínico }\end{array}$ & VO & $\mathrm{I}$ & $\mathrm{R}$ & $\begin{array}{c}\text { Aphios } \\
\text { Corporation }\end{array}$ & $\begin{array}{c}\text { (ZIJLSTRA; } \\
\text { HEINEMANN; } \\
\text { PLUM- } \\
\text { MORSCHEL, } \\
\text { 2014) }\end{array}$ \\
\hline $\begin{array}{l}\text { Nanopartículas } \\
\text { de insulina } \\
\text { (CobOralT }\end{array}$ \\
$\begin{array}{l}\text { Insulin) } \\
\begin{array}{l}\text { Trabi-OralTM } \\
\text { (TBL1002OI) }\end{array}\end{array}$ & Pré-clínica & $\begin{array}{c}\text { Teste Pré- } \\
\text { clínico }\end{array}$ & VO & $\mathrm{I}$ & $\mathrm{R}$ & $\begin{array}{c}\text { Access } \\
\text { Pharmaceuticals, } \\
\text { Inc }\end{array}$ & $\begin{array}{c}\text { (ZIJLSTRA; } \\
\text { HEINEMANN; } \\
\text { PLUM- } \\
\text { MORSCHEL, } \\
\text { 2014) }\end{array}$ \\
\hline
\end{tabular}

SIGLAS: I: tecnologia para liberação de insulina no organismo; R: rápida; VA: via de administração; VO: via oral.

Fonte: Elaboração própria.

Algumas insulinas orais (Oral-lynt e HDV-Insulin) já iniciaram estudos clínicos de fase 3 para verificar a segurança e eficácia do produto. Caso a conclusão desses estudos seja satisfatória, o próximo passo será a solicitação de registro para obtenção da autorização para comercialização. Entre os produtos que já tem autorização nos Estados Unidos da América (EUA) estão os produtos Solo ${ }^{\mathrm{TM}}$ Finesse $^{\mathrm{TM}}$ e, o Axcess $^{\mathrm{TM}}$ (Capsulin $^{\mathrm{TM}} \mathrm{OAD}$ ) na Índia (Tabela 8).

A absorção da insulina oral (IO) se tornou viável em jejum. A Insulina Oral em comprimido (EMISPHERE; Emisphere Technologies) demonstrou no ensaio clínico um rápido início e uma curta duração de ação, além de uma elevada variabilidade na absorção (Tabela 8). O Bioadesivo com tecnologia NP (Nodlin; NOD Pharmaceuticals / Shanghai Biolaxy) apresentou em ensaio clínico de fase II um perfil do tempo de ação semelhante ao da insulina NPH e não foi detectado aumento na concentração da insulina sérica (Tabela 8). A insulina com um sistema de liberação oral, POD ${ }^{\mathrm{TM}}$ (ORMD-0801; Oramed, Inc) em ensaio clínico de fase II esteve associada com uma redução significativa nas frequências de glicose (> $200 \mathrm{mg} / \mathrm{dL}$ ), com uma maior diminuição no início da noite. As cápsulas de insulina oral 
ORMD-0801 em conjunto aplicações subcutâneas, reduziu significativamente a glicemia ao longo do dia (Tabela 8).

Tabela 8. Horizonte tecnológico das formulações orais para liberação de insulina em estudo clínico.

\begin{tabular}{|c|c|c|c|c|c|c|c|c|}
\hline Formulação & $\begin{array}{c}\text { Fase do } \\
\text { estudo }\end{array}$ & $\begin{array}{l}\mathbf{N}^{\mathbf{o}} \text { estudo } \\
\text { clínico }\end{array}$ & Status & $\mathbf{V A}$ & Função & $\begin{array}{c}\text { Categoria } \\
\text { de ação }\end{array}$ & Responsável & Fonte \\
\hline $\begin{array}{l}\text { Comprimido } \\
\text { (IN-105 DM2) }\end{array}$ & Clínica (I) & NCT01035801 & & $\mathrm{VO}$ & I & $\mathrm{R}$ & Biocon & $\begin{array}{l}\text { (MO et al., } \\
2014)\end{array}$ \\
\hline $\begin{array}{l}\text { Comprimido } \\
\text { (EMISPHERE) }\end{array}$ & Clínica (I) & NCT00982254 & $\mathrm{C}$ & $\mathrm{VO}$ & I & $\mathrm{R}$ & $\begin{array}{c}\text { Emisphere } \\
\text { Technologies }\end{array}$ & $\begin{array}{c}\text { (MO et al., } \\
2014)\end{array}$ \\
\hline Intesulin & Clínica (I) & & & $\mathrm{VO}$ & I & & Coremed & $\begin{array}{l}\text { ("Diabetes } \\
\text { Forecast.2 } \\
\text { 7", 2015) }\end{array}$ \\
\hline $\begin{array}{l}\text { JPM Insulina } \\
\text { Oral: } \\
\text { Nanopatículas } \\
\text { de quitosana } \\
\text { em sistema } \\
\text { líquido }\end{array}$ & Clínica (I) & & & $\mathrm{VO}$ & I & & $\begin{array}{c}\text { Jordanian } \\
\text { Pharmaceutic } \\
\text { al }\end{array}$ & $\begin{array}{l}\text { (ZIJLSTR } \\
\text { A; } \\
\text { HEINEM } \\
\text { ANN; } \\
\text { PLUM- } \\
\text { MORSCH } \\
\text { EL, 2014) }\end{array}$ \\
\hline $\begin{array}{lr}\text { Insulina } & \\
\text { análoga } & \text { com } \\
\text { sistema } & \text { de } \\
\text { liberação } & \text { oral, } \\
\text { GIPET } & \\
(\mathrm{NN} 1952) & \\
\end{array}$ & Clínica (I) & NCT01028404 & $\mathrm{C}$ & $\mathrm{VO}$ & I & $\mathrm{R}$ & $\begin{array}{l}\text { Novo } \\
\text { Nordisk }\end{array}$ & $\begin{array}{l}\text { (ZIJLSTR } \\
\text { A; } \\
\text { HEINEM } \\
\text { ANN; } \\
\text { PLUM- } \\
\text { MORSCH } \\
\text { EL, 2014) }\end{array}$ \\
\hline $\begin{array}{lr}\begin{array}{l}\text { Insulina } \\
\text { análoga } \\
\text { sistema }\end{array} & \begin{array}{r}\text { com } \\
\text { liberação }\end{array} \\
\text { GIPET } & \text { oral, } \\
\text { (OI287GT } & \text { - } \\
\text { NN1956) } & \\
\end{array}$ & Clínica (I) & NCT01809184 & $\mathrm{C}$ & $\mathrm{VO}$ & I & $\mathrm{L}$ & $\begin{array}{c}\text { Novo } \\
\text { Nordisk }\end{array}$ & $\begin{array}{c}\text { (ZIJLSTR } \\
\text { A; } \\
\text { HEINEM } \\
\text { ANN; } \\
\text { PLUM- } \\
\text { MORSCH } \\
\text { EL, 2014) }\end{array}$ \\
\hline $\begin{array}{lr}\begin{array}{l}\text { Insulina } \\
\text { análoga } \\
\text { sistema }\end{array} \\
\text { liberação } \\
\text { GIPET }^{\circledR} \\
\text { (OI338GT } \\
\text { NN1953) }\end{array}$ & Clínica (I) & $\begin{array}{l}\text { NCT01334034 } \\
\text { NCT01931137 } \\
\text { NCT01796366 }\end{array}$ & $\mathrm{C}$ & $\mathrm{VO}$ & I & $\mathrm{L}$ & $\begin{array}{c}\text { Novo } \\
\text { Nordisk }\end{array}$ & $\begin{array}{l}\text { (ZIJLSTR } \\
\text { A; } \\
\text { HEINEM } \\
\text { ANN; } \\
\text { PLUM- } \\
\text { MORSCH } \\
\text { EL, 2014) }\end{array}$ \\
\hline $\begin{array}{lr}\begin{array}{l}\text { Insulina } \\
\text { análoga }\end{array} & \text { com } \\
\text { sistema } & \text { de } \\
\text { liberação } & \text { oral, } \\
\text { GIPET } & \\
\text { (OI362GT } & \text { - } \\
\text { NN1954) } & \end{array}$ & Clínica (I) & NCT01597713 & $\mathrm{C}$ & $\mathrm{VO}$ & I & $\mathrm{L}$ & $\begin{array}{c}\text { Novo } \\
\text { Nordisk }\end{array}$ & $\begin{array}{c}\text { (ZIJLSTR } \\
\text { A; } \\
\text { HEINEM } \\
\text { ANN; } \\
\text { PLUM- } \\
\text { MORSCH } \\
\text { EL, 2014) }\end{array}$ \\
\hline
\end{tabular}


Continuação Tabela 8.

\begin{tabular}{|c|c|c|c|c|c|c|c|c|}
\hline Formulação & $\begin{array}{l}\text { Fase do } \\
\text { estudo }\end{array}$ & $\begin{array}{l}\mathbf{N}^{0} \text { estudo } \\
\text { clínico }\end{array}$ & Status & VA & Função & $\begin{array}{c}\text { Categoria } \\
\text { de ação }\end{array}$ & Responsável & Fonte \\
\hline VIAtab & Clínica (I) & & & VO & I & & Biodel & $\begin{array}{l}\text { ("Diabetes } \\
\text { Forecast.2 } \\
7 \text { 7", 2015) }\end{array}$ \\
\hline $\begin{array}{l}\text { Insulina com } \\
\text { nanoencapsulação } \\
\text { soro-específica } \\
\text { (SSNe) }\end{array}$ & $\begin{array}{l}\text { Clínica } \\
\text { (ND) }\end{array}$ & & & VO & I & & $\begin{array}{c}\text { Tamarisk } \\
\text { Technologies/ } \\
\text { Deliv-RX }\end{array}$ & $\begin{array}{l}\text { (ZIJLSTR } \\
\text { A; } \\
\text { HEINEM } \\
\text { ANN; } \\
\text { PLUM- } \\
\text { MORSCH } \\
\text { EL, 2014) }\end{array}$ \\
\hline $\begin{array}{lr}\text { Bioadesivo } & \text { com } \\
\text { tecnologia } & \mathrm{NP} \\
\text { (Nodlin) } & \\
\end{array}$ & Clínica (II) & $\begin{array}{l}\text { ChiCTR- } \\
\text { TRC- } \\
12001872\end{array}$ & & VO & I & I & $\begin{array}{c}\text { NOD } \\
\text { Pharmaceutic } \\
\text { als / Shanghai } \\
\text { Biolaxy }\end{array}$ & $\begin{array}{c}\text { (MO et al., } \\
2014)\end{array}$ \\
\hline $\begin{array}{lr}\text { Insulina } & \text { com } \\
\text { sistema } & \text { de } \\
\text { liberaçãa } & \\
\text { Axcess } & \\
\text { (Capsulin } & \\
\text { OAD) } & \\
& \end{array}$ & Clínica (II) & & & VO & I & $\mathrm{R}$ & Diabetology & $\begin{array}{l}\text { (ZIJLSTR } \\
\text { A; } \\
\text { HEINEM } \\
\text { ANN; } \\
\text { PLUM- } \\
\text { MORSCH } \\
\text { EL, 2014) }\end{array}$ \\
\hline $\begin{array}{lr}\text { Insulina } & \text { com } \\
\text { sistema } & \text { de } \\
\text { liberação oral } & \text { de } \\
\text { proteína, PODTM } \\
\text { (ORMD-0801) }\end{array}$ & Clínica (II) & $\begin{array}{c}\text { NCT00867 } \\
594 \\
\text { NCT01889 } \\
667\end{array}$ & $\mathrm{C}$ & VO & I & $\mathrm{R}$ & Oramed, Inc & $\begin{array}{l}\text { (ZIJLSTR } \\
\text { A; } \\
\text { HEINEM } \\
\text { ANN; } \\
\text { PLUM- } \\
\text { MORSCH } \\
\text { EL, 2014) } \\
\end{array}$ \\
\hline $\begin{array}{l}\text { Insulina } \\
\text { conjugada } \quad \text { (IN- } \\
105)\end{array}$ & Clínica (II) & $\begin{array}{c}\text { NCT01035 } \\
801\end{array}$ & & VO & I & $\mathrm{R}$ & $\begin{array}{c}\text { Biocon/Bristo } \\
\text { 1-Myers } \\
\text { Squibb }\end{array}$ & $\begin{array}{l}\text { (ZIJLSTR } \\
\text { A; } \\
\text { HEINEM } \\
\text { ANN; } \\
\text { PLUM- } \\
\text { MORSCH } \\
\text { EL, 2014) }\end{array}$ \\
\hline $\begin{array}{l}\text { Insulina, } \\
\text { proinsulina, e C- } \\
\text { peptídeo em } \\
\text { carreador Oshadi } \\
\text { (Oshadi Icp) }\end{array}$ & Clínica (II) & $\begin{array}{c}\text { NCT01120 } \\
912 \\
\text { NCT01973 } \\
920 \\
\text { NCT01772 } \\
251\end{array}$ & $\begin{array}{c}\mathrm{C} \\
\mathrm{REC} \\
\mathrm{C}\end{array}$ & VO & I & $\mathrm{R}$ & Oshadi Drug & $\begin{array}{l}\text { (ZIJLSTR } \\
\text { A; } \\
\text { HEINEM } \\
\text { ANN; } \\
\text { PLUM- } \\
\text { MORSCH } \\
\text { EL, 2014) }\end{array}$ \\
\hline $\begin{array}{l}\text { Cápsula (ORMD } \\
0901 \text { - ORAL } \\
\text { GLP-1 DM2) }\end{array}$ & Clínica (II) & $\begin{array}{c}\text { NCT02535 } \\
715\end{array}$ & REC & VO & Adj & & Oramed & $\begin{array}{l}\text { ("CenterW } \\
\text { atch.", } \\
\text { 2015) }\end{array}$ \\
\hline
\end{tabular}


Continuação Tabela 8.

\begin{tabular}{|c|c|c|c|c|c|c|c|c|}
\hline Formulação & $\begin{array}{l}\text { Fase do } \\
\text { estudo }\end{array}$ & $\begin{array}{l}\mathbf{N}^{\circ} \text { estudo } \\
\text { clínico }\end{array}$ & Status & VA & Função & $\begin{array}{c}\text { Categoria } \\
\text { de ação }\end{array}$ & Responsável & Fonte \\
\hline $\begin{array}{l}\text { Cápsula (ORMD- } \\
0801 \text { DM2 e } \\
\text { DM1) }\end{array}$ & Clínica (II) & $\begin{array}{c}\text { NCT02496 } \\
000 \\
\text { NCT02535 } \\
715 \\
\text { NCT02094 } \\
534\end{array}$ & $\begin{array}{l}\text { REC } \\
\text { REC } \\
\text { C }\end{array}$ & $\mathrm{VO}$ & Adj & & Oramed & $\begin{array}{c}\text { (MO et al. } \\
2014)\end{array}$ \\
\hline Spray (Oral-lyn) & $\begin{array}{l}\text { Clínica } \\
\text { (III) }\end{array}$ & $\begin{array}{c}\text { NCT00668 } \\
850 \\
\text { NCT00948 } \\
493\end{array}$ & & VO & I & $\mathrm{R}$ & Generex & \begin{tabular}{|c} 
(MO et al. \\
$2014)$
\end{tabular} \\
\hline \begin{tabular}{l}
\multicolumn{2}{l}{ Vesícula } \\
nanocarreadora de \\
insulina com \\
direcionamento \\
hepático (HDV- \\
Insulin)
\end{tabular} & $\begin{array}{l}\text { Clínica } \\
\text { (III) }\end{array}$ & $\begin{array}{c}\text { NCT00521 } \\
378 \\
\text { NCT00814 } \\
294\end{array}$ & $\begin{array}{l}\text { C } \\
\text { SI }\end{array}$ & VO & I & $\mathrm{R}$ & $\begin{array}{c}\text { Diasome } \\
\text { Pharmaceutic } \\
\text { als }\end{array}$ & \begin{tabular}{|l} 
(ZIJLSTR \\
A; \\
HEINEM \\
ANN; \\
PLUM- \\
MORSCH \\
EL, 2014)
\end{tabular} \\
\hline
\end{tabular}

SIGLAS: Adj: Terapia adjuvante; C: o estudo clínico terminou, e os participantes não estão mais sendo examinados ou tratados; I: tecnologia para liberação de insulina no organismo; L: lenta; R: rápida; REC: o estudo clínico está neste momento recrutando participantes; SI: o estudo clínico não possui ainda status (fase de recrutamento de pacientes, ou ativo, mas sem pacientes recrutados ainda) confirmado nos últimos 2 anos; VA: via de administração; VO: via oral.

Fonte: Elaboração própria.

Em outra vertente, estudos vêm sendo realizados no desenvolvimento de formulações bucais, com objetivo da insulina ser absorvida na cavidade oral, pelas mucosas da bochecha (AL-TABAKHA; ARIDA, 2008; KUMRIA; GOOMBER, 2011). Apesar das numerosas pesquisas para aumentar a biodisponibilidade oral e bucal da insulina, a maioria dos produtos se concentram em fases clínicas I e II. Até o momento não há qualquer formulação para administração oral comercialmente disponível no Brasil. 


\subsubsection{Formulações para liberação de insulina via intranasal e pulmonar}

No âmbito farmacoterapêutico, a região intranasal possui um grande potencial como via de administração por ter uma grande área de absorção, com alta vascularização e carreamento proteico diretamente para a circulação sanguínea, que impede o metabolismo de primeira passagem hepato-intestinal. O pulmão, por sua vez, possui uma das maiores áreas disponível para absorção de substâncias, com algumas características importantes, como epitélio com alta permeabilidade e vascularização, permitindo rápida absorção (MO et al., 2014).

A administração nasal de insulina vem sendo pesquisada há pelo menos três décadas, com resultados significativos (ASPDEN; ILLUM; SKAUGRUD, 1996; SINTOV; LEVY; BOTNER, 2010; TSUNEJI et al., 1984). Contudo, apenas recentemente, foi apontada a evidência de que a insulina administrada por via nasal pode induzir à imuno-tolerância a insulina, apresentando um efeito imunológico análogo a uma reexposição ao antígeno. Mais estudos para confirmar essa possibilidade podem levar a sua aplicação para prevenir o desenvolvimento do diabetes tipo 1 (FOURLANOS et al., 2011).

Atualmente, várias empresas vêm desenvolvendo inaladores, tanto para insulina em pó, quanto para insulina líquida (Tabela 9). O spray intranasal (Nasulin; CPEX Pharmaceuticals) apresentou em estudos clínicos de fase II alguns eventos adversos quando comparado ao AI, glargina. 
Tabela 9. Horizonte das formulações intranasais para liberação de insulina em estudo clínico.

\begin{tabular}{l|c|c|c|c|c|c|c|c}
\hline \multicolumn{1}{c|}{ Formulação } & $\begin{array}{c}\text { Fase do } \\
\text { estudo }\end{array}$ & $\begin{array}{c}\mathbf{N}^{\mathbf{0}} \text { estudo } \\
\text { clínico }\end{array}$ & Status & VA & Função & $\begin{array}{c}\text { Categoria } \\
\text { de ação }\end{array}$ & Responsável & Fonte \\
\hline Spray Intranasal & Clínica (II) & NCT00624767 & C & IN & I & R & Nastech & $\begin{array}{c}\text { (MO et } \\
\text { al., } \\
2014)\end{array}$ \\
\hline Spray Intranasal & Clínica (II) & & & IN & I & R & MDRNA & $\begin{array}{c}\text { (MO et } \\
\text { al., } \\
2014)\end{array}$ \\
\hline $\begin{array}{l}\text { Spray Intranasal } \\
\text { (Nasulin) }\end{array}$ & Clínica (II) & $\begin{array}{c}\text { NCT00850096 } \\
\text { NCT00850161 }\end{array}$ & $\begin{array}{c}\text { RE } \\
\text { RE IN }\end{array}$ & I & & CPEX & $\begin{array}{c}\text { (“Diab } \\
\text { etes } \\
\text { Pharmaceuti } \\
\text { Forecas } \\
\text { t.27”, } \\
\text { cals }\end{array}$ \\
\hline
\end{tabular}

SIGLAS: C: o estudo clínico terminou, e os participantes não estão mais sendo examinados ou tratados; I: tecnologia para liberação de insulina no organismo; IN: intranasal; R: rápida; RE: o estudo clínico parou antes de matricular o primeiro participante; VA: via de administração.

Fonte: Elaboração própria.

$\mathrm{Na}$ administração pulmonar, a complexação com ciclodextrina (AGUIAR; RODRIGUES; SILVA CUNHA, 2004; UNGARO et al., 2009), uso de dendrímeros (TAYLOR; TANNA; SAHOTA, 2010) e a incorporação em diversas nanopartículas (ALQADI et al., 2012; ANDRADE et al., 2015; ZHAO et al., 2012) foram relatadas como potenciais na liberação da insulina e sua distribuição pelas vias aéreas, permeando as barreiras da mucosa e do epitélio pulmonar.

Como exemplo, um grupo de pesquisa encapsulou insulina em nanopartículas lipídicas sólidas e administrou pela via pulmonar em camundongos diabéticos. Após 4 h, os níveis glicêmicos foram reduzidos para $39,41 \%$ e a biodisponibilidade farmacológica de insulina chegou a $24,33 \%$, o que corresponde a um aumento de 4 vezes em relação ao controle de injeção subcutânea (LIU et al., 2008).

Em 2006, foi aprovada para comercialização a primeira formulação de insulina inalatória em forma de pó, desenvolvida pela Pfizer. Naquele momento era a única opção não injetável de liberação de insulina no organismo. Comercialmente, Exubera ${ }^{\circledR}$ (Figura 11A) possuía atividade equiparada ao de uma insulina de ação rápida, mas foi retirada do mercado devido à baixa comercialização atribuída ao custo e ao volume do dispositivo. Diante disso, um dispositivo mais discreto e com uma formulação mais segura para o paciente foi aprovada 
recentemente pela agência norte-americana que é responsável pela aprovação de alimentos e fármacos (FDA). A Afrezza ${ }^{\circledR}$ (Figura 11B) é uma insulina em pó inalatório veiculada em microesferas com função pulmonar e de ação ultrarrápida que deve ser inalada antes das refeições (VEISEH et al., 2014) (Tabela 10).

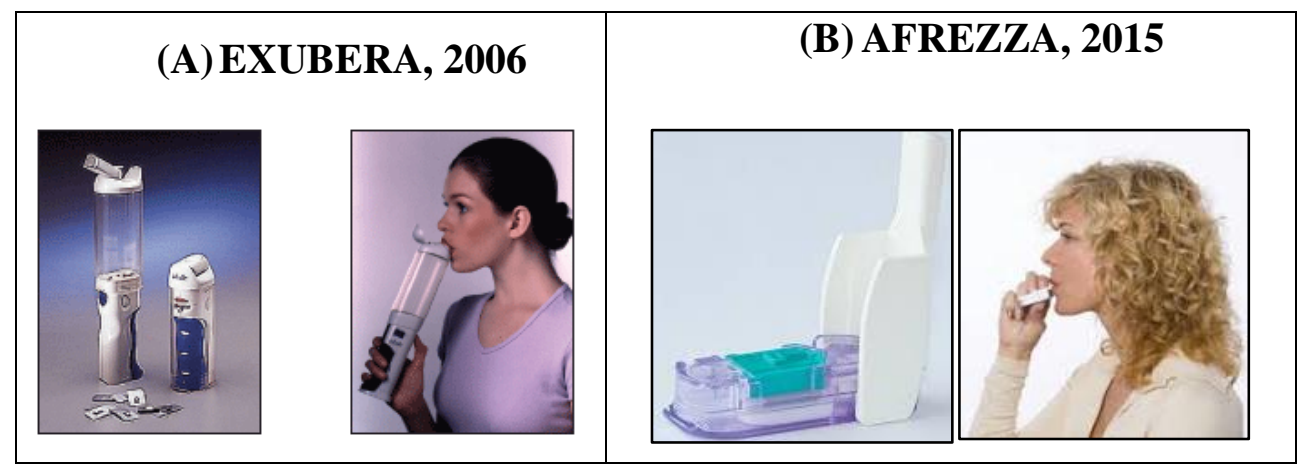

Figura 11AB. Evolução dos dispositivos de administração de insulina via pulmonar.

As insulinas inalatórias (Afrezza, AERx iDM e AERxs insulin) já iniciaram estudos clínicos de fase 3 para verificar a segurança e eficácia do produto. Entre os produtos que já tem autorização estão Afrezza $^{\circledR}$, nos Estados Unidos (Tabela 10). O inalador em pó seco, HIIP, (Eli Lilly / Alkermes, Inc.) com função pulmonar vem sendo bastante estudado (Tabela 10), resultados preliminares indicam que o sistema HIIP é fácil de usar e que a maioria dos pacientes aprende a usá-lo lendo a bula sem assistência de profissionais de saúde. Outro inalador em pó seco com função pulmonar, $\mathrm{AIR}^{\circledR}$ Inhaled Insulin Powder (Eli Lilly), demonstrou em ensaio clínico de fase III maiores taxas de HbA1c quando comparada à IA, lispro (Tabela 10). 
Tabela 10. Horizonte das formulações pulmonares para liberação de insulina em estudo clínico.

\begin{tabular}{|c|c|c|c|c|c|c|c|c|}
\hline Formulação & $\begin{array}{l}\text { Fase do } \\
\text { estudo }\end{array}$ & $\begin{array}{l}\mathrm{N}^{\circ} \text { estudo } \\
\text { clínico }\end{array}$ & Status & VA & Função & $\begin{array}{c}\text { Categoria } \\
\text { de ação }\end{array}$ & Responsável & Fonte \\
\hline $\begin{array}{l}\text { Inalador em pó } \\
\text { seco } \\
\text { (Technosphere } \\
\text { insulin (TI), } \\
\text { SAR439065, } \\
\text { Afrezza) } \\
\end{array}$ & Clínica (I) & $\begin{array}{l}\text { NCT02485327 } \\
\text { NCT02470637 } \\
\text { NCT02527265 }\end{array}$ & $\mathrm{C}$ & $\mathrm{P}$ & I & UR & $\begin{array}{l}\text { Mannkind / } \\
\text { Sanofi }\end{array}$ & $\begin{array}{l}\text { (MO et } \\
\text { al., } \\
2014) .\end{array}$ \\
\hline $\begin{array}{l}\text { Inalador em pó } \\
\text { seco (HIIP) }\end{array}$ & $\begin{array}{l}\text { Clínica } \\
\text { (III) }\end{array}$ & $\begin{array}{l}\text { NCT00437112 } \\
\text { NCT00355849 } \\
\text { NCT00356109 } \\
\text { NCT00391209 } \\
\text { NCT00157339 } \\
\text { NCT00325364 } \\
\text { NCT00099515 } \\
\text { NCT00063128 } \\
\text { NCT00447213 } \\
\text { NCT00490854 }\end{array}$ & $\mathrm{C}$ & $\mathrm{P}$ & I & $\mathrm{R}$ & $\begin{array}{l}\text { Eli Lilly / } \\
\text { Alkermes, } \\
\text { Inc. }\end{array}$ & \begin{tabular}{|c} 
(ZIJLS \\
TRA; \\
HEINE \\
MANN \\
; \\
PLUM- \\
MORS \\
CHEL, \\
2014)
\end{tabular} \\
\hline $\begin{array}{l}\text { Insulina líquida } \\
\text { (AERx iDMS) }\end{array}$ & $\begin{array}{l}\text { Clínica } \\
\text { (III) }\end{array}$ & $\begin{array}{c}\text { NCT0041189 } \\
\text { NCT00523042 }\end{array}$ & $\begin{array}{l}\mathrm{C} \\
\mathrm{C}\end{array}$ & $\mathrm{P}$ & I & UR & $\begin{array}{l}\text { Novo } \\
\text { Nordisk }\end{array}$ & \begin{tabular}{|c} 
(MO et \\
al., \\
$2014)$
\end{tabular} \\
\hline $\begin{array}{lc}\text { Inalador } & \text { eme pó } \\
\text { seco } & \text { (AIR® } \\
\text { Inhaled } & \text { Insulin } \\
\text { Powder) } & \\
\end{array}$ & $\begin{array}{l}\text { Clínica } \\
\text { (III) }\end{array}$ & NCT00356109 & $\mathrm{CP}$ & $\mathrm{P}$ & I & $\mathrm{R}$ & Eli Lilly & $\begin{array}{l}\text { (MO et } \\
\text { al., } \\
\text { 2014) }\end{array}$ \\
\hline
\end{tabular}

SIGLAS: C: o estudo clínico terminou, e os participantes não estão mais sendo examinados ou tratados; CP: estudo clínico completado; I: tecnologia para liberação de insulina no organismo; P: função pulmonar; R: rápida; UR: ultrarrápida; VA: via de administração.

Fonte: Elaboração própria.

Em relação à via de administração pulmonar, há preocupações quanto ao depósito intralveolar de insulina em longo prazo, uma vez que, concentrações muito elevadas desse peptídeo podem levar à expressão de fatores de crescimento (AL-TABAKHA; ARIDA, 2008). Esse efeito está relacionado ao aumento da proliferação celular e possível desenvolvimento de tumores (GALLAGHER; LEROITH, 2010). Essa preocupação pode ser extrapolada para outros órgãos e tecidos nos quais a insulina pode vir a se acumular.

Apesar das numerosas pesquisas (maioria dos produtos se concentram em fases avançadas de estudo clínico) para aumentar a biodisponibilidade e diminuir os potenciais 
efeitos colaterais da insulina intranasal ou de função pulmonar, até o momento não há qualquer formulação comercialmente autorizada para uso no Brasil.

\subsubsection{Formulações para liberação de insulina via transdérmica}

A administração pela via transdérmica pode ser a técnica de melhor adesão do paciente por não ser invasiva e não envolver dor, além de evitar o metabolismo de primeira passagem hepato-intestinal. Contudo, essa via apresenta o estrato córneo como barreira significativa para a permeação de substâncias, principalmente macromoléculas como a insulina. Por esse motivo, esforços vêm sendo empregados no desenvolvimento de formulações e seu uso em conjunto com métodos físicos para superar essas dificuldades (BORGHETI-CARDOSO et al., 2015).

Em relação à insulina, a sua aplicação na forma livre em solução sobre a pele apresenta permeação insignificante $\left(0,005 \pm 0,001 \mu \mathrm{g} / \mathrm{cm}^{2}\right)$. Pesquisas em pele de camundongo observaram que a utilização de nanocarreadores de insulina aumentou sua permeação em 1,7 vezes. Quando utilizada a técnica de eletroporação previamente à aplicação das nanopartículas, o acúmulo de insulina obtido foi 4 vezes maior (RASTOGI; ANAND; KOUL, 2010).

A utilização de ultrassom (US) para aumentar a permeação transdérmica de insulina foi estudada em camundongos, coelhos e porcos. No estudo com camundongos foram observados quatro grupos, onde no primeiro houve aplicação tópica passiva de um uma solução de insulina através de um reservatório acoplado à pele, o segundo grupo utilizou solução salina com aplicação de US, o terceiro e o quarto grupo usaram solução de insulina com aplicação de US por 20 e 60 minutos, respectivamente. Enquanto para os dois primeiros grupos não houve efeito nas taxas de glicose, para o grupo que usou 60 minutos de US, as taxas caíram para $-267,5 \pm 61,9 \mathrm{mg} / \mathrm{dL}$ em relação à linha de base, resultado que foi muito próximo ao grupo de 20 minutos, indicando que o tempo de aplicação do US pode ser o menor estudado (SMITH; LEE; SHUNG, 2003).

No estudo com coelhos, houve dois grupos controle (insulina sem US e solução salina com US) e o grupo teste, no qual o reservatório de insulina foi acoplado topicamente e o US foi aplicado por 60 minutos. Observou-se nesse estudo que nos dois grupos controle os níveis de glicose alcançaram $+75 \mathrm{mg} / \mathrm{dL}$ em relação aos níveis basais, enquanto o grupo teste caiu 
para $-132,6 \pm 35,7 \mathrm{mg} / \mathrm{dL}$ após uma hora. Mesmo após a retirada do sistema, a taxa glicêmica do grupo teste continuou a cair, alcançando $-208,1 \pm 29 \mathrm{mg} / \mathrm{dL}$ (LEE et al., 2004). Já no estudo com porcos, o grupo controle recebeu insulina sem aplicação de US e o grupo teste foi tratado com US e insulina por 60 minutos. Para o grupo controle, os níveis glicêmicos aumentaram para $31 \pm 21 \mathrm{mg} / \mathrm{dL}$ após 90 minutos, comparado à linha de base, enquanto no grupo que usou US houve um decréscimo para $-72 \pm 5 \mathrm{mg} / \mathrm{dL}$ em 60 minutos, chegando a -91 $\pm 23 \mathrm{mg} / \mathrm{dL}$ após 90 minutos (PARK; WERNER; SMITH, 2007).

Outro método físico em estudo é a iontoforese, que utiliza a corrente elétrica para permear substâncias através do estrato córneo. Essa técnica se mostra bastante viável para moléculas hidrofóbicas e de pequeno tamanho molecular (BORGHETI-CARDOSO et al., 2015), o que dificulta o seu uso com moléculas proteicas, de perfil hidrofílico e fracamente ionizáveis como a insulina. De fato, experimentos em humanos demonstraram que o uso da iontoforese para administrar insulina na sua forma livre resultou em fracasso (RL; TJ; SC, 1984).

No entanto, o uso da nanotecnologia para modificar as características físico-químicas da insulina possibilita o uso deste método para auxiliar no transporte transdérmico da molécula. Estudos in vitro em pele suína apontaram que a utilização da iontoforese em um gel contendo transferossomas de insulina aumentou o fluxo de permeação do peptídeo $(17,60 \pm$ $\left.0,03 \mu \mathrm{g} / \mathrm{cm}^{2} / \mathrm{h}\right)$ em relação à aplicação do gel de modo passivo $\left(13,50 \pm 0,22 \mu \mathrm{g} / \mathrm{cm}^{2} / \mathrm{h}\right) \mathrm{e}$ com esse resultado não justificou o uso da iontoforese (MALAKAR et al., 2012). Outro estudo avaliou a liberação da insulina encapsulada em lipossomas, com aplicação da iontoforese in vivo. Foi observado que, após $18 \mathrm{~h}$ da aplicação, os níveis de glicose diminuíram cerca de $20 \%$ em comparação aos níveis basais em modelos de camundongos diabéticos (KAJIMOTO et al., 2011).

Outra abordagem é a utilização de microagulhas (MN) (Figura 12), que são agulhas pequenas $(25-2000 \mu \mathrm{m})$ o suficiente para serem aplicadas na pele sem que haja dor, mas possuem o tamanho necessário para criar canais temporários através do estrato córneo para permitir o transporte e liberação de substâncias de forma rápida pela via transdérmica (BORGHETI-CARDOSO et al., 2015). Estudos in vivo com camundongos diabéticos desprovidos de pelos demonstraram o transporte transdérmico de insulina de forma rápida e contínua durante o período de aplicação das MNs, seguida de estabilização dos níveis de glicose depois da retirada do sistema. Os estudos ainda indicaram que parâmetros como a 
concentração de insulina, tempo de inserção da agulha e número de repetições de inserção influenciam nas taxas de insulina transportadas (MARTANTO et al., 2004). Outro estudo observou que o efeito da força de inserção pode ser significativo na dose permeada de insulina (NORDQUIST et al., 2007).

Tipos de microagulhas transdermais

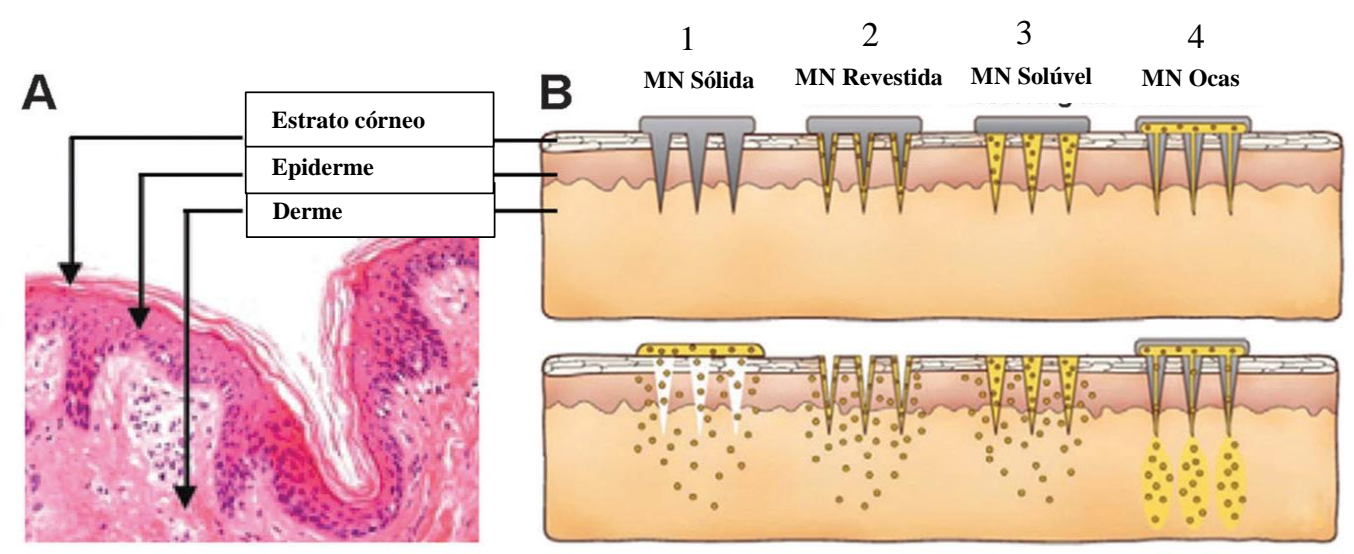

Nota: (1) MN sólidas microincorporadas na pele administram a droga topicamente através de um adesivo método conhecido como "Poke and patch"; (2) MN sólidas revestidas com drogas são inseridas na pele para liberação da droga instável - método conhecido como "Coat and poke"; (3) MN sólidas compostos por polímeros biodegradáveis utilizam drogas encapsuladas que ao penetrarem na pele se dissolvem e liberam a droga - método conhecido como "Poke and release"; (4) MN ocas (em inglês, Hollow MN) abrem fístulas na epiderme, facilitando a infusão direta de preparações líquidas de insulina na pele sem remoção das MNs método conhecido como 'Poke and flow'.

Fonte: Ran Mo et al., 2014.

Figura 12. Tipos de microagulhas transdérmicas $(\mathrm{MN})$ na liberação de insulina.

A combinação do uso de microagulhas com iontoforese para liberar insulina a partir de nanovesículas carregadas positivamente resultou em taxas de permeação 713,3 vezes maior que na aplicação passiva das nanovesículas sem a aplicação da iontoforese. Além disso, testes in vivo demonstraram uma queda dos níveis de glicose em 33\% após 4 horas da aplicação das técnicas combinadas em camundongos diabéticos (CHEN et al., 2009). 
Existem algumas formulações em desenvolvimento em fase de estudo clínico I ou II, tanto na forma de adesivo, como também géis e sistema de liberação por meio de microagulhas (Tabela 11).

Tabela 11. Horizonte das formulações transdermais para liberação de insulina em estudo clínico.

\begin{tabular}{l|c|c|c|c|c|c|c|c}
\hline Formulação & $\begin{array}{c}\text { Fase do } \\
\text { estudo }\end{array}$ & $\begin{array}{c}\mathbf{N}^{\mathbf{0}} \text { estudo } \\
\text { clínico }\end{array}$ & Status & VA & Função & $\begin{array}{c}\text { Categoria } \\
\text { de ação }\end{array}$ & Responsável & Fonte \\
\hline Adesivo & Clínica (I) & & & TD & I & UR & Dermisonics & $\begin{array}{c}\text { (“CenterWa } \\
\text { tch.”, 2015) }\end{array}$ \\
\hline $\begin{array}{l}\text { Adesivo } \\
\text { (PassPort } \\
\text { AT1391) }\end{array}$ & $\begin{array}{c}\text { Clínica } \\
\text { (II) }\end{array}$ & NCT00519623 & C & TD & I & & $\begin{array}{c}\text { Altea } \\
\text { Therapeutics }\end{array}$ & $\begin{array}{c}\text { (MO et al., } \\
2014)\end{array}$ \\
\hline $\begin{array}{l}\text { Insulina gel } \\
\text { (TPM-02) }\end{array}$ & $\begin{array}{c}\text { Clínica } \\
\text { (II) }\end{array}$ & & & TD & I & L & $\begin{array}{c}\text { Phosphagenic } \\
\text { s }\end{array}$ & $\begin{array}{c}\text { (MO et al., } \\
\text { 2014) }\end{array}$ \\
\hline $\begin{array}{l}\text { Sistema de } \\
\text { liberação via } \\
\text { microagulhas } \\
\text { (MN) }\end{array}$ & $\begin{array}{c}\text { Clínica (I } \\
\text { / II) }\end{array}$ & NCT01061216 & C & TD & I & & $\begin{array}{c}\text { Becton, } \\
\text { Dickinson } \\
\text { and Company }\end{array}$ & $\begin{array}{c}\text { (PAUDEL al., 2010) } \\
\text { (PAt and }\end{array}$ \\
\hline
\end{tabular}

SIGLAS: C: o estudo clínico terminou, e os participantes não estão mais sendo examinados ou tratados; I: tecnologia para liberação de insulina no organismo; L: lenta; R: rápida; TD: transdérmico; UR: ultrarrápida; VA: via de administração.

Fonte: Elaboração própria.

O avanço para utilização da via transdérmica, dependerá da capacidade de superação dos desafios em relação à irritação da pele e à permeabilidade da insulina (PAUDEL et al., 2010). Entre as abordagens estudadas, a utilização de microagulhas se mostra como uma das mais promissoras. Recentemente foi desenvolvido um adesivo com microagulhas contendo nanopartículas de insulina capazes de detectar o nível sanguíneo de glicose por meio da atividade enzimática da glicose oxidase presente na nanopartícula. Essas características permitem que o sistema responda rapidamente a alterações glicêmicas para promover uma liberação controlada de insulina de acordo com sua necessidade real. A tecnologia já mostra resultados positivos em testes in vitro, mas ainda requer mais estudos para determinar sua viabilidade de uso em humanos (VEISEH; LANGER, 2015). 
Diante de tais resultados, espera-se que mais pesquisas sejam realizadas no uso de métodos físicos para melhorar a performance de sistemas nanoparticulados, a fim de aumentar a permeabilidade da insulina na administração transdérmica e possibilitar que dispositivos eficientes cheguem ao mercado. Até o momento não foi verificado nenhuma formulação transdérmica para liberação de insulina autorizada para comercialização no Brasil.

\subsection{TERAPIAS NÃO BASEADAS NA LIBERAÇÃO DE INSULINA}

Os estudos em terapias para o diabetes sem administração de insulina estão em expansão. Como exemplo, o transplante de pâncreas que tem o objetivo de restaurar o controle glicêmico que não ocorre nos indivíduos acometidos com diabetes. As técnicas atualmente disponíveis são cirurgia aberta e cirurgia minimamente invasiva. No entanto, a incidência de complicações cirúrgicas é ainda elevada (25 a 30\%) e as taxas de relaparotomias situam-se entre 31 e 32\%. Além disso, uma limitação importante está relacionada à necessidade de doadores do órgão a ser transplantado (TZVETANOV et al., 2014).

Pesquisas de terapia celular em diabéticos têm como objetivo regenerar as células $\beta$, reprogramar as células nativas a secretar insulina ou transplantar células produtoras de insulina para restaurar a produção de acordo com a demanda do organismo. No entanto, a introdução de células produtoras de insulina no organismo pode ativar o sistema imune, provocando rejeição. Para diminuir esse efeito, alguns pesquisadores estudam encapsular as células produtoras de insulina em nanopartículas para garantir a sua viabilidade após o transplante (ROBERTSON, 2004).

\subsection{PANORAMA TECNOLÓGICO DAS TECNOLOGIAS NÃO BASEADAS NA LIBERAÇÃO DE INSULINA PARA O MANEJO E GESTÃO DO DIABETES}

A terapia genética ex vivo, células do paciente são removidas do corpo, genes terapêuticos são inseridos nessas células em meio de cultura e, por fim, as células com capacidade de produzir insulina são reimplantadas. Esse método é invasivo e não é eficaz no caso de pacientes com diabetes tipo 1, uma vez que apresentam o processo autoimune de destruição das células. Outro método de terapia genética envolve a utilização de genes vetorizados a diferentes tecidos, que podem incluir aqueles relacionados ao maior uso de glicose pelas células como os dos músculos ou inibição da produção de glicose pelo fígado. Ainda pode ser utilizada a terapia genética para síntese de células $\beta$ em outros órgãos. $O$ uso 
de nanopartículas vem sendo estudado como uma alternativa para carrear esses genes (NOSE et al., 2012; TIWARI, 2015).

Em longo prazo, a estratégia mais promissora não baseada em insulina é a vacina (Tabela 12), que tem como mecanismo de ação o impedimento da destruição autoimune das células $\beta$. A nanotecnologia está sendo utilizada para aprimorar as formulações, diminuindo a necessidade de antígenos adjuvantes e pela possibilidade de serem mais específicas. A pesquisa concentra-se em promover efeitos imunomoduladores relacionadas às células $\beta$, sem comprometimento da imunidade global (ORYNBAYEVA; SENSENIG; POLYAK, 2015; VEISEH et al., 2014). Ainda, seguindo a linha de que o diabetes tipo 1 pode surgir após infecção enteroviral, as vacinas poderiam encontrar aplicação na prevenção do desenvolvimento da doença (HEATH, 2010).

Tabela 12. Horizonte das formulações não baseadas na liberação de insulina para o diabetes em estudo clínico.

\begin{tabular}{|c|c|c|c|c|c|c|c|}
\hline Formulação & $\begin{array}{l}\text { Fase do } \\
\text { estudo }\end{array}$ & $\begin{array}{l}\mathrm{N}^{\circ} \text { estudo } \\
\text { clínico }\end{array}$ & Status & VA & Função & Responsável & Fonte \\
\hline $\begin{array}{l}\begin{array}{l}\text { Biodel's } \\
\text { glucagon }\end{array} \\
\end{array}$ & Clínica (I) & NCT02403648 & A & $\mathrm{SC}$ & GLU & Biodel & $\begin{array}{c}\text { (“Diabetes } \\
\text { Forecast.27", 2015) }\end{array}$ \\
\hline E1-INT & Clínica (I) & $\begin{array}{l}\text { NCT00239187 } \\
\text { NCT00239148 }\end{array}$ & $\mathrm{C}$ & $\mathrm{SC}$ & NI & $\begin{array}{c}\text { Transition } \\
\text { Therapeutics/No } \\
\text { vo Nordisk }\end{array}$ & $\begin{array}{l}\text { (“CenterWatch.", } \\
\text { 2015) }\end{array}$ \\
\hline $\begin{array}{l}\text { Pepitídeo, } \\
\text { Exsulin } \\
\text { (INGAP) }\end{array}$ & Clínica (II) & $\begin{array}{l}\text { NCT00071422 } \\
\text { NCT00995540 } \\
\text { NCT00071409 }\end{array}$ & $\mathrm{C}$ & $\mathrm{SC}$ & NI & $\begin{array}{c}\text { Exsulin } \\
\text { Corporation }\end{array}$ & $\begin{array}{l}\text { (“CenterWatch.”, } \\
\text { 2015) }\end{array}$ \\
\hline $\begin{array}{l}\text { Peptídeo } \\
\text { (DiaPep277; } \\
\text { Vacina) }\end{array}$ & Clínica (III) & $\begin{array}{l}\text { NCT01103284 } \\
\text { NCT00615264 }\end{array}$ & $\mathrm{C}$ & $\mathrm{SC}$ & NI & $\begin{array}{l}\text { Andromeda } \\
\text { Biotech }\end{array}$ & $\begin{array}{c}\text { ("Diabetes } \\
\text { Forecast.", 2015) }\end{array}$ \\
\hline $\begin{array}{l}\text { Vacina } \\
\text { (Diamyd) }\end{array}$ & Clínica (III) & $\begin{array}{l}\text { NCT00723411 } \\
\text { NCT00751842 }\end{array}$ & $\mathrm{C}$ & $\mathrm{SC}$ & NI & Diamyd Medical & $\begin{array}{c}\text { (“Diabetes } \\
\text { Forecast.27", 2015) }\end{array}$ \\
\hline $\begin{array}{l}\text { LX4211 } \\
\text { (Sotagliflozin) }\end{array}$ & Clínica (III) & NCT02421510 & REC & $\mathrm{VO}$ & NI & $\begin{array}{c}\text { Lexicon } \\
\text { Pharmaceuticals }\end{array}$ & $\begin{array}{l}\text { (“CenterWatch.”, } \\
\text { 2015) }\end{array}$ \\
\hline
\end{tabular}

SIGLAS: A: o estudo clínico está em curso (ou seja, os participantes estão recebendo uma intervenção ou estão sendo examinados), mas potenciais participantes ainda não foram recrutados ou matriculados; C: o estudo clínico terminou, e os participantes não estão mais sendo examinados ou tratados; GLU: tecnologia para liberação de glucagom no organismo; I: tecnologia para liberação de insulina no organismo; NI: tecnologia não baseada na liberação de insulina no organismo; REC: o estudo clínico está neste momento recrutando participantes; SC: subcutâneo; VA: via de administração; VO: via oral.

Fonte: Elaboração própria. 
As vacinas têm grande potencial de impedir o desenvolvimento do diabetes, podendo ser uma estratégia no sentido da cura. Algumas vacinas (DiaPep277 e Diamyd) já terminaram os estudos clínicos de fase 3 (Tabela 12), porém ainda não foram verificados registros nas principais agências internacionais, como o FDA e a agência europeia (EMA). Espera-se que até 2019, as vacinas para o diabetes estejam bem estudas e com autorização para comercialização no Brasil.

\subsubsection{Dispositivos para diagnóstico e monitoramento da glicemia}

O monitoramento dos níveis de glicose no sangue fornece aos pacientes e profissionais de saúde a compreensão da progressão do diabetes, bem como a eficácia do tratamento. Os glicosímetros utilizados pela maior parte dos diabéticos realizam a leitura eletrônica de amostras de sangue obtidas por meio de picadas no dedo repetidas vezes ao dia. Além de ser um método invasivo, muitas vezes o resultado não é preciso e confiável (CASH; CLARK, 2010).

Para tentar diminuir essas limitações de uso, a nanotecnologia vem sendo empregada. Os nanossensores com a enzima glicose oxidase ou proteínas de ligação da glicose ou pequenas moléculas de ligação da glicose, reagem com as moléculas, por meio de reações físico-químicas, que possibilita detectar os níveis de glicose do meio. Após acoplamento das moléculas a nanopartículas, que funcionam como transdutores, é possível promover um monitoramento mais precisa das taxas glicêmicas por longos períodos e com maior conforto ao paciente (VEISEH et al., 2014).

Tabela 13. Horizonte tecnológico de dispositivos em desenvolvimento para o controle da glicemia.

\begin{tabular}{c|c|c|c|c|c|c}
\hline Dispositivo & $\begin{array}{c}\text { Fase do } \\
\text { estudo }\end{array}$ & $\begin{array}{c}\mathbf{N}^{\mathbf{0}} \text { estudo } \\
\text { clínico }\end{array}$ & VA & Função & $\begin{array}{c}\text { Responsáve } \\
\mathbf{l}\end{array}$ & Fonte \\
\hline $\begin{array}{l}\text { Google[x] Glucose- } \\
\begin{array}{l}\text { Sensing Lentes de } \\
\text { Contato }\end{array}\end{array}$ Pré-clínica & $\begin{array}{c}\text { Teste Pré- } \\
\text { clínico }\end{array}$ & OCULAR & SniMCG & $\begin{array}{c}\text { Google e } \\
\text { Novartis }\end{array}$ & $\begin{array}{c}\text { ("Diabetes } \\
\text { Forecast.27”, } \\
\text { 2015) }\end{array}$ \\
\hline
\end{tabular}

SIGLAS: SniMCG: Sistema não invasivo de monitoramento contínuo de glicose; VA: via de administração.

Fonte: Elaboração própria. 
Nesse âmbito, as inovações consideradas mais promissoras estão nas pesquisas de nanossensores não invasivos, que detectam os níveis de glicose na saliva ou no fluído lacrimal (CLAUSSEN et al., 2012). Como exemplo, lentes de contato (Tabela 13) vêm sendo desenvolvidas por empresas como Google, Novartis e Microsoft (Figura 13). Espera-se que essas lentes não provoquem irritações e forneçam uma resposta estável, sensível e específica, com tempo mínimo necessário entre a detecção e a leitura, particularmente nos avisos de risco de eventos hipo/hiperglicêmicos (FARANDOS et al., 2015).
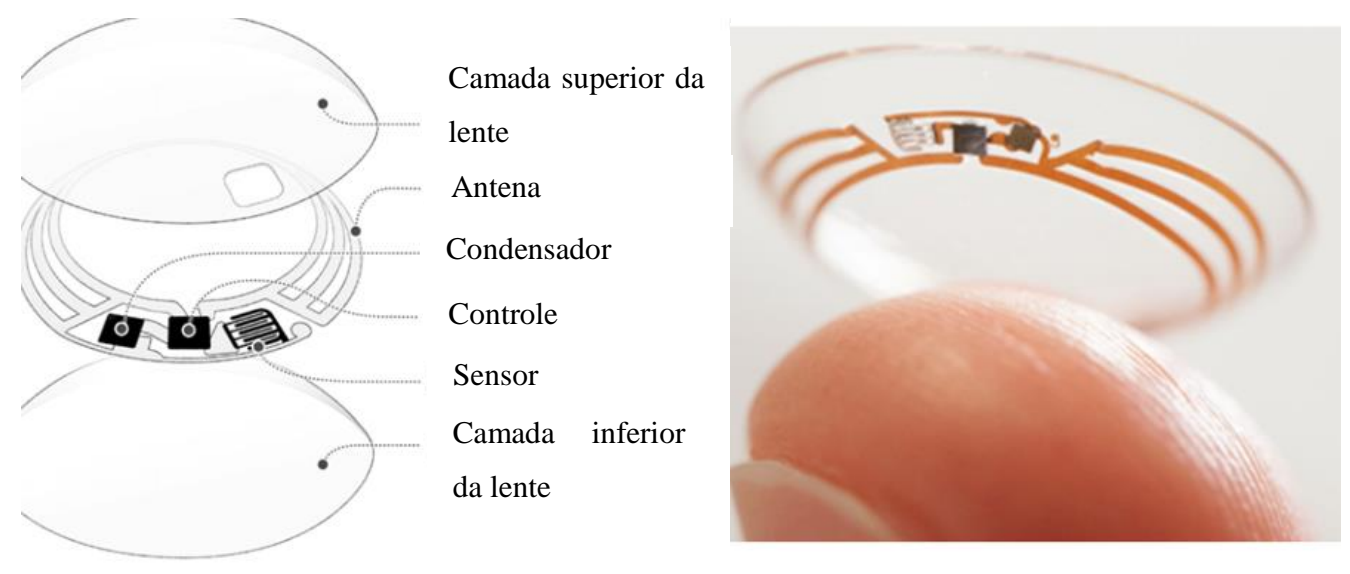

Fonte: Banco de imagens Google.

Figura 13. Lente de Contato para Monitoramento Glicêmico (Google X).

Tem-se estudado também aplicativos que são acoplados aos sistemas de monitoramento contínuo da glicemia (MCG), como por exemplo, o DiAs system (Dexcom). Estudo preliminar revelou que o sensor Dexcom G4 de MCG junto com o DiAs system (Tabela 14) favoreceu maior precisão do que o sensor Enlite (Medtronic) na fase inicial (1-3 dias) e também a posteriori (4-6 dias), além disso os pacientes relataram uma melhor experiência (Tabela 14). 
Tabela 14. Horizonte tecnológico de dispositivos e aplicações no controle e gestão da glicemia em clínico.

\begin{tabular}{|c|c|c|c|c|c|c|c|}
\hline Dispositivo & Fase do estudo & $\begin{array}{l}\mathbf{N}^{\circ} \text { estudo } \\
\text { clínico }\end{array}$ & Status & VA & Função & Responsável & Fonte \\
\hline $\begin{array}{lr}\text { Dexcom } & \text { G4 } \\
\text { Platinum } & \text { MCG } \\
\text { com } & \text { DiAs } \\
\text { system } & \end{array}$ & Comparativo & NCT02159638 & REC & $\mathrm{SC}$ & SiMCG & Dexcom & $\begin{array}{l}\text { ("Diabe } \\
\text { tes } \\
\text { Forecas } \\
\text { t.27", } \\
2015)\end{array}$ \\
\hline $\begin{array}{l}\text { Sensor } \quad \text { Enlite } \\
\text { Glucose }\end{array}$ & $\begin{array}{c}\text { Observacional } \\
\mathrm{e} \\
\text { Intervencional }\end{array}$ & $\begin{array}{l}\text { NCT01464346 } \\
\text { NCT02423798 }\end{array}$ & $\mathrm{C}$ & $\mathrm{SC}$ & SiMCG & Medtronic & $\begin{array}{l}\text { ("Diabe } \\
\text { tes } \\
\text { Forecas } \\
\text { t.27", } \\
2015 \text { ) }\end{array}$ \\
\hline $\begin{array}{l}\text { FreeStyle } \\
\text { Precision meter }\end{array}$ & Intervencional & NCT02553408 & & $\mathrm{SC}$ & SiMCG & Abbott & $\begin{array}{l}\text { ("Diabe } \\
\text { tes } \\
\text { Forecas } \\
\text { t.27", } \\
2015)\end{array}$ \\
\hline $\begin{array}{l}\text { Guardian sensor } \\
\text { (Guardian } \\
\text { REAL-time } \\
\text { system }+ \\
\text { Paradigm } \mathrm{Veo}^{\mathrm{TM}} \text { ) }\end{array}$ & Intervencional & $\begin{array}{l}\text { NCT01429467 } \\
\text { NCT00824148 } \\
\text { NCT00494078 } \\
\text { NCT00536549 } \\
\text { NCT01331343 } \\
\text { NCT00554281 } \\
\text { NCT01474889 } \\
\text { NCT01016457 }\end{array}$ & $\begin{array}{l}\mathrm{C} \\
\mathrm{C} \\
\mathrm{C} \\
\mathrm{C} \\
\mathrm{C} \\
\mathrm{C}\end{array}$ & $\mathrm{SC}$ & SiMCG & Medtronic & $\begin{array}{l}\text { ("Diabe } \\
\text { tes } \\
\text { Forecas } \\
\text { t.27", } \\
2015 \text { ) }\end{array}$ \\
\hline $\begin{array}{l}\text { Aplicativo Dario } \\
\text { (Dario app) }\end{array}$ & Intervencional & $\begin{array}{l}\text { NCT02352298 } \\
\text { NCT02357043 } \\
\text { NCT02053584 }\end{array}$ & $\begin{array}{c}\mathrm{C} \\
\mathrm{REC} \\
\mathrm{C}\end{array}$ & & G & $\begin{array}{l}\text { LabStyle } \\
\text { Innovations } \\
\text { Ltd. }\end{array}$ & $\begin{array}{l}\text { ("Diabe } \\
\text { tes } \\
\text { Forecas } \\
\text { t.27", } \\
2015)\end{array}$ \\
\hline
\end{tabular}

SIGLAS: C: o estudo clínico terminou, e os participantes não estão mais sendo examinados ou tratados; G: auxiliar a gestão da diabetes; REC: o estudo clínico está neste momento recrutando participantes; SC: subcutâneo; SiMCG: Sistema invasivo de monitoramento contínuo de glicose;; VA: via de administração.

Fonte: Elaboração própria.

Observam-se várias empresas internacionais estão trabalhando para desenvolver novas formulações, técnicas, materiais, dispositivos e tecnologias para melhorar o manejo do diabetes (ZIJLSTRA; HEINEMANN; PLUM-MORSCHEL, 2014). Apesar de vários estudos não estarem registrados em bancos de dados internacionais, destaca-se que existem dezenas de produtos que já estão em fase avançada de pesquisa. Além disso, detecta-se, portanto, que o horizonte tecnológico para o diabetes envolve diferentes formulações e dispositivos. 
Alguns desafios importantes ainda necessitam de atenção. Primeiramente, no desenvolvimento de formulações para vias alternativas de administração de insulina (Tabela 6), a dose administrada necessária pode ser muito mais elevada do que a dose usual subcutânea. A utilização de promotores de permeação nas formulações pode não ser uma alternativa viável considerando-se que o tratamento é crônico, pois, o uso contínuo de algumas destas substâncias pode causar danos aos tecidos. Para evitar o risco de futuras complicações celulares, seria necessário diminuir a dose de insulina ou utilizar essas vias para uso de análogos de insulina de ação prolongada (MO et al., 2014; ZIJLSTRA; HEINEMANN; PLUM-MORSCHEL, 2014).

Visando utilizar doses menores, uma abordagem que vem sendo bastante estudada é o nanoencapsulamento da insulina. Contudo, uma preocupação relativa a esses sistemas é que apesar da possibilidade de controle da dose liberada, essa liberação não é sempre associada à real necessidade do organismo. Nesse sentido, a liberação de quantidades inadequadas de insulina pode provocar eventos de hipo ou hiperglicemia.

Diante desses desafios, diferentes grupos vêm buscando progredir em suas pesquisas, levando-as para além do laboratório, ao realizar experimentos clínicos. No Brasil, não é diferente, existe alguns grupos de pesquisas no âmbito do diabetes.

\subsection{PANORAMA DAS PESQUISAS EM DIABETES NO BRASIL}

Até o momento, não foram encontrados registros de estudos clínicos em alternativas tecnológicas para o controle ou cura do diabetes liderados por instituições brasileiras. Contudo, atualmente existem 141 linhas de pesquisa relacionadas ao diabetes cadastradas no Diretório de Grupos de Pesquisa no Brasil ("Conselho Nacional de Desenvolvimento Científico e Tecnológico", 2015). A maioria dos grupos está vinculada a alguma instituição pública de ensino superior e trabalha no âmbito de levantamentos epidemiológicos, educação em diabetes e estudos relacionados ao controle da dieta e práticas de exercícios. Especificamente no desenvolvimento de produtos tecnológicos, vem sendo realizadas pesquisas na área de biologia molecular, imunogenética e farmacologia de plantas medicinais.

Um grupo de pesquisa identificou que a mutação dominante E1506K ABCC8 é responsável pelo hiperinsulinismo congênito de infância, levando à intolerância à glicose e ao desenvolvimento do diabetes ao avançar da idade (VIEIRA et al., 2010). Além disso, foi 
observado que o polimorfismo no gene HNF1A (A98V e S487N) é comum no diabetes hereditário, onde o 127L demostra um efeito protetivo perante hipertrigliceridemia em pacientes diabéticos tipo 2 (GIUFFRIDA et al., 2009). Esses resultados podem contribuir para o diagnóstico e monitoramento da doença.

Ainda na área de diagnóstico, estudos avaliam microRNAs e seus mecanismos moleculares envolvidos, como potenciais biomarcadores do diabetes em diferentes fases da doença (COLLARES et al., 2013; TAKAHASHI et al., 2014).

Outro grupo, verificando as variações genéticas que podem levar a efeitos deletérios e protetivos no diabetes, identificou que o gene Janus Kinase (JAK2) pode ser o mediador da fosforilação do receptor de insulina (IRS-1) induzido pelo hormônio do crescimento (BAGAROLLI; SAAD; SAAD, 2010; THIRONE; CARVALHO; SAAD, 1999). Eles também verificaram que a inibição da proteína desacopladora 2 (UCP2) por um período curto melhora o desempenho da insulina no organismo e, consequentemente, provoca uma melhora metabólica e na síndrome hiperglicêmica (DE SOUZA et al., 2007). Outra pesquisa relevante desse grupo foi a identificação do efeito do infliximabe na homeostase da glicose e na transdução do sinal insulina, diminuindo, em curto prazo, os níveis de glicose no sangue, além de aumentar a transdução em alguns órgãos, podendo ser um tratamento importante para o diabetes (ARAÚJO et al., 2007).

$\mathrm{Na}$ área de fitoterapia, pesquisas demonstram que o extrato da raiz da Bowdichia virgilioides apresenta efeito anti-hiperglicemiante (SILVA et al., 2015). Outro estudo avaliou a atividade antidiabética do extrato de flores de Combretum lanceolatum Pohl., e observou que o seu efeito é semelhante ao da metformina, através da inibição da gluconeogênese (PORTO DECHANDT et al., 2013). Também foi verificado o efeito antidiabético do extrato da entrecasca da Vatairea macrocarpa, e os resultados mostraram que o seu uso a longo prazo poderá contribuir no tratamento do diabetes (OLIVEIRA et al., 2008). Outro achado relevante foi o uso da suplementação da dieta com fibras solúveis de farinha da casca do maracujáamarelo (Passiflora edulis f. flavicarpa) nos níveis glicêmicos e lipídicos dos pacientes diabéticos (JANEBRO et al., 2008).

No banco de dados do Instituto Nacional da Propriedade Industrial (INPI), a busca de patentes relacionadas ao diabetes resultou em 1033 processos (BRASIL, 2015). Contudo, quase a totalidade dos depósitos foi realizada por titulares estrangeiros. Entre os poucos 
pedidos de patente de produtos tecnológicos depositados por brasileiros (Tabela 15), cerca de $50 \%$ inclui a utilização de alguma espécie vegetal no desenvolvimento de formulações inovadoras. Esses dados apontam para a valorização da biodiversidade pelos pesquisadores nacionais. Entretanto, a pequena porcentagem de pedidos brasileiros frente ao total dos depósitos, demonstra que a maioria das pesquisas realizadas pelos grupos de pesquisa nacionais não tem caminhado rumo ao desenvolvimento de produtos e processos que venham a ser disponibilizados no mercado.

Tabela 15. Pedidos de patente de processos e produtos para diagnóstico, profilaxia ou cura do diabetes depositados por brasileiros no INPI.

\begin{tabular}{|c|c|c|c|c|}
\hline Título & Processo/Produto & Pedido & $\begin{array}{l}\text { Data de } \\
\text { depósito }\end{array}$ & Depositante \\
\hline $\begin{array}{lll}\text { Sistema } & \text { para administração } & \text { de } \\
\text { radiação intravascular com laser } \\
\text { hélio-neônio de baixa potência }\end{array}$ & $\begin{array}{l}\text { Modelo de Utilidade } \\
\text { para Administração } \\
\text { de Radiação }\end{array}$ & MU 7800871-9 U2 & $05 / 05 / 98$ & Pessoa física \\
\hline $\begin{array}{l}\text { Chá e extrato obtidos a partir do } \\
\text { cogumelo Agaricus blazei Murril. }\end{array}$ & $\begin{array}{l}\text { Formulação para uso } \\
\text { oral }\end{array}$ & PI 9802526-0 A2 & $23 / 06 / 98$ & Pessoa física \\
\hline $\begin{array}{l}\text { Um novo processo de síntese de aza- } \\
\text { açúcares com atividade biológica }\end{array}$ & $\begin{array}{l}\text { Formulação para uso } \\
\text { geral }\end{array}$ & PI 9902585-0 A2 & $11 / 02 / 99$ & UFRJ \\
\hline $\begin{array}{l}\text { Processo de aproveitamento dos } \\
\text { componentes da raiz de purga de } \\
\text { batata ou batata de caboclo que } \\
\text { misturados com óleo de mamona, } \\
\text { enxofre, arsênico e açúcar mascavo } \\
\text { são usados para a cura do diabetes }\end{array}$ & $\begin{array}{l}\text { Formulação para uso } \\
\text { oral }\end{array}$ & PI 9903505-7 A2 & 18/08/99 & Pessoa física \\
\hline $\begin{array}{l}\text { Processo de fabricação e obtenção de } \\
\text { produto final terapêutico a base de } \\
\text { soja }\end{array}$ & $\begin{array}{l}\text { Formulação para uso } \\
\text { geral }\end{array}$ & PI 0000363-8 A2 & $11 / 02 / 00$ & Pessoa física \\
\hline $\begin{array}{l}\text { Composições farmacêuticas para o } \\
\text { tratamento de diabetes, a partir de } \\
\text { extratos de Myrcia multiflora e } M \text {. } \\
\text { uniflora }\end{array}$ & $\begin{array}{l}\text { Formulação para uso } \\
\text { oral }\end{array}$ & PI 0001842-2 A2 & $27 / 03 / 00$ & $\begin{array}{l}\text { Hebron } \\
\text { Farmacêutica }\end{array}$ \\
\hline $\begin{array}{l}\text { Sistema aplicado na monitorização de } \\
\text { seres humanos e animais viventes }\end{array}$ & $\begin{array}{l}\text { Equipamento para } \\
\text { monitoração }\end{array}$ & PI 0105253-5 A2 & $10 / 09 / 01$ & Pessoa física \\
\hline $\begin{array}{l}\text { Uso de compostos de ácido graxos de } \\
\text { até } 22 \text { átomos de carbono e seus } \\
\text { derivados para preparar fármacos e/ou } \\
\text { reagentes analíticos com ação } \\
\text { sinérgica e insulinomimética }\end{array}$ & $\begin{array}{l}\text { Formulação para uso } \\
\text { geral }\end{array}$ & PI 0200944-7 A2 & $15 / 03 / 02$ & USP, FAPESP \\
\hline
\end{tabular}




\section{Continuação Tabela 15.}

\begin{tabular}{|c|c|c|c|c|}
\hline Título & Processo/Produto & Pedido & $\begin{array}{l}\text { Data de } \\
\text { depósito }\end{array}$ & Depositante \\
\hline $\begin{array}{l}\text { Nova modalidade de aplicação } \\
\text { terapêutica à talidomida no diabete } \\
\text { mellitus }\end{array}$ & $\begin{array}{l}\text { Formulação para uso } \\
\text { oral }\end{array}$ & PI 0203709-2 A2 & $06 / 09 / 02$ & Pessoa física \\
\hline $\begin{array}{l}\text { Nova modalidade de uso terapêutico } \\
\text { da Bauhinia sp aplicada no diabetes } \\
\text { mellitus }\end{array}$ & $\begin{array}{l}\text { Formulação para uso } \\
\text { geral }\end{array}$ & PI 0300582-8 A2 & $28 / 02 / 03$ & Pessoa física \\
\hline $\begin{array}{l}\text { Mecanismos e drogas utilizados no } \\
\text { tratamento de diabetes, obesidade e } \\
\text { controle dos distúrbios da fome }\end{array}$ & $\begin{array}{l}\text { Formulação para uso } \\
\text { geral }\end{array}$ & PI 0304390-8 A2 & $23 / 06 / 03$ & FAPESP \\
\hline $\begin{array}{l}\text { Complemento alimentar para auxiliar } \\
\text { no tratamento e controle de diabetes }\end{array}$ & $\begin{array}{l}\text { Formulação para uso } \\
\text { oral }\end{array}$ & PI 0401061-2 A2 & $22 / 01 / 04$ & Pessoa física \\
\hline $\begin{array}{l}\text { Uso farmacológico de inibidor da } \\
\text { expressão da proteína coativador } 1 \\
\text { alfa do receptor ativado por } \\
\text { proliferador do peroxisoma (PGC- } \\
\text { 1(alfa)) para o tratamento de diabetes } \\
\text { mellitus, resistência à insulina e } \\
\text { síndrome metabólica, seu composto e } \\
\text { sua composição farmacêuticos }\end{array}$ & $\begin{array}{l}\text { Formulação para uso } \\
\text { geral }\end{array}$ & PI 0500959-6 A8 & $23 / 03 / 05$ & UNICAMP \\
\hline $\begin{array}{l}\text { Processo de extração de proteínas de } \\
\text { endosperma de sementes }\end{array}$ & $\begin{array}{l}\text { Proteína recombinante } \\
\text { pró-insulina }\end{array}$ & PI 0505457-5 A8 & $01 / 12 / 05$ & UNICAMP \\
\hline Hidropletismômetro & 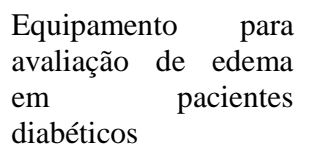 & PI 0606099-4 A2 & $22 / 12 / 06$ & UFMG \\
\hline $\begin{array}{l}\text { Processo de obtenção de ácido } \\
\text { rosmarínico e de derivados semi- } \\
\text { sintéticos a partir da espécie vegetal } \\
\text { Origanum vulgare e formulações para } \\
\text { o tratamento de diabetes contendo tais } \\
\text { substâncias }\end{array}$ & $\begin{array}{l}\text { Formulação para uso } \\
\text { oral }\end{array}$ & PI 0802688-2 A2 & $25 / 06 / 08$ & ACEF \\
\hline $\begin{array}{l}\text { Composto ativo fitoterápico } \\
\text { antihiperglicêmico e antiobesidade }\end{array}$ & $\begin{array}{l}\text { Formulação para uso } \\
\text { oral }\end{array}$ & PI 0905103-1 A2 & $25 / 09 / 09$ & Uniube \\
\hline $\begin{array}{l}\text { Sistema polimérico de confinamento } \\
\text { de amilina humana e análogos } \\
\text { agonistas, processo e uso; processo de } \\
\text { avaliação funcional de amilina } \\
\text { liberada }\end{array}$ & Formulação injetável & PI $1003424-2$ A2 & 08/09/10 & UFRJ \\
\hline $\begin{array}{l}\text { Sistema polimérico de confinamento } \\
\text { de insulina, processo e uso de dito } \\
\text { sistema }\end{array}$ & Formulação injetável & PI 1103164-6 A2 & $16 / 03 / 11$ & UFRJ \\
\hline $\begin{array}{l}\text { Método para a regulação específica da } \\
\text { resposta inflamatória mediada por } \\
\text { células T através da utilização de } \\
\text { anticorpos IGM contra seus } \\
\text { receptores clonais com o objetivo de } \\
\text { prevenir ou tratar processos } \\
\text { inflamatórios, auto-imunes ou não }\end{array}$ & Vacina & PI 1101990-5 A2 & 08/04/11 & Pessoa física \\
\hline
\end{tabular}


Continuação Tabela 15.

\begin{tabular}{|c|c|c|c|c|}
\hline Título & Processo/Produto & Pedido & $\begin{array}{l}\text { Data de } \\
\text { depósito }\end{array}$ & Depositante \\
\hline $\begin{array}{l}\text { Formulação da mistura dos extratos } \\
\text { hidroalcóolicos liofilizados das folhas } \\
\text { de Averrhoa carambola e de } \\
\text { Syzygium cumini, suas composições } \\
\text { farmacêuticas e seu uso na prevenção } \\
\text { e no tratamento do diabetes tipo II e } \\
\text { suas complicações }\end{array}$ & $\begin{array}{l}\text { Formulação para uso } \\
\text { geral }\end{array}$ & $\begin{array}{l}\text { BR } 102012005787 \\
5 \text { A2 }\end{array}$ & $01 / 03 / 12$ & UFMA \\
\hline $\begin{array}{l}\text { Kit para realização de diagnóstico } \\
\text { e/ou prognóstico, método diagnóstico } \\
\text { e/ou prognóstico para dosagens de } \\
\text { níveis de aloxano em amostras } \\
\text { biológicas e processos de produção de } \\
\text { reagente para referido kit }\end{array}$ & Kit diagnóstico & $\begin{array}{c}\text { BR } 102012015352 \\
1 \mathrm{~A} 2\end{array}$ & $22 / 06 / 12$ & UFSM \\
\hline $\begin{array}{l}\text { Preparação farmacêutica contendo } \\
\text { Chrisobalanus icaco para o } \\
\text { tratamento de diabetes }\end{array}$ & $\begin{array}{l}\text { Formulação para uso } \\
\text { geral }\end{array}$ & $\begin{array}{c}\text { BR } 102012018734 \\
5 \mathrm{~A} 2\end{array}$ & $27 / 07 / 12$ & UFSE \\
\hline $\begin{array}{l}\text { Formulação farmacêutica contendo } \\
\text { extrato de Hovenia dulcis, processo } \\
\text { de obtenção e uso da mesma na } \\
\text { preparação de alimento funcional e } \\
\text { fitopreparado para o tratamento da } \\
\text { diabetes, hiperglicemias } \\
\text { dislipidemias }\end{array}$ & $\begin{array}{l}\text { Formulação para uso } \\
\text { oral }\end{array}$ & $\begin{array}{c}\text { BR } 102012018924 \\
0 \text { A2 }\end{array}$ & $30 / 07 / 12$ & $\begin{array}{l}\text { UFV, } \\
\text { UFJF }\end{array}$ \\
\hline $\begin{array}{l}\text { Processo de extração e uso de } \\
\text { Baccharis dracunculifolia para } \\
\text { amplificar a secreção de insulina in } \\
\text { vivo }\end{array}$ & $\begin{array}{l}\text { Formulação para uso } \\
\text { oral }\end{array}$ & $\begin{array}{c}\text { BR } 102012020540 \\
8 \text { A2 }\end{array}$ & $16 / 08 / 12$ & Unicentro \\
\hline $\begin{array}{l}\text { Composição } \quad \text { farmacêutica } \\
\text { nanométrica e seus usos }\end{array}$ & $\begin{array}{l}\text { Formulação para uso } \\
\text { geral }\end{array}$ & $\begin{array}{c}\text { BR } 102012025132 \\
9 \text { A2 }\end{array}$ & $02 / 10 / 12$ & $\begin{array}{l}\text { USP, UFTGS, } \\
\text { FUB }\end{array}$ \\
\hline $\begin{array}{l}\text { Formulação fitoterápica } \\
\text { extrato de embaúba com } \\
\text { hipoglicemiante }\end{array}$ & $\begin{array}{l}\text { Formulação para uso } \\
\text { oral }\end{array}$ & $\begin{array}{c}\text { BR } 102013006733 \\
4 \text { A2 }\end{array}$ & $25 / 03 / 13$ & UFJF, FAPEMIG \\
\hline $\begin{array}{l}\text { Kit para diagnóstico auxiliar e } \\
\text { preditivo do diabetes mellitus }\end{array}$ & Kit diagnóstico & $\begin{array}{c}\text { BR } 102013013204 \\
7 \text { A2 }\end{array}$ & $28 / 05 / 13$ & Pessoa física \\
\hline $\begin{array}{l}\text { Composição } \\
\text { efervescente e uso de extrato } \\
\text { etanólico de Bauhiniaforticata }\end{array}$ & $\begin{array}{l}\text { Formulação para uso } \\
\text { oral }\end{array}$ & $\begin{array}{c}\text { BR } 102013024150 \\
4 \text { A2 }\end{array}$ & $20 / 09 / 13$ & UFPE \\
\hline $\begin{array}{l}\text { Fitomedicamento anti-inflamatório, } \\
\text { antidiabético e anti-hipertensivo } \\
\text { produzido a partir do extrato do jucá }\end{array}$ & $\begin{array}{l}\text { Formulação para uso } \\
\text { geral }\end{array}$ & $\begin{array}{c}\text { BR } 102014003945 \\
7 \text { A2 }\end{array}$ & $02 / 02 / 14$ & UFPE \\
\hline
\end{tabular}

Fonte: Instituto Nacional de Propriedade Industrial, 2015.

Adicionalmente, apesar do grande número global de pedidos de depósitos, atualmente existem apenas 18 patentes concedidas pelo INPI, que estão relacionadas ao diagnóstico, profilaxia ou tratamento do diabetes. No entanto, nenhuma dessas patentes foi depositada por titulares do Brasil, mas pertencem a detentores da Alemanha, Estados Unidos, Índia, Japão, México, Reino Unido e Rússia (BRASIL, 2015). 


\subsection{TECNOLOGIA APTA PARA USO EM PACIENTES DIABÉTICOS NO ÂMBITO DO} SUS

Para uma tecnologia ser comercializada no país, ela precisa ser aprovada e obter o registro pela Agência Nacional de Vigilância Sanitária (ANVISA). De todas as tecnologias promissoras como alternativa à terapia MDI no manejo do diabetes, o SIC está autorizado para comercialização no país.

O SIC é uma alternativa à aplicação múltipla diária de insulina (MDI) (CUMMINS et al., 2010). Esse sistema visa favorecer ao paciente diabético um perfil similar ao fisiológico (MCCULLOCH; NATHAN; MULDER, 2015). Segundo ensaios clínicos e observacionais, os principais benefícios dessa tecnologia para os pacientes DM1 são: melhor controle dos níveis de glicose e hemoglobina glicada (HbA1c); diminuição de problemas relacionados à hipoglicemia; possibilidade de diminuição da dosagem de insulina e ganhos na qualidade de vida (CUMMINS et al., 2010; JEITLER et al., 2008; MISSO, 2010). Atualmente existem vários estudos em andamento investigando o uso dessa tecnologia em pacientes diabéticos tipo 2 e diabetes gestacional (ANITA LI; CHI HO TSANG, 2012; ASHLEY FULTON; JERIC UY; KATE KENNEDY, 2015; O’NEILL et al., 2015).

Um estudo australiano de 2007 comparou SIC (utilizando as insulinas Novorapid ${ }^{\circledR}$ ou Humalog $^{\circledR}$ ) versus MDI (utilizando as insulinas NPH mais Novorapid ${ }^{\circledR}$ ou Humalog ${ }^{\circledR}$ ) em pacientes DM1. Eles identificaram menores incidências de complicações ao longo da vida dos pacientes quando utilizaram o SIC, como por exemplo, redução de $12 \%$ na perda da visão ou cegueira, redução de $16 \%$ de doença renal, $16 \%$ menos incidência de doença vascular periférica e $4 \%$ na redução de infarto do miocárdio. Além disso, os pesquisadores demonstraram um ganho incremental considerável na análise de custo-efetividade para adultos e adolescentes, que sugere um ganho não só na qualidade vida, mas também em valores monetários ao utilizar o SIC nessa população (COHEN et al., 2007).

Uma revisão sistemática (RS) da Nova Zelândia em 2008 avaliou a eficácia, segurança e custo-efetividades do SIC versus MDI em pacientes diabéticos. A conclusão da RS foi que o SIC contribuiu na melhoria dos níveis de HA1c nos pacientes avaliados (adultos DM1, crianças e adolescentes DM1 e adultos DM2). Além disso, o SIC evitou ataques hipoglicêmicos severos por dois anos e melhorou consideravelmente a qualidade de vida dos pacientes. Também identificaram um ganho incremental por mais de seis anos (ciclo de vida 
de um SIC) na análise de custo-efetividade, que sugere um ganho não só na qualidade vida, mas também em valores monetários ao utilizar o SIC em pacientes DM1 (CAMPBELL et al., 2008).

Ao pesquisar na ANVISA por registro de produtos para saúde com o termo "Sistema de Infusão Contínua de Insulina" foram encontrados 2 produtos autorizados para comercialização no país (Tabela 16). Nota-se que ambos os registros se encontram vencidos desde 2011. Quando utilizado o termo "Bomba de Contínua de Insulina" não foi identificado nenhum registro.

Tabela 16. Sistemas de Infusão Contínua de Insulina com registro aprovado pela ANVISA.

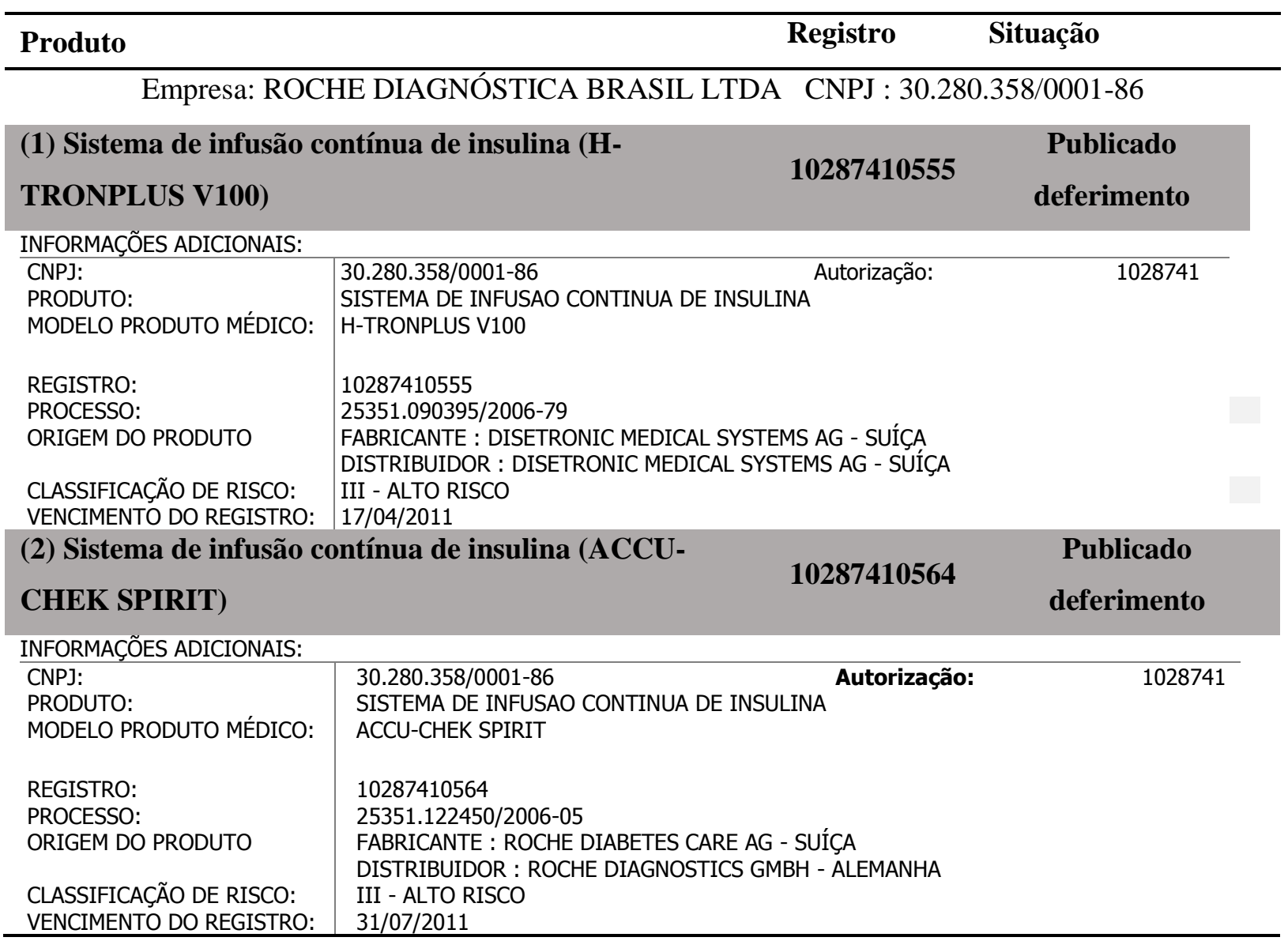

Fonte: ANVISA, 2015.

Já a pesquisa na ANIVISA com o termo "Bomba Externa de Infusão de Insulina" foram identificados 2 produtos autorizados para comercialização no país (Tabela 17). 
Tabela 17. Bomba Externa de Infusão de Insulina com registro aprovada pela ANVISA.

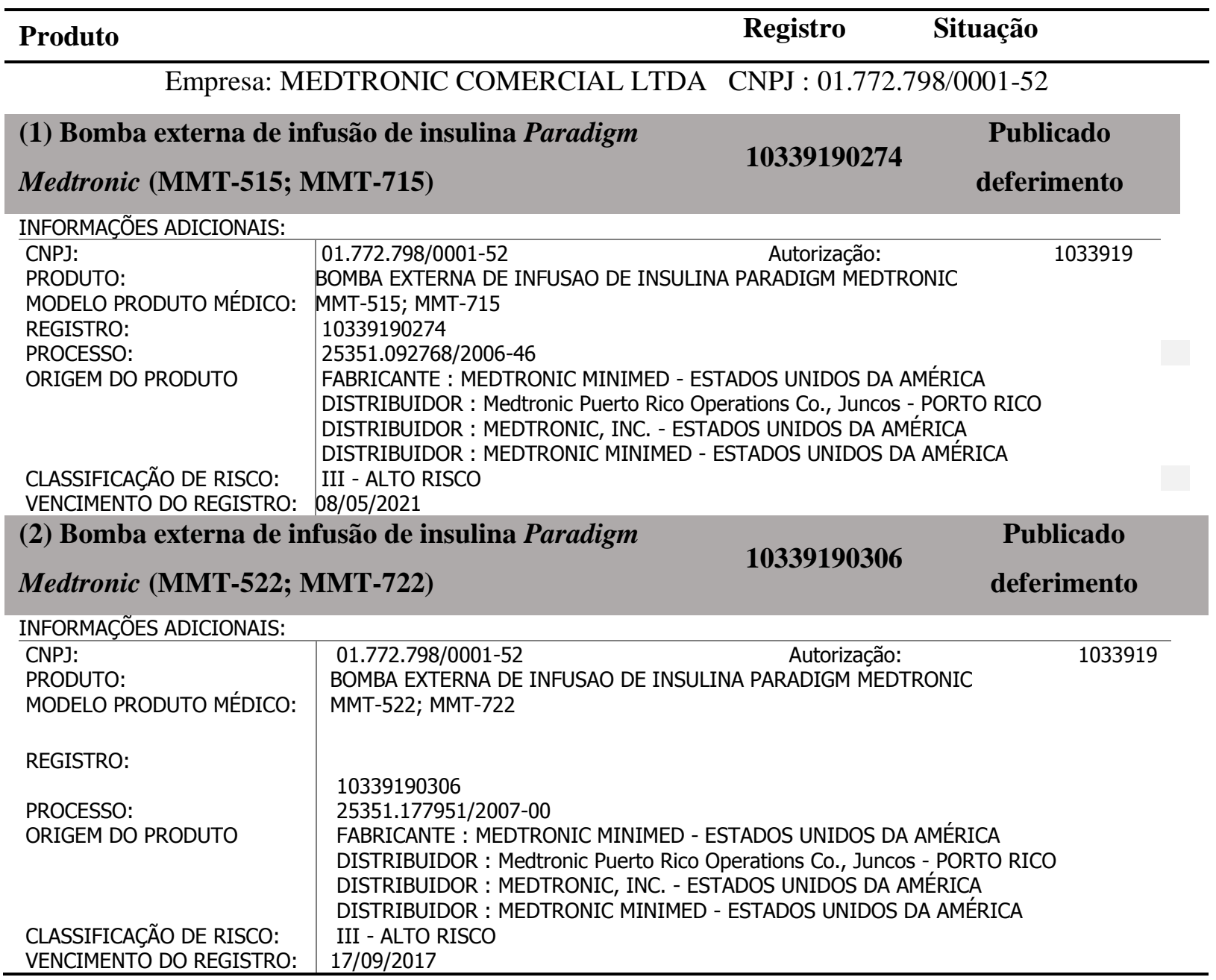

Fonte: ANVISA, 2015.

Uma pesquisa no Portal de Compras do Governo Federal (Comprasnet) por "Sistema de Infusão Contínua de Insulina" e "Bomba Externa de Infusão de Insulina" foram identificadas compras realizadas pelos Estados de São Paulo (Apêndice C), Ceará (Apêndice D), Roraima (Apêndice E) e Pará (Apêndice F).

O SIC é um produto para saúde mecânico com comandos eletrônicos (Figura 14), com peso que varia de acordo com o modelo e fabricante. Esse sistema possui um reservatório ou uma seringa com insulina (cartucho, figura 14), que é ligado a um tubo plástico fino que no final possui uma cânula flexível ou um cateter que inserido no tecido subcutâneo do paciente, geralmente do abdômen (Figura 15). A insulina é liberada continuamente em microdoses, 
representando a infusão basal (variando de 0,4 a 2 U/hora), ou em pulsos (bolus). O regime bolus geralmente é utilizado antes das refeições, que é programado individualmente de acordo com as necessidades de cada paciente. Também é possível programar períodos em que não será liberado nenhuma dose de insulina, dependendo do regime de cada paciente. A cânula ou cateter e o tubo, são denominados consumíveis, ou seja, precisam ser trocados periodicamente de acordo com a recomendação do fabricante.

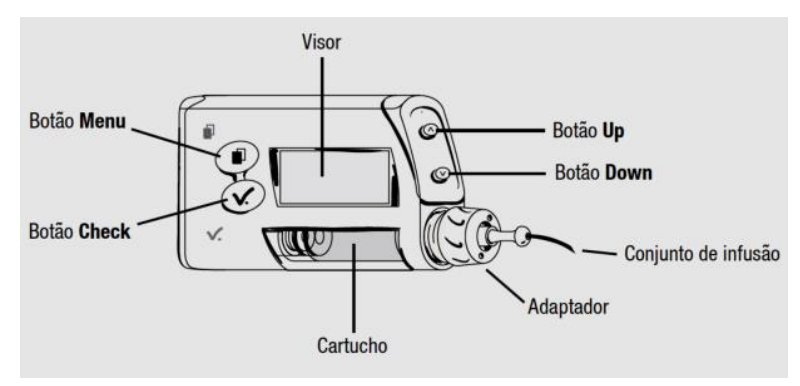

Fonte: Guia do Utilizador, Accu-Chek Spirit versão 2.XX, Roche.

Figura 14. Modelo de um Sistema de infusão contínua de insulina (Accu-Chek Spirit).

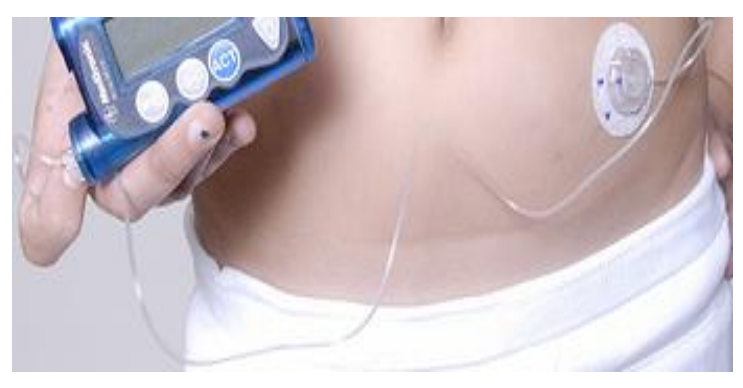

Fonte: Banco de imagens Google.

Figura 15. Imagem de um Sistema de infusão contínua de insulina em uso pelo paciente.

O uso de um SIC requer profissionais capacitados e treinamento dos usuários, principalmente como resolver alguns erros que podem apresentar ou nos casos de desconexão de algum item ou troca da bateria. Também algumas habilidades geralmente comuns para um paciente diabético, como por exemplo, contagem de carboidratos da dieta para calcular a relação carboidrato / insulina nas doses de bolus, são mais exigidos nesse sistema, uma vez que influenciam nos resultados esperados.

Em 2011, foi sancionada a Lei 12.401 que, dentre outras resoluções, estabelece que a incorporação, a exclusão ou a alteração de novos medicamentos, produtos ou procedimentos 
no SUS, bem como a criação ou alteração dos protocolos clínicos ou orientações terapêuticas, estão sob a responsabilidade de uma nova instituição: a Comissão Nacional de Incorporação de Tecnologias no SUS (CONITEC) (BRASIL, 2011). Ademais, essa lei dispõe que a avaliação das tecnologias ou procedimentos basear-se-á na evidência científica sobre a eficácia, a precisão, a segurança e custo-benefício do tratamento. Essa lei também estabelece que a incorporação, exclusão ou alteração de tratamentos deve ser feita mediante um processo administrativo aberto e transparente, com audiências e consultas públicas. Além disso, a decisão tem de ser feita no prazo de 180 dias a partir do início do processo administrativo e prorrogado por mais 90 dias, se necessário (BRASIL, 2011).

Diante disso, para que o SIC seja introduzido nos protocolos de tratamento dos pacientes diabéticos usuários do SUS, ele precisará ser analisado conforme estabelece a lei supracitada e ser aprovado em audiência pública. Ressalta-se que até o momento, não foram identificados registros de solicitações para o SIC no banco de dados de produtos avaliados e em avaliação para incorporação pela CONITEC.

\subsubsection{Cenário Nacional}

Para identificar as experiências com relação ao SIC nas secretarias nacionais foi aplicado a todas elas o questionário 1 (Quadro 1). No Brasil, a Lei 8080/90 determina o direito à assistência terapêutica integral (BRASIL, 1990). E conforme previsto na CF/88: "A saúde é um direito de todos e dever do Estado [...]" (BRASIL, 1988). Para garantir esse direito, o Poder Judiciário tem determinado ações à administração pública para fornecimento de serviços ou tecnologias em saúde, quando estes não se encontram disponíveis no SUS.

Em Minas Gerais, entre 1999 a 2009, 36,4\% dos procedimentos demandados judicialmente se referiam à solicitação do SIC (GOMES et al., 2014b). De 2009 a 2012, o diabetes esteve presente entre as principais indicações das demandas judiciais (GOMES et al., 2014a). Ademais se observa que as ações judiciais em saúde contra a União vêm crescendo paulatinamente: 10.486 casos novos em 2009, 11.203 em 2010, 12.811 em 2011 e 13.051 em 2012 (GOMES et al., 2014a). No Estado de São Paulo, as determinações judiciais em saúde passaram de 80 para 600 solicitações mensais, com um aumento de $650 \%$ no intervalo de seis anos. O princípio do direito à atenção integral é aplicado na maioria das ações (SANTOS et al., 2011). 
Participaram seis SES (Tocantins, Santa Catarina, São Paulo, Minas Gerais, Goiás e Amapá). Cinco dessas SES já haviam recebido demandas judiciais para o SIC (83\%) e todas, exceto Tocantins, têm notado aumento na demanda judicial para uso do SIC nos últimos 5 anos (Figura 16). Dentre as secretarias que participaram apenas Amapá e São Paulo informaram que estavam avaliando a tecnologia baseada em evidências científicas.

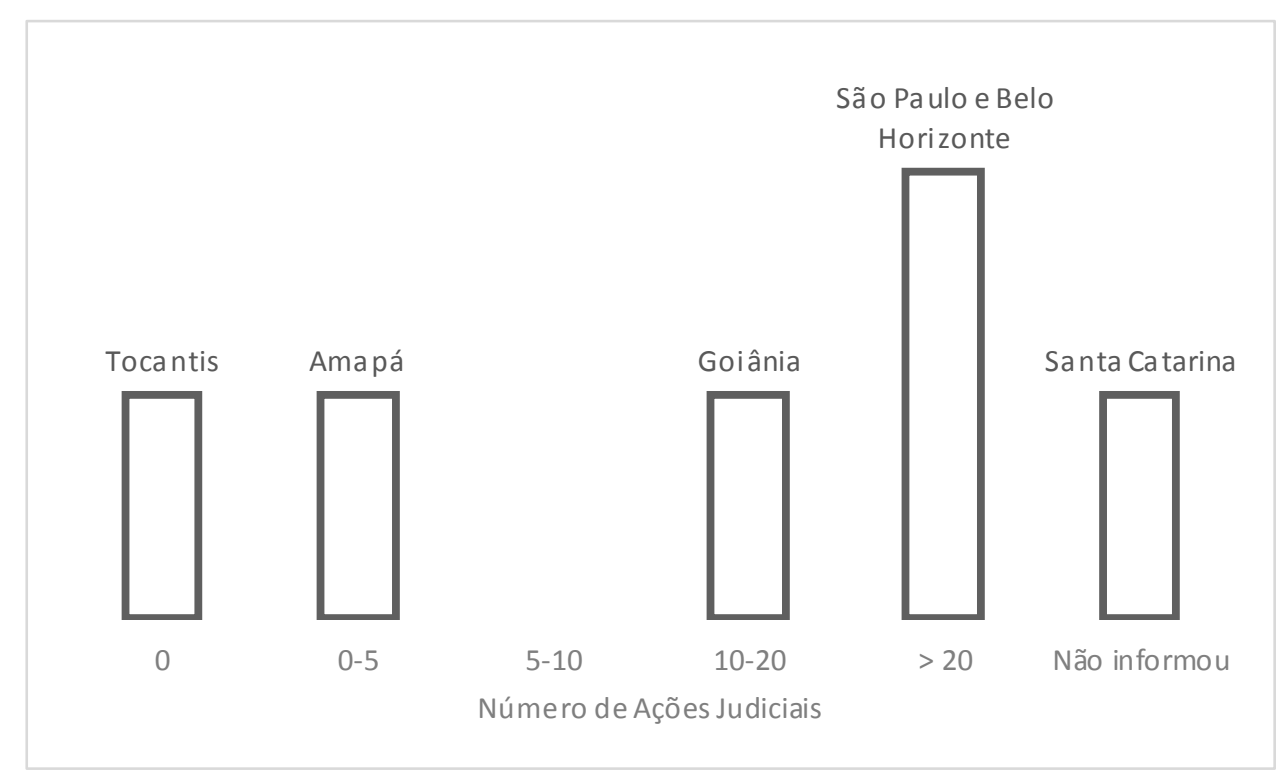

Fonte: Elaboração própria.

Figura 16. Secretarias de Saúde (SES): número de ações judiciais em saúde de Bomba de Infusão Contínua de Insulina nos últimos 5 anos.

O MS informou que de 2011 até 2014 foram adquiridas 88 SIC por via judicial direto da União, ou seja, não estão contabilizados Estados e Municípios, ao preço de R \$ 12.500,00 cada (Apêndice B).

\subsubsection{Cenário Internacional}

Para obter as experiências de organizações internacionais de ATS sobre o uso do SIC nos seus respectivos países, foi aplicado o questionário 2 (Quadro 1) em 15 países (Figura 1). Algumas organizações de vários países, como Uruguai, Argentina, Itália, Austrália, Reino Unido, Espanha, Lituânia e Finlândia, não responderam o questionário, pois não estiveram 
envolvidos no processo de avaliação/incorporação do SIC nos respectivos países/organizações, e, portanto, foram excluídas das análises.

Das 17 organizações que responderam às perguntas (Figura 1), 71\% não estiveram envolvidos no processo de incorporação, mas foram responsáveis pela avaliação do SIC que subsidiou a tomada de decisão nos seus respectivos países. As principais indicações do SIC foram para DM1 estratificados em 47\% para adultos, 23,5\% para crianças até 12 anos, 18\% para mulheres grávidas e $12 \%$ para crianças entre 13 e 18 anos.

Os principais benefícios do SIC, elencados pelas organizações foram a redução das taxas de hipoglicemia (30\%), menores variações das taxas de glicose do sangue (18\%), baixa HbA1c (17,5\%), redução da concentração de glicose no sangue $(17,5 \%)$ e melhoria na qualidade de vida e satisfação do tratamento (6\%).

A estimativa do número de pessoas que estão autorizadas a utilizar o SIC foi de 0 a 250.000 pessoas para $50 \%$ dos países pesquisados, seguida pela faixa de 250.000 a 500.000 (6\%) e no máximo 500.000 pessoas $(6 \%)$.

O preço de aquisição do SIC pode variar de 12 a 15 mil reais, excetuando-se gastos mensais com consumíveis. Dos países que participaram, 47\% reembolsam completamente, $29 \%$ parcialmente, $12 \%$ não disponibilizam à comunidade e $6 \%$ reembolsam via organizações privadas de saúde. Apenas Canadá não respondeu.

De acordo com a literatura, a MDI pode provocar algumas complicações, como incidentes técnicos ou metabólicos, hipoglicemia e cetonúria, por exemplo (MEDICAL ADVISORY SECRETARIAT, 2009). Nesse sentido foi solicitado aos países participantes que classificassem as complicações mais recorrentes com o uso do SIC. Dos 13 países que responderam, a hipoglicemia severa foi a mais recorrente $(33,3 \%)$, seguida de infecções na pele $(27 \%)$ e em menor grau a cetoacidose diabética $(7 \%)$.

No Reino Unido o SIC já foi incorporado, e até 2010 o SIC era utilizado em 1\% dos pacientes com DM1 - muito menos quando se compara os dados de outros países da Europa e da América do Norte (10-20\%) no mesmo período (CUMMINS et al., 2010). Diante disso, foi solicitado que as organizações descrevessem uma taxa de pacientes que utilizaram o SIC nos últimos 3 anos. Chile, Espanha e França responderam com uma taxa de 5 a 10\%, e Suécia 
com taxa de uso acima dos 30\% (Figura 1). Essa alta taxa na Suécia pode ser explicada por ter sido uma das pioneiras na incorporação do SIC (1980).

Como exposto, alguns estudos tem demonstrado alguns benefícios ao iniciar o uso do SIC. No entanto, os benefícios estão vinculados a um custo adicional de aproximadamente R\$ 9500,00 quando comparado a MDI (CUMMINS et al., 2010). Esse custo se refere principalmente aos consumíveis, tais como tubos e cânulas do SIC.

Para que o SUS possa sustentar esse custo adicional é necessário realizar estudos clínicos com análises de custo levando em consideração os critérios e a população local. Nos poucos estudos existentes, é possível identificar que o SIC em DM1 é custo-efetivo se a redução do nível de HbA1c foi igual ou superior a 0,9\% ou mais (MEDICAL ADVISORY SECRETARIAT, 2009).

As respostas das 17 organizações internacionais demonstram que esse tema já está solucionado nesses países e que a população com diabetes usufrui há algum tempo de uma nova terapia com possibilidade de obter melhor qualidade de vida.

Apesar da pouca participação das SES brasileiras na pesquisa, é evidente a necessidade de se realizar estudos que acompanhem os pacientes utilizando o SIC por um período necessário para se verificar os benefícios dessa tecnologia a longo prazo, como por exemplo, se tal tecnologia irá diminuir as incidências de complicações relacionadas ao diabetes e as mortes. Além disso, são necessários estudos de custos levando em consideração o ganho na qualidade de vida para subsidiar futuras decisões na perspectiva de sua possível incorporação no SUS.

Cabe ressaltar que no cenário internacional participou organizações de ATS de 15 países, no entanto, a grande maioria não possui um sistema de saúde universal e com critérios de reembolso de tecnologias similares ao Brasil. Também existe várias diferenças econômicas e na geração de produtos inovadores entre os países entrevistados e o Brasil. 


\section{CONSIDERAÇÕES FINAIS}




\section{CONSIDERAÇÕES FINAIS}

Não ter acesso a tecnologias potencialmente efetivas e a cuidados de saúde, é alarmante, uma vez que as tecnologias estão em fase de amplo desenvolvimento no mundo (por exemplo, tecnologias que utilizam algoritmos para tentar prever funções e ações do organismo, terapia celular e gênica, vacinas e nanotecnologia/nanosensores).

Percebe-se que no Brasil existem várias particularidades quando se trata de saúde. A constituição brasileira proporciona direitos, como cuidado integral à saúde. O sistema de saúde público brasileiro é universal, com equidade de acesso ao cuidado. Esses direitos e princípios promovem litígios individuais ou coletivos entres os que necessitam de acesso ao cuidado em saúde, que por algum motivo ele não foi concebido, e o gestor de saúde. Quase sempre esses litígios se concluem a favor dos demandantes e penalizam o Estado. Essa penalização obriga o Estado a ofertar aos litigantes o cuidado solicitado de forma imediata por período e condições determinados pelo profissional de saúde envolvido no litígio.

Os inquéritos realizados sinalizam a desigualdade de acesso aos diabéticos brasileiros. Este resultado é reforçado pelo fato de que em várias regiões os litígios obrigaram o Estado a subsidiar o SIC para um determinado indivíduo ou grupo de indivíduos por preço de mercado, sem tempo ou condições favoráveis para conseguir uma economia de escala. Ademais, estudos que avaliaram essa tecnologia encontraram benefícios e a recomendam, apesar das poucas evidências de custo - efetividade.

Diante do elevado grau de inovação e da velocidade com que surgem novas alternativas para o manejo do diabetes. Este trabalho pretende contribuir não só para apontar uma nova alternativa terapêutica que possibilite um ganho na qualidade de vida dos pacientes diabéticos usuários do SUS, mas também contribuir para o fortalecimento das pesquisas nacionais. 


\section{CONCLUSÃO}




\section{CONCLUSÃO}

Dentre as novas tecnologias para o manejo do diabetes tipo 1 , as que mais vem se destacando em número de usuários e na melhora na qualidade de vida são os Sistemas de Infusão Subcutânea Contínua de Insulina. Diante do elevado grau de inovação e da velocidade com que surgem novas alternativas, é importante a promoção do acesso da população brasileira a essa tecnologia. Foi constatado neste estudo que $47 \%$ das organizações internacionais entrevistadas já reembolsam o SIC nos seus respectivos países. Nesse sentido é evidente a necessidade de estudos clínicos e de custo - efetividade na perspectiva do SUS levando em consideração ganhos na qualidade de vida. Adicionalmente, seriam necessários esforços para que as pesquisas nacionais evoluíssem da fase de bancada em que se encontram atualmente e avançassem possibilitando a geração de novos produtos nacionais. Uma vez que a importação de produtos tecnológicos promove um impacto excessivamente alto para a economia e para sustentabilidade do SUS dado o número atual e a expectativa de aumento da prevalência do diabetes no Brasil. 


\section{ARTIGOS SUBMETIDOS}




\section{ARTIGOS SUBMETIDOS}

1. Silveira D., Angelo T., Pinheiro R. M., Gratieri T. Horizonte tecnológico do diabetes e o cenário das pesquisas no Brasil. Rev. Saúde Pública.

2. Silveira D., Angelo T., Pinheiro R. M., Gratieri T. Infusão Subcutânea Contínua de Insulina: Cenário Nacional e Internacional. Cadernos Saúde Coletiva. 


\section{GLOSSÁRIO}

Avaliação de Tecnologias de Saúde (ATS): processo de investigação das consequências clínicas, econômicas e sociais da utilização das tecnologias em saúde em curto e longo prazo, bem como seus efeitos diretos e indiretos, desejados ou não. Permite apresentar alternativas de tratamento e, frequentemente, proporciona elementos que orientam a tomada de decisões estratégicas relacionadas à cobertura dos serviços ou à alocação de recursos, incluindo a aquisição de equipamentos. A ATS inclui grupos interdisciplinares e uma variedade de métodos de análise.

Avaliação econômica de custo - efetividade: avaliação econômica em que os custos são medidos em unidades monetárias e os desfechos (consequências em saúde) são medidos em unidades não monetárias, por exemplo, mortes evitadas, anos de vida ganhos, entre outros.

Análise de Impacto orçamentário: avaliação econômica que dimensiona os custos com a introdução de uma nova intervenção em saúde. Possibilita ao gestor verificar a viabilidade econômica da nova intervenção.

Anos de vida perdidos ajustados por incapacidade (disability adjusted life of years; DALY): uma medida de carga da doença, expressa pelo número de anos perdidos devido a problemas de saúde, incapacidade ou morte precoce.

Anos de vida perdidos (number of years of life lost; YLLS): medida utilizada para medir a morbidade ou os anos vividos com incapacidade e pode ser obtido calculando a diferença entre a idade ao morrer e a expectativa de vida ao nascer.

Nível glicêmico nadir: o ponto mais baixo da glicemia capilar ou à menor concentração de glicose.

Razão incremental de custo-efetividade - RICE (Incremental cost-effectiveness ratioICER): custo adicional por unidade extra de efeito (por exemplo, anos de vida ajustados por qualidade - AVAQ ou em inglês, quality adjusted life year - QALY) para o tratamento mais efetivo. É um método para apresentar o resultado de uma análise de custo-efetividade.

Relaparotomia: reoperação em cirurgia abdominal. 


\section{REFERÊNCIAS}

AGUIAR, M. M. G.; RODRIGUES, J. M.; SILVA CUNHA, A. Encapsulation of insulincyclodextrin complex in PLGA microspheres: a new approach for prolonged pulmonary insulin delivery. Journal of Microencapsulation, v. 21, n. 5, p. 553-564, 2004.

AL-QADI, S. et al. Microencapsulated chitosan nanoparticles for pulmonary protein delivery: In vivo evaluation of insulin-loaded formulations. Journal of Controlled Release, v. 157, n. 3, p. 383-390, 2012.

AL-TABAKHA, M.; ARIDA, A. Recent challenges in insulin delivery systems: A review. Indian Journal of Pharmaceutical Sciences, v. 70, n. 3, p. 278-286, 2008.

ANDRADE, F. et al. Biological assessment of self-assembled polymeric micelles for pulmonary administration of insulin. Nanomedicine: Nanotechnology, Biology and Medicine, v. 11, n. 7, 2015.

ANHALT, H.; BOHANNON, N. J. V. V. Insulin Patch Pumps: Their Development and Future in Closed-Loop Systems. Diabetes Technology \& Therapeutics, v. 12, n. S1, p. S51-S-58, 2010.

ANITA LI; CHI HO TSANG. The effectiveness and appropriateness of educational components and strategies associated with insulin pump therapy (IPT): an updated systematic review. PROSPERO, 2012.

ARAÚJO, E. P. et al. Infliximab restores glucose homeostasis in an animal model of dietinduced obesity and diabetes. Endocrinology, v. 148, n. 12, p. 5991-7, 2007.

ASHLEY FULTON; JERIC UY; KATE KENNEDY. The effectiveness of continuous subcutaneous insulin infusion on quality of life of families and glycaemic control among children with type 1 diabetes: a systematic review. PROSPERO, 2015. 
ASPDEN, T. J.; ILLUM, L.; SKAUGRUD, O. Chitosan as a nasal delivery system: Evaluation of insulin absorption enhancement and effect on nasal membrane integrity using rat models. European Journal of Pharmaceutical Sciences, v. 4, n. 1, p. 23-31, 1996.

BAGAROLLI, R. A.; SAAD, M. J. A.; SAAD, S. T. O. Toll-like receptor 4 and inducible nitric oxide synthase gene polymorphisms are associated with Type 2 diabetes. Journal of diabetes and its complications, v. 24, n. 3, p. 192-8, 2010.

BALSELLS, M. et al. Glibenclamide, metformin, and insulin for the treatment of gestational diabetes: a systematic review and meta-analysis. BMJ (Clinical research ed.), v. 350, n. h102, p. 1-12, 2015.

Bionic Pancreas. Disponível em: <http://sites.bu.edu/bionicpancreas/>. Acesso em: 6 out. 2015 .

BORGHETI-CARDOSO, L. N. et al. Topical and transdermal delivery of drug-loaded nano/microsystems with application of physical enhacement techniques. Current Drug Targets, n. [Epub ahead of print], 2015.

BOTEGA, A. Consumption of human insulin in Brazil: a multivariate analysis. [s.l: s.n.].

BRASIL. Constituição da República Federativa do Brasil de 1988. Imprensa Nacional, p. 1139, 1988.

BRASIL. Lei $n^{0}$ 8080/1990. Dispõe sobre as condições para a promoção, proteção e recuperação da saúde, a organização e o funcionamento dos serviços correspondentes e dá outras providências.Legislação, 1990.1 Disponível em: <http://www.planalto.gov.br/ccivil_03/leis/L8080.htm>

BRASIL. Lei n ${ }^{\circ}$ 12.401, de 28 de abril de 2011. Diário Oficial da União, 2011.

BRASIL. Portaria $n^{\circ} .1 .555$, de 30 de julho de 2013. Diário Oficial da União, v. 3, n. I, p. 71, 
2013.

BRASIL. Ministério da Saúde, Portaria $n^{0}$ 1.358, de 20 de agosto de 2014Diário Oficial da União, 2014.

BRASIL. Instituto Nacional da Propriedade Industrial. Disponível em: <http://www.inpi.gov.br>. Acesso em: 26 out. 2015.

BRASIL. MINISTÉRIO DA SAÚDE. VIGITEL Brasil 2013: vigilância de fatores de risco e proteção para doenças crônicas por inquérito telefônico.Vigitel. [s.l: s.n.].

BRASIL. MINISTÉRIO DA SAÚDE. VIGITEL BRASIL 2014: vigilância de fatores de risco e proteção para doenças crônicas por inquérito telefônico.Vigitel. [s.l: s.n.].

CAMPBELL, S. et al. Systematic review update and economic evaluation for the New Zealand setting: Subcutaneous insulin pump therapy. [s.l: s.n.].

CASH, K. J.; CLARK, H. A. Nanosensors and nanomaterials for monitoring glucose in diabetes. Trends in Molecular Medicine, v. 16, n. 12, p. 584-593, 2010.

CenterWatch. Disponível em: <http://www.centerwatch.com/clinical-trials/results/newtherapies/nmt-details.aspx?CatID=55>. Acesso em: 25 out. 2015.

CGU. Lei no 12.527: Lei de Acesso á informação. [s.l: s.n.].

CHATURVEDI, K. et al. Polymeric hydrogels for oral insulin delivery. Journal of controlled release : official journal of the Controlled Release Society, v. 165, n. 2, p. 129 38, 2013.

$\mathrm{CHEN}, \mathrm{H}$. et al. Iontophoresis-driven penetration of nanovesicles through microneedleinduced skin microchannels for enhancing transdermal delivery of insulin. Journal of the Controlled Release, v. 139, n. 1, p. 63-72, 2009. 
CHEN, M.-C. et al. A review of the prospects for polymeric nanoparticle platforms in oral insulin delivery. Biomaterials, v. 32, n. 36, p. 9826-38, 2011.

$\mathrm{CHO}, \mathrm{H}$. J. et al. Chondroitin sulfate-capped gold nanoparticles for the oral delivery of insulin. International Journal of Biological Macromolecules, v. 63, p. 15-20, 2014.

CLAUSSEN, J. C. et al. Nanostructuring Platinum Nanoparticles on Multilayered Graphene Petal Nanosheets for Electrochemical Biosensing. Advanced Functional Materials, v. 22, n. 16, p. 3399-3405, 2012.

COBAS, R. A. et al. The cost of type 1 diabetes: A nationwide multicentre study in Brazil. Bulletin of the World Health Organization, v. 91, n. 6, p. 434-440, 2013.

COHEN, N. et al. Continuous Subcutaneous Insulin Infusion versus Multiple Daily Injections of Insulin: Economic Comparison in Adult and Adolescent Type 1 Diabetes Mellitus in Australia. Pharmaeconomics, v. 25, n. 10, p. 881-897, 2007.

COLLARES, C. V. A. et al. Identifying common and specific microRNAs expressed in peripheral blood mononuclear cell of type 1 , type 2 , and gestational diabetes mellitus patients. BMC Research Notes, v. 6, n. 1, p. 491, 2013.

Conselho Nacional de Desenvolvimento Científico e Tecnológico. Disponível em: <http://dgp.cnpq.br/buscagrupo/>. Acesso em: 20 out. 2015.

CUMMINS, E. et al. Clinical effectiveness and cost-effectiveness of continuous subcutaneous insulin infusion for diabetes: systematic review and economic evaluation. Health technology assessment (Winchester, England), v. 14, n. 11, p. iii-iv, xi-xvi, 1-181, 2010.

D 'SOUZA, B. et al. Development of b-cyclodextrin-based sustained release microparticles for oral insulin delivery. Drug Development and Industrial Pharmacy Ind Pharm, v. 9045, n. 1, p. 1-6, 2014. 
DAMGÉ, C. et al.. Diabetes, v. 37, n. 2, p. 246-51, 1988.

DE SOUZA, C. T. et al. Inhibition of UCP2 expression reverses diet-induced diabetes mellitus by effects on both insulin secretion and action. The FASEB Journal, Federation of American Societies for Experimental Biology, v. 21, n. 4, p. 1153-63, 2007.

DENECKE, C. The bionic pancreas: novel perspectives on insulin replacement therapies. Transplantation, v. 99, n. 2, p. 268-9, fev. 2015.

Diabetes Forecast. Disponível em: <http://www.diabetesforecast.org/2012/sep/on-thehorizon-new-diabetes-drugs-and-devices-underinvestigation.html?_utma $=227028104.1590656640 .1445798235 .1445798235 .1445798235 .1$ \&_utmb $=227028104.1 .10 .1445798235 \& \_u t m c=227028104 \& \_u t m x=-$ \&_utmz $=227028104.1445>$. Acesso em: 25 out. 2015.

Diabetes Forecast.27. Disponível em: <http://www.diabetesforecast.org/2009/may/diabetesmeds-on-the-horizon.html?referrer=https://www.google.com.br/>. Acesso em: 25 out. 2015.

FARANDOS, N. M. et al. Contact lens sensors in ocular diagnostics. Advanced Healthcare Materials, v. 4, n. 6, p. 792-810, 2015.

FOURLANOS, S. et al. Evidence that nasal insulin induces immune tolerance to insulin in adults with autoimmune diabetes. Diabetes, v. 60, n. 4, p. 1237-1245, 2011.

GALLAGHER, E. J.; LEROITH, D. The Proliferation Role of Insulin and Insulin Like Growth Factors in Cancer. Trend Endorinology Metabolism, v. 21, n. 10, p. 610-618, 2010.

GARBER, A. J. Will the next generation of basal insulins offer clinical advantages? Diabetes, Obesity and Metabolism, v. 16, n. 6, p. 483-91, 2014. 
GIUFFRIDA, F. M. A. et al. HNF1A gene polymorphisms and cardiovascular risk factors in individuals with late-onset autosomal dominant diabetes: a cross-sectional study. Cardiovascular Diabetology, v. 8, n. 2, p. 28, 2009.

GLOBAL BURDEN OF DISEASE (GBD). Institute for Health Metrics and Evaluation. Disponível em: <https://www.healthdata.org/sites/default/files/files/country_profiles/GBD/ihme_gbd_country _report_brazil.pdf>. Acesso em: 7 nov. 2015.

GLOBAL BURDEN OF DISEASE (GBD). Institute for Health Metrics and Evaluation. Disponível em: <http://www.healthdata.org/brazil>. Acesso em: 10 nov. 2015.

GOMES, D. F. et al. Judicialization of health and public hearing convened by the Supreme Court in 2009: what has changed since then? Saúde em Debate, v. 38, n. 100, p. 139-156, 2014a.

GOMES, F. DE F. C. et al. Acesso aos procedimentos de média e alta complexidade no Sistema Único de Saúde: uma questão de judicialização. Cadernos de Saúde Pública, v. 30, n. 1, p. 31-43, 2014b.

GU, Z. et al. Injectable Nano-Network for Glucose-Mediated Insulin Delivery. ACS Nano, v. 7, n. 5, p. 4194-4201, 28 maio 2013.

HEATH, V. A crossroads for diabetes care? Nature Reviews Endocrinology, v. 6, n. 3, p. $117-117,2010$.

HEMMINGSEN, B. et al. Sulfonylurea versus metformin monotherapy in patients with type 2 diabetes: a Cochrane systematic review and meta-analysis of randomized clinical trials and trial sequential analysis. CMAJ Open, v. 2, n. 3, p. E162-175, 2014.

HERNANDEZ, M. et al. Insulin secretion in patients with latent autoimmune diabetes (LADA): half way between type 1 and type 2 diabetes: action LADA 9. BMC Endocrine Disorders, n. doi 10.1186/1472-6823-15-1, 2015. 
International Diabetes Federation. IDF Diabetes Atlas. 6. ed. [s.1.] International Diabetes Federation, 2013.

ISER, B. P. M. et al. Prevalência de diabetes autorreferido no Brasil: resultados da Pesquisa Nacional de Saúde 2013. Epidemiologia e Serviços de Saúde, v. 24, n. 2, p. 305-314, 2015.

JAIN, S. et al. Polysialylated insulin: synthesis, characterization and biological activity in vivo. Biochimica et Biophysica Acta (BBA) - General Subjects, v. 1622, n. 1, p. 42-49, 2003.

JANEBRO, D. I. et al. Effect of the flour of the yellow passion fruit peel (Passiflora edulis $\mathrm{f}$. flavicarpa Deg.) in the glycemic and lipid levels of type 2 diabetes patients. Revista Brasileira de Farmacognosia, v. 18, n. supl, p. 724-732, 2008.

JEITLER, K. et al. Continuous subcutaneous insulin infusion versus multiple daily insulin injections in patients with diabetes mellitus: systematic review and meta-analysis. Diabetologia, v. 51, n. 6, p. 941-51, 2008.

KAJIMOTO, K. et al. Noninvasive and persistent transfollicular drug delivery system using a combination of liposomes and iontophoresis. International Journal of Pharmaceutics, v. 403, n. 1-2, p. 57-65, jan. 2011.

KARNOOSH-YAMCHI, J. et al. Preparation of $\mathrm{pH}$ sensitive insulin-loaded nano hydrogels and evaluation of insulin releasing in different $\mathrm{pH}$ conditions. Molecular Biology Reports, v. 41, n. 10, p. 6705-6712, 2014.

KIM, B. S. et al. Insulin-loaded microcapsules for in vivo delivery. Molecular Pharmaceutics, v. 6, n. 2, p. 353-365, 2009.

KING, H.; AUBERT, R. E.; HERMAN, W. H. Global Burden of Diabetes, 1995-2025: Prevalence, numerical estimates, and projections. Diabetes Care, v. 21, n. 9, p. 1414-1431, 1998. 
KUMRIA, R.; GOOMBER, G. Emerging trends in insulin delivery: Buccal route. Journal of Diabetology, v. 2, n. 1, p. 1-9, 2011.

LEE, S. et al. Noninvasive ultrasonic transdermal insulin delivery in rabbits using the lightweight cymbal array. Diabetes Technology \& Therapeutics, v. 6, n. 6, p. 808-815, 2004.

LIU, J. et al. Solid lipid nanoparticles loaded with insulin by sodium cholatephosphatidylcholine-based mixed micelles: Preparation and characterization. International Journal of Pharmaceutics, v. 340, n. 1-2, p. 153-162, 2007.

LIU, J. et al. Solid lipid nanoparticles for pulmonary delivery of insulin. International Journal of Pharmaceutics, v. 356, n. 1-2, p. 333-344, 2008.

MALAKAR, J. et al. Formulation, optimization and evaluation of transferosomal gel for transdermal insulin delivery. Saudi Pharmaceutical Journal, v. 20, n. 4, p. 355-63, 2012.

MALTA, D. C.; MORAIS NETO, O. L. DE; SILVA JUNIOR, J. B. DA. Apresentação do plano de ações estratégicas para o enfrentamento das doenças crônicas não transmissíveis no Brasil, 2011 a 2022. Epidemiologia e Serviços de Saúde, v. 20, n. 4, p. 425-438, 2011.

MARTANTO, W. et al. Transdermal delivery of insulin using microneedle rollers in vivo. Pharmaceutical Research, v. 21, n. 6, p. 947-952, 2004.

MATHERS, C. D.; LONCAR, D. Projections of global mortality and burden of disease from 2002 to 2030. PLoS Medicine, v. 3, n. 11, p. e442, 2006.

MCCULlOCH, D. K.; NATHAN, D. M.; MULDER, J. E. UPTODATE. Disponível em: $<$ http://www.uptodate.com/contents/general-principles-of-insulin-therapy-in-diabetesmellitus>. Acesso em: 6 out. 2015.

MEDICAL ADVISORY SECRETARIAT. Continuous Subcutaneous Insulin Infusion (CSII) Pumps for Type 1 and Type 2 Adult Diabetic Populations: An Evidence-Based Analysis. 
Ontario health technology assessment series, v. 9, n. 20, p. 1-58, 2009.

MISSO, M. L. Continuous subcutaneous insulin infusion (CSII) versus multiple insulin injections for type 1 diabetes mellitus. Journal of Evidence-Based Medicine, v. 3, n. 3, p. 186-186, 2010.

MO, R. et al. Emerging micro- and nanotechnology based synthetic approaches for insulin delivery. Chemical Society Reviews, v. 43, n. 10, p. 3595-629, 2014.

MOHAN, V. et al. Addressing barriers to effective basal insulin therapy. The Journal of the Association of Physicians of India, v. 62, n. 1 Suppl, p. 10-4, 2014.

MUKHOPADHYAY, P. et al. Strategies for effective oral insulin delivery with modified chitosan nanoparticles: A review. Progress in Polymer Science, v. 37, n. 11, p. 1457-1475, 2012.

NISHIMURA, A. et al. Controlled release of insulin from self-assembling nanofiber hydrogel, PuraMatrix(TM): Application for the subcutaneous injection in rats. European Journal of Pharmaceutical Sciences, v. 45, n. 1-2, p. 1-7, 2012.

NIU, M. et al. Enhanced oral absorption of insulin-loaded liposomes containing bile salts: A mechanistic study. International Journal of Pharmaceutics, v. 460, n. 1-2, p. 119-130, 2014.

NORDQUIST, L. et al. Novel microneedle patches for active insulin delivery are efficient in maintaining glycaemic control: An initial comparison with subcutaneous administration. Pharmaceutical Research, v. 24, n. 7, p. 1381-1388, 2007.

NOSE, K. et al. Gold nanorods in an oil-base formulation for transdermal treatment of type 1 diabetes in mice. Nanoscale, v. 4, n. 12, p. 3776-80, 2012.

O'NEILL, S. M. et al. Different insulin types and regimens for pregnant women with preexisting diabetes (Protocol). Cochrane Database of Systematic Reviews, v. 9, n. 9, 2015. 
OAK, M.; SINGH, J. Chitosan-zinc-insulin complex incorporated thermosensitive polymer for controlled delivery of basal insulin in vivo. Journal of Controlled Release, v. 163, n. 2, p. 145-153, 2012.

OLIVEIRA, A. F. DE et al. Global burden of disease attributable to diabetes mellitus in Brazil. Cadernos de Saúde Pública, v. 25, n. 6, p. 1234-1244, 2009.

OLIVEIRA, H. C. et al. Antidiabetic activity of Vatairea macrocarpa extract in rats. Journal of Ethnopharmacology, v. 115, n. 3, p. 515-9, 2008.

ORYNBAYEVA, Z.; SENSENIG, R.; POLYAK, B. Metabolic and structural integrity of magnetic nanoparticle-loaded primary endothelial cells for targeted cell therapy. Nanomedicine, v. 10, n. 10, p. 1555-1568, maio 2015.

PARK, E. J.; WERNER, J.; SMITH, N. B. Ultrasound mediated transdermal insulin delivery in pigs using a lightweight transducer. Pharmaceutical Research, v. 24, n. 7, p. 1396-1401, 2007.

PAUDEL, K. S. et al. Challenges and opportunities in dermal/transdermal delivery. Therapeutic Delivery, v. 1, n. 1, p. 109-31, 2010.

PENG, Q. et al. Injectable and biodegradable thermosensitive hydrogels loaded with PHBHHx nanoparticles for the sustained and controlled release of insulin. Acta Biomaterialia, v. 9, n. 2, p. 5063-5069, 2013.

PORTO DECHANDT, C. R. et al. Combretum lanceolatum flowers extract shows antidiabetic activity through activation of AMPK by quercetin. Revista Brasileira de Farmacognosia, v. 23, n. 2, p. 291-300, 2013.

RASTOGI, R.; ANAND, S.; KOUL, V. Electroporation of polymeric nanoparticles: an alternative technique for transdermal delivery of insulin. Drug Development and Industrial Pharmacy, v. 36, n. 11, p. 1303-1311, nov. 2010. 
RL, S.; TJ, P.; SC, J. Potential novel methods for insulin administration: I. Iontophoresis.Biomedica biochimica acta, 1984.

ROBERTSON, K. E.; GLAZER, N. B.; CAMPBELL, R. K. The latest developments in insulin injection devices. The Diabetes Educator, v. 26, n. 1, p. 135-8, 1999.

ROBERTSON, R. P. Islet Transplantation as a Treatment for Diabetes - A Work in Progress. The New England Journal of Medicine, v. 350, p. 694-705, 2004.

RUSSELL, S. Bionic Pancreas. Disponível em: <ttp://www.artificialpancreas.org/>. Acesso em: 6 out. 2015 .

SAJEESH, S.; SHARMA, C. P. Cyclodextrin-insulin complex encapsulated polymethacrylic acid based nanoparticles for oral insulin delivery. International Journal of Pharmaceutics, v. 325, n. 1-2, p. 147-154, 2006.

SANTOS, E. C. B. DOS et al. Políticas públicas e direitos dos usuários do Sistema Único de Saúde com diabetes mellitus. Revista Brasileira de Enfermagem, v. 64, n. 5, p. 952-957, 2011.

SARMENTO, B. et al. Oral insulin delivery by means of solid lipid nanoparticles. International Journal of Nanomedicine, v. 2, n. 4, p. 743-9, 2007.

SILVA, A. C. M. et al. Acute and Subchronic Antihyperglycemic Activities of Bowdichia virgilioides Roots in Non Diabetic and Diabetic Rats. Journal of Intercultural Ethnopharmacology, v. 4, n. 1, p. 57-63, 2015.

SINTOV, A. C.; LEVY, H. V.; BOTNER, S. Systemic delivery of insulin via the nasal route using a new microemulsion system: In vitro and in vivo studies. Journal of Controlled Release, v. 148, n. 2, p. 168-176, 2010.

SMITH, N. B.; LEE, S.; SHUNG, K. K. Ultrasound-mediated transdermal in vivo transport of 
insulin with low-profile cymbal arrays. Ultrasound in Medicine and Biology, v. 29, n. 8, p. 1205-1210, 2003.

SONG, L.; ZHI, Z. L.; PICKUP, J. C. Nanolayer encapsulation of insulin- chitosan complexes improves efficiency of oral insulin delivery. International Journal of Nanomedicine, v. 9, n. 1, p. 2127-2136, 2014.

TAKAHASHI, P. et al. MicroRNA expression profiling and functional annotation analysis of their targets in patients with type 1 diabetes mellitus. Gene, v. 539, n. 2, p. 213-23, 2014.

TAKEUCHI, H. et al. Enteral absorption of insulin in rats from mucoadhesive ChitosanCoated liposomesPharmaceutical Research, 1996.

TAYLOR, M. J.; TANNA, S.; SAHOTA, T. In vivo study of a polymeric glucose-sensitive insulin delivery system using a rat model. Journal of Pharmaceutical Sciences, v. 99, n. 10, p. $4215-4227,2010$.

THIRONE, A. C.; CARVALHO, C. R.; SAAD, M. J. Growth hormone stimulates the tyrosine kinase activity of JAK2 and induces tyrosine phosphorylation of insulin receptor substrates and Shc in rat tissues. Endocrinology, v. 140, n. 1, p. 55-62, 1999.

TIWARI, P. Recent Trends in Therapeutic Approaches for Diabetes Management: A Comprehensive Update. Journal of Diabetes Research, n. http://dx.doi.org/10.1155/2015/340838, 2015.

TSUNEJI, N. et al. Powder dosage form of insulin for nasal administration. Journal of Controlled Release, v. 1, n. 1, p. 15-22, 1984.

TURCHENIUK, $\mathrm{K}$. et al. Insulin loaded iron magnetic nanoparticle-graphene oxide composites: synthesis, characterization and application for in vivo delivery of insulin. RSC Advances, v. 4, n. 2, p. 865-875, 2014.

TZVETANOV, I. et al. Robotic-assisted pancreas transplantation: where are we today? Current Opinion in Organ Transplantation, v. 19, n. 1, p. 80-2, 2014. 
UEHATA, K. et al. Peak-less hypoglycemic effect of insulin glargine by complexation with maltosyl- $\beta$-cyclodextrin. International Journal of Pharmaceutics, v. 422, n. 1-2, p. 33-9, 2012.

UNGARO, F. et al. Insulin-loaded PLGA/cyclodextrin large porous particles with improved aerosolization properties: In vivo deposition and hypoglycaemic activity after delivery to rat lungs. Journal of Controlled Release, v. 135, n. 1, p. 25-34, 2009.

VEISEH, O. et al. Managing diabetes with nanomedicine: challenges and opportunities. Nature Reviews Drug Discovery, v. 14, n. 1, p. 45-57, 2014.

VEISEH, O.; LANGER, R. Diabetes: A smart insulin patch. Nature, v. 524, n. 7563, p. 3940, 2015.

VIEIRA, T. C. et al. Hyperinsulinemic hypoglycemia evolving to gestational diabetes and diabetes mellitus in a family carrying the inactivating ABCC8 E1506K mutation. Pediatric Diabetes, v. 11, n. 7, p. 505-8, 2010.

WHO. 2013. World Health Organization. Disponível em: <http://www.who.int/healthinfo/global_burden_disease/projections/en/>. Acesso em: 7 nov. 2015.

WHO. 2014. World Health Organization. Disponível em: <http://www.who.int/nmh/publications/ncd-profiles-2014/en/>. Acesso em: 7 nov. 2015.

WHO. 2014. World Health Organization. Luxembourg: WHO Library Cataloguing-inPublication Data, 2015.

ZHANG, N. et al. Lectin-modified solid lipid nanoparticles as carriers for oral administration of insulin. International Journal of Pharmaceutics, v. 327, n. 1-2, p. 153-159, 2006. 
ZHANG, X. et al. Biotinylated liposomes as potential carriers for the oral delivery of insulin. Nanomedicine: Nanotechnology, Biology and Medicine, v. 10, n. 1, p. 167-176, 2014.

ZHAO, Y.-Z. et al. Experiment on the feasibility of using modified gelatin nanoparticles as insulin pulmonary administration system for diabetes therapy. Acta Diabetologica, v. 49, n. 4, p. 315-25, 2012.

ZIJLSTRA, E.; HEINEMANN, L.; PLUM-MORSCHEL, L. Oral Insulin Reloaded: A Structured Approach. Journal of Diabetes Science and Technology, v. 8, n. 3, p. 458-465, 2014. 
APÊNDICE 


\section{APÊNDICE A: Formulário LAI respondido pela Secretaria de Atenção à Saúde/MS}

Dados do Pedido
Protocolo
Solicitante
Data de abertura
Orgão Superior Destinatário
Orgão Vinculado Destinatário
Prazo de atendimento
Situação
Status da Situação
Forma de recebimento da resposta
Resumo

Detalhamento

25820001586201591

DAYANE GABRIELE ALVES SILVEIRA

26/05/2015 23:05

MS - Ministério da Saúde

$16 / 06 / 2015$

Respondido

Acesso Concedido (Resposta solicitada inserida no e-SIC)

Pelo sistema (com avisos por email)

Solicito à Coordenação Geral de Atenção as Pessoas com Doenças Crônicas / Departamento de Atenção Especializada e Temática / SAS / MS informações sobre demandas de bombas de insulina pelos usuários do SUS.

Está aprovado para comercialização no Brasil a bomba de infusão para administração de insulina. Na literatura científica disponível, em algumas indicações específicas, os estudos têm demonstrado que a bomba de infusão apresenta maior precisão e acurácia, ou seja, promove uma administração mais próxima da dose desejada. No Brasil, o cidadão pode utilizar a via judicial para obter tecnologias que não estão disponíveis no SUS. Diante do cenário apenas citado, solicito as seguintes informações sobre solicitação de bomba de insulina por usuários do SUS ao Ministério da Saúde:

1) Ano 2011:

a. Número de solicitações de bomba de infusão em 2011 indeferida por

Estado;

b. Número de solicitações de bomba de infusão em 2011 deferida por

Estado;

c. O custo médio das bombas de infusão deferidas em 2011;

d. Características dos pacientes que tiveram as solicitações deferidas em 2011;

2) Ano 2012:

a. Número de solicitações de bomba de infusão em 2012 indeferida por

Estado:

b. Número de solicitações de bomba de infusão em 2012 deferida por Estado:

c. $O$ custo médio das bombas de infusão deferidas em 2012;

d. Características dos pacientes que tiveram as solicitações deferidas em 2012;

3) Ano 2013

a. Número de solicitações de bomba de infusão em 2013 indeferida por Estado;

b. Número de solicitações de bomba de infusão em 2013 deferida por Estado;

c. O custo médio das bombas de infusão deferidas em 2013;

d. Características dos pacientes que tiveram as solicitações deferidas em 2013;

4) Ano 2014

a. Número de solicitações de bomba de infusão em 2014 indeferida por

Estado;

b. Número de solicitações de bomba de infusão em 2014 deferida por

Estado;

c. O custo médio das bombas de infusão deferidas em 2014;

d. Características dos pacientes que tiveram as solicitações deferidas em 2014;

5) Modelo/Especificação de bomba de insulina que obteve maior número de solicitações nesses quatro anos.

6) Das solicitações indeferidas, quais foram os motivos predominantes. 
Dados da Resposta

Data de resposta

Tipo de resposta

Classificação do Tipo de resposta

Resposta
$12 / 06 / 201512: 36$

\section{Acesso Concedido}

Resposta solicitada inserida no e-SIC

Prezada Sra. Dayane Gabriele Alves Silveira,

O Serviço de Informação ao Cidadão (SIC) do Ministério da Saúde já dispõe das informações solicitadas por Vossa Senhoria, pedido 25820001586201591, que segue abaixo os esclarecimentos:

Não há no Ministério da Saúde politica de distribuição e fornecimento de bombas de infusão já que não se trata de insumo incorporado pelo SUS. Assim, não existem dados quanto ao quantitativo conforme solicitado, tendo em vista que não há uma politica de fornecimento das referidas bombas.

O Ministério da Saúde sempre esteve atento às novas tecnologias visando um maior bem estar da população brasileira, inclusive, com estudos elaborados pela CONITEC tratando da incorporação dos análogos de insulina em que não comprovaram a superioridade do tratamento com estes agentes em relação ao tratamento com insulina $\mathrm{NPH}$ e insulina regular fornecidos pelo SUS, nos principais parâmetros de controle da doença.

Quanto aos dados relativos à Judicialização, os mesmos podem ser obtidos nos bancos de dados do Conselho Nacional de Justiça, que mantém cadastro sobre todos os pleitos dos cidadãos.

Área responsável: SECRETARIA DE ATENÇÃO À SAÚDE - SAS

$\mathrm{Na}$ oportunidade, o Ministério da Saúde coloca-se à disposição de Vossa Senhoria sempre que necessário.

Atenciosamente,

Ministério da Saúde

Serviço de Informação ao Cidadão

Classificação do Pedido

$\begin{array}{ll}\text { Categoria do pedido } & \text { Saúde } \\ \text { Subcategoria do pedido } & \text { Participação e controle social em saúde }\end{array}$

Número de perguntas

6

\section{Histórico do Pedido}

\begin{tabular}{|l|l|l|}
\hline Data do evento & Descrição do evento & \multicolumn{1}{|l}{ Responsável } \\
\hline 26/05/2015 23:05 & $\begin{array}{l}\text { Pedido Registrado para o Órgão MS - Ministério } \\
\text { da Saúde }\end{array}$ & SOLICITANTE \\
\hline $12 / 06 / 201512: 36$ & Pedido Respondido & MS - Ministério da Saúde \\
\hline
\end{tabular}




\section{APÊNDICE B: Formulário LAI respondido pelo Gabinete do Ministro / MS}

\section{Dados do Pedido}

Protocolo

Solicitante

Data de abertura

Orgão Superior Destinatário

Orgão Vinculado Destinatário

Prazo de atendimento

Situação

Status da Situação

Forma de recebimento da resposta

Resumo

Detalhamento
25820001617201512

DAYANE GABRIELE ALVES SILVEIRA

27/05/2015 21:10

MS - Ministério da Saúde

$17 / 06 / 2015$

Respondido

Acesso Concedido (Resposta solicitada inserida no e-SIC)

Pelo sistema (com avisos por email)

Solicito à Consultoria Jurídica junto ao Ministério da Saúde (CONJUR) informações sobre demandas por via judicial de bombas de insulina pelos usuários do SUS.

Está aprovado para comercialização no Brasil a bomba de infusão para administração de insulina. Na literatura científica disponível, em algumas indicações específicas, os estudos têm demonstrado que a bomba de infusão apresenta maior precisão e acurácia, ou seja, promove uma administração mais próxima da dose desejada. No Brasil, o cidadão pode utilizar a via judicial para obter tecnologias que não estão disponíveis no SUS. Diante do cenário apenas citado, solicito as seguintes informações sobre solicitação de bomba de insulina por usuários do SUS ao Ministério da Saúde:

1) Ano 2011

a. Número de solicitações de bomba de infusão em 2011 indeferida por Estado;

b. Número de solicitações de bomba de infusão em 2011 deferida por Estado;

c. O custo médio das bombas de infusão deferidas em 2011;

d. Características dos pacientes que tiveram as solicitações deferidas em 2011;

2) Ano 2012:

a. Número de solicitações de bomba de infusão em 2012 indeferida por Estado;

b. Número de solicitações de bomba de infusão em 2012 deferida por Estado;

c. O custo médio das bombas de infusão deferidas em 2012;

d. Características dos pacientes que tiveram as solicitações deferidas em 2012;

3) Ano 2013

a. Número de solicitações de bomba de infusão em 2013 indeferida por Estado;

b. Número de solicitações de bomba de infusão em 2013 deferida por Estado;

c. O custo médio das bombas de infusão deferidas em 2013;

d. Características dos pacientes que tiveram as solicitações deferidas em 2013;

4) Ano 2014

a. Número de solicitações de bomba de infusão em 2014 indeferida por

Estado;

b. Número de solicitações de bomba de infusão em 2014 deferida por Estado;

c. O custo médio das bombas de infusão deferidas em 2014;

d. Características dos pacientes que tiveram as solicitações deferidas em 2014;

5) Modelo/Especificação de bomba de insulina que obteve maior número de solicitações nesses quatro anos.

6) Das solicitações indeferidas, quais foram os motivos predominantes.

Dados da Resposta 
Tipo de resposta

Classificação do Tipo de resposta

Resposta
Acesso Concedido

Resposta solicitada inserida no e-SIC

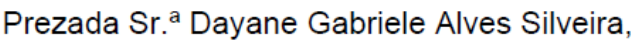

O Serviço de Informação ao Cidadão (SIC) do Ministério da Saúde, em atenção ao pedido de Vossa Senhoria, 25820001617201512, dispõe das informações solicitadas, conforme esclarecimentos da área:

SEGUEM OS DADOS ACERCA DO CUMPRIMENTO DE ORDENS JUDICIAIS NA ESFERA FEDERAL NO TOCANTE AO FORNECIMENTO DE BOMBAS DE INSULINA, CONTABILIZADOS ATÉ 2014.

ESTAS INFORMAÇÕES RETRATAM DECISÕES JUDICIAIS QUE IMPUTARAM OBRIGAÇÃO À UNIÃO, NÃO REPRESENTAM A REALIDADE NACIONAL, TENDO EM VISTA QUE NÃO EXISTEM INFORMAÇÕES NOS SISTEMAS DO MINISTÉRIO DA SAÚDE RELATIVAS ÀS CONDENAÇÕES DE ESTADOS E MUNICÍPIOS. DESSE MODO, SUGERE-SE ENCAMINHAR PEDIDO TAMBÉM ÀS SECRETARIAS DE SAÚDE DOS ESTADOS.

ESCLARECE-SE AINDA O FORMATO DAS INFORMAÇÕES DISPONIBILIZADAS DECORRE DA ESPECIFICIDADE DA ORGANIZAÇÃO ADOTADA INTERNAMENTE NO ÂMBITO MINISTÉRIO DA SAÚDE. ASSIM, AINDA QUE NÃO ESTEJAM CONSOLIDADAS EXATAMENTE COMO SOLICITADAS NA PRESENTE DEMANDA, DE ACORDO COM O DISPOSTO NO ART. 13 DO DECRETO N. 7724/12 QUE REGULAMENTA A LEI DE ACESSO À INFORMAÇÃO, COMPETE AO ÓRGÃO PROVIDENCIAR AS INFORMAÇÕES NO FORMATO DISPONÍVEL E A PARTIR DELAS O CIDADÃO PODERÁ REALIZAR A INTERPRETAÇÃO, CONSOLIDAÇÃO OU TRATAMENTO DE DADOS.

ENTRE 2011 E 2014 FORAM ADQUIRIDAS 88 BOMBAS DE INFUSÃO, AO PREÇO MÉDIO DE R\$12.500,00.

DESCRIÇÃO DO OBJETO NA PLATAFORMA COMPRASNET: BOMBA INFUSÃO PORTÁTIL, SISTEMA INFUSÃO CONTÍNUA DE INSULINA, FORNECIMENTO PROGRAMADO, PORTÁTIL, MÍNIMA O,1 U/H E MÁXIMA DE 25 U/H, BATERIA, ADAPTADOR, CHAVE BATERIA, TAMPA BATERIA, CONJUNTOS DE INFUSÃO E CARTUCHO PLÁSTICO 3,15 ML OPORTUNO INFORMAR TAMBÉM QUE O INSUMO USUALMENTE CHAMADO DE "BOMBA DE INSULINA", NÃO ESTÁ INCORPORADO AO SISTEMA ÚNICO DE SAÚDE. NESSE PONTO, INSTA SALIENTAR QUE O SUS DISPÕE DE AMPLO PROGRAMA DE ATENÇÃO AOS PORTADORES DE DIABETES MELITUS, INCLUSIVE COM FORNECIMENTO GRATUITO DE MEDICAMENTOS NO ÂMBITO DO PROGRAMA FARMÁCIA POPULAR, COM FARMÁCIAS ESPALHADAS POR TODO O PAIIS.

ADEMAIS, A APLICAÇÃO DA INSULINA NÃO DEPENDE DA BOMBA; PODE SER APLICADA COM SERINGA ESPECÍFICA QUE É FORNECIDA PELO SUS. (...) O SUCESSO DO PROCESSO TERAPÊUTICO SÓ SE DARÁ COM A INEFICÁCIA DO CONJUNTO DESSAS AÇÕES E NÃO SÓ DA DISPONIBILIDADE DE MEDICAMENTOS OU INSUMOS.

REITERA-SE A PLENA DISPONIBILIDADE NO SUS DE MEDICAMENTOS E INSUMOS ABSOLUTAMENTE EFICAZES NO CONTROLE DA DOENÇA, DEVENDO-SE COMPREENDER QUE A POLÍTICA PÚBLICA DEVE TER COMO FOCO O TRATAMENTO DO AGRAVO EM SAÚDE, E NÃO AS CHAMADAS PERFUMARIAS FARMACÊUTICAS, QUE, EMBORA TENHAM A POSSIBILIDADE DE FACILITAR O TRATAMENTO, TÊM UM CUSTO QUE NÃO JUSTIFICA A SUA UNIVERSALIZAÇÃO, CONSIDERANDO-SE A PLENA EFETIVIDADE DAS ALTERNATIVAS TERAPÊUTICAS JÁ DISPONIVEIS. 
ÁREA RESPONSÁVEL: GABINETE DO MINISTRO

Na oportunidade, o Ministério da Saúde coloca-se à disposição de Vossa Senhoria sempre que necessário.

Atenciosamente,

Ministério da Saúde (MS)

Serviço de Informação ao Cidadão (SIC)

Classificação do Pedido

Categoria do pedido

Saúde

Subcategoria do pedido

Participação e controle social em saúde

Número de perguntas

20

\section{Histórico do Pedido}

\begin{tabular}{|l|l|l|}
\hline Data do evento & Descrição do evento & Responsável \\
\hline 27/05/2015 21:10 & $\begin{array}{l}\text { Pedido Registrado para o Órgão MS - Ministério } \\
\text { da Saúde }\end{array}$ & SOLICITANTE \\
\hline $17 / 06 / 201516: 45$ & Pedido Respondido & MS - Ministério da Saúde \\
\hline
\end{tabular}


APÊNDICE C: Demonstrativo de compra de SIC pelo Estado de São Paulo no Portal de Compras do Governo Federal (Comprasnet) 
APÊNDICE D: Demonstrativo de compra de SIC pelo Estado do Ceará no Portal de Compras do Governo Federal (Comprasnet) 
APÊNDICE E: Demonstrativo de compra de SIC pelo Estado de Roraima no Portal de Compras do Governo Federal (Comprasnet) 
APÊNDICE F: Demonstrativo de compra de SIC pelo Estado do Pará no Portal de Compras do Governo Federal (Comprasnet) 